\title{
The Hydraulic Geometry of Stream Channels and \\ Some Physiographic \\ Implications
}

By LUNA B. LEOPOLD and THOMAS MADDOCK, JR.

GEOLOGICAL SURVEY PROFESSIONAL PAPER 252

Quantitative measurement of some of the hydraulic factors that help to determine the shape of natural stream channels: depth, width, velocity, and suspended load, and how they vary with discharge as simple power functions. Their interrelations are described by the term "hydraulic geometry."

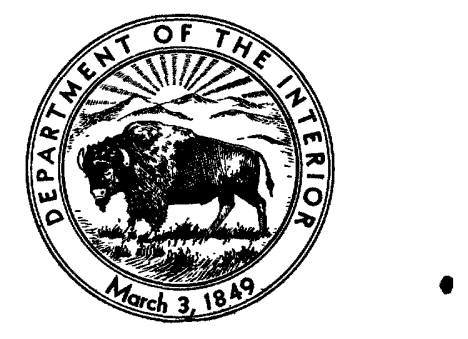

UNITED STATES GOVERNMENT PRINTING OFFICE, WASHINGTON : 1953 


\section{UNITED STATES DEPARTMENT OF THE INTERIOR}

Oscar L. Chapman, Secretary

\section{GEOLOGICAL SURVEY}

W. E. Wrather, Director

For sale by the Superintendent of Documents, U. S. Government Printing Office Washington 25, D. C. - Price 35 cents (paper cover) 


\section{PREFACE}

This report was prepared by the Technical Coordination Branch of the Water Resources Division of the Geological Survey as a part of the investigation of water-utilization problems. The junior author, Mr. Maddock, is assistant chief of the Hydrology Division, Bureau of Reclamation.

The authors have benefited greatly from constructive suggestions made by many friends and colleagues. Particular acknowledgment is due J. Hoover Mackin and Walter B. Langbein whose counsel and criticism contributed greatly to whatever of value is contained in this report. Among the persons who read an early draft and whose suggestions are highly valued are A. N. Strahler, John P. Miller, E. W. Lane, L. C. Gottschalk, K. B. Schroeder, C. C. Nikiforoff, Charles E. Stearns, and W. M. Borland. The continuous encouragement of W. W. Rubey is appreciated.

L. B. L. 


\section{GLOSSARY}

Antidune. A transient form of ripple on the stream bed analogous to a sand dune; an antidune progressively moves upstream.

Control. The "control" of a stream-gaging station refers to the nature of the channel downstream from the measuring section which determines the stage-discharge relation.

Current meter. An instrument for measuring water speed; consists of cups which are rotated by the flowing water; rate of rotation is a function of water speed.

Cumulative frequency, or flow-duration, curve. Graph of rate of daily discharge in relation to curnulative frequency, indicating the percent of time a given discharge is equalled or exceeded.

Discharge. The amount of water flowing in a channel expressed as volume per unit of time.

Froude number. A measure of tranquility of flow defined as $\frac{v}{\sqrt{g d}}$

Gage height. The water-surface elevation referred to some arbitrary datum.

Hydraulic gradient: The slope of the energy grade line; or slope of the line representing the sum of kinetic and

- potential energy along the channel length. It is equal to the slope of the water surface in steady, uniform flow.

Hydraulic radius. A measure of water depth in a channel defined as cross-sectional area of flowing water divided by the length of wetted perimeter; approximates mean depth in a wide channel.

Manning formula. A formula including empiric constants relating open-channel water velocity to hydraulic gradient, hydraulic radius, and channel roughness.

Rating curve. The graph of discharge plotted against water-surface elevation for a given cross sectior of a stream.

Sediment station. A river section where samples of suspended load are taken each day, or periodically.

Stage, or river stage. Synonymous with gage height.

Stream-gaging station. An installation including a mechanical continuous recorder of water-surface elevation; at the same cross section periodic velocity measurements are made, and are used to construst the rating curve for the station. These two types of data are used to furnish a continuous record of water flow.

Suspended sediment-discharge curve. A graph of water discharge plotted against concomitant measured suspended-sediment load.

\section{SYMBOLS}

a coefficient representing width at unit discharge

$b$ exponent in width-discharge relation

$c$ coefficient representing depth at unit discharge

$C$ Chezy coefficient in $v=C \sqrt{R s}$

$d$ mean depth

$D$ pipe diameter

$f$ exponent in depth-discharge relation

$F$ a function of

$\bar{g}$ sediment-grain diameter

$g$ acceleration due to gravity

$j$ exponent in suspended load-discharge relation

Iv $k$ coefficient representing velocity at unit discharge

$L$ suspended-sediment load, weight per unit of time

$m$ exponent in velocity-discharge relation

$n$ Manning roughness factor

$p$ coefficient representing load at unit dis harge

$Q$ water discharge in cubic feet per second (cfs)

$R$ hydraulic radius, approximately equal to mean depth in wide channels

$s$ slope of water surface in open channels

$v$ velocity

$w$ width 


\section{CONTENTS}

Abstract.

General statement ....................................

The hydraulic geometry of stream channels Concept of frequency of discharge . . . . . . . . . .

Variation of hydraulic characteristics in a particular cross section of a river

Variation of hydraulic characteristics in a downstream direction.

Relation of channel shape to frequency of discharge.

The hydraulic geometry of stream channels in relation to sediment load

Relations of suspended sediment to discharge in a particular cross section of a river.

Relations of suspended sediment to discharge in the downstream direction .......................

Interrelations of width, depth, velocity, and suspended load at a given discharge

\begin{tabular}{|c|c|}
\hline ge & \\
\hline 1 & The hydraulic geometry of stream channels in relation to \\
\hline 1 & sediment load-Continued \\
\hline 2 & Interrelations of width, depth, velocity, and sus- \\
\hline 2 & pended load to a variable discharge $\ldots . .$. \\
\hline & Interrelations of width, depth, velocity, and bed load \\
\hline 4 & at a given discharge \\
\hline & Channel-shape adjustment during individual floods_- \\
\hline 9 & The role of channel roughness and slope in the adjust- \\
\hline 16 & ment of channel shape to sediment load. \\
\hline & Some physiographic implications \\
\hline 19 & $\begin{array}{l}\text { The stable irrigation canal-an analogy to a graded } \\
\text { river }\end{array}$ \\
\hline 19 & Sediment and the longitudinal profile \\
\hline & Summary and interpretation \\
\hline 21 & References_.... \\
\hline & Appendix ... \\
\hline 23 & Index $\ldots \ldots \ldots$ \\
\hline
\end{tabular}

\section{ILLUSTRATIONS}

Figure 1. Cumulative frequency, or flow-duration, curve for Powder River at Arvada, Wyo .

2. Comparison of different rates of discharge at a station and downstream

3. Typical relations among width, depth, velocity, discharge, and gage height, Cheyenne River near Eagle Butte, S. Dak

4. Relation of width, depth, and velocity to discharge, Powder River at Arvada, Wyo., and at Locate, Mont....

5. Width, depth, and velocity in relation to mean annual discharge as discharge increases downstream, Powder River and tributaries, Wyoming and Montana

6. Width, depth, and velocity in relation to mean annual discharge as discharge increases downstream, Bighorn River and tributaries, Wyoming and Montana

7. Width, depth, and velocity in relation to mean annual discharge as discharge increases downstream, Arikaree, Republican, Smoky Hill, and Kansas Rivers in the Kansas River system, Kansas and Nebraska..........

8. Width, depth, and velocity in relation to mean annual discharge as discharge increases downstream, main trunk of Missouri and lower Mississippi Rivers _..

9. Width, depth, and velocity in relation to mean annual discharge as discharge increases downstream in various river systems.

10. Width, depth, and velocity in relation to discharges representing two frequencies, Maumee and Scioto River basins, Ohio

11. Width, depth, and velocity in ration to discharge of various frequencies, Maumee and Scioto River basins, Ohio

12. Diagrammatic relations of width, depth, and velocity to discharge at a station and downstream

13. Relation of suspended-sediment load to discharge, Powder River at Arvada, Wyo

14. Typical relations in the hydraulic geometry of natural stream channel systems . . . . . . . . . . . . . . . .

15. Average relation of suspended-sediment load to cnannel-shape factors at a constant discharge of $500 \mathrm{cfs}$ (from river data in appendix) . .

16. Average relation of suspended-sediment load to channel-shape factors at four discharge rates (from river data in appendix)

17. Example of width, depth, velocity in relation to discharge (constructed from fig. 16)

18. Relation of $b, \frac{m}{f}$, and $j$ (constructed from fig. 16)

19. Average hydraulic geometry of river channels

20. Relation of bed load to channel-shape factors at constant discharge, from Gilbert data

21. Changes in channel-shape factors, San Juan River near Bluff, Utah, during flood of September-December 1941.

22. Channel cross sections during progress of flood, September-December 1941, San Juan River near Bluff, Utah.--

23. Changes in width, depth, velocity, water-surface elevation, and stream-bed elevation with discharge during flood of December 1940-June 1941, Colorado River at Grand Canyon, Ariz

3

4

5

6

10

11 
Figure 24. Channel cross sections during progress of flood, December 1940-June 1941, Colorado River at Grand Canyon, Ariz.

25. Changes in channel shape factors during progress of flood, May-June 1948, Rio Grande near Bernalillo, N. Mex.

26. Channel cross sections during progress of flood, May-June 1948, Rio Grande near Bermalillo, N. Mex .......-

27. Relation of width, depth, velocity, water-surface elevation, and stream-bed elevation to discharge, Colorado River at Yuma, Ariz . . . . .

28. Progressive changes of Colorado River at Yuma, Ariz., resulting from the construction of engineering works upstream . . . .

29. River profiles in reach of Colorado River near Yuma, Ariz

30. Channel roughness (Manning $n$ ) in relation to discharge for various sizes of sediment (from flume data) ........

31. Relation of width, depth, and velocity to discharge for stable (regime) irrigation canals in India (Lacey data) ..

32. Variation of velocity and depth downstream for three assumed longitudinal profiles. 


\title{
THE HYDRAULIC GEOMETRY OF STREAM GHANNELS AND SOME PHYSIOGRAPHIC IMPLICATIONS
}

\author{
By Luna B. Leopold and Thomas Maddock, $J_{R}$.
}

\section{ABSTRACT}

Some hydraulic characteristics of stream channels-depth, width, velocity, and suspended load-are measured quantitatively and vary with discharge as simple power functions at a given river cross section. Similar variations in relation to discharge exist among the cross sections along the length of a river under the condition that discharge at all points is equal in frequency of occurrence. The functions derived for a given cross section and among various cross sections along the river differ only in numerical values of coefficients and exponents. These functions are:

$$
\begin{aligned}
& w=a Q^{b} \\
& d=c Q^{f} \\
& v=k Q^{m} \\
& L=p Q^{j}
\end{aligned}
$$

where

$$
\begin{aligned}
& w=\text { width } \\
& d=\text { mean depth } \\
& v=\text { mean velocit } y \\
& L=\text { suspended-sediment load, in units of weight per unit time } \\
& Q=\text { water discharge, in cubic feet per second (cfs); } a, c, k, p \text {, } \\
& b, f, m \text {, and } j \text { are numerical constants. }
\end{aligned}
$$

These relationships at a given channel cross section and downstream when plotted on graphs are greatly similar even for river systems very different in physiographic setting. The relationships are described by the term "hydraulic geometry."

In the data studied it appeared that when discharges are of equal frequency at different points along a river, that is, equalled or exceeded the same percent of time, the velocity as well as the width and depth of flow, increases with discharge downstream. This increase of velocity downstream results from the fact that the increase in depth overcompensates for the decrease in slope. The tendency for velocity to increase downstream exists on most streams despite the decreasing particle size downstream. This indicates that the mean velocity in a given reach is not merely a function of the size of particles which must be transported but is governed by a more complex interaetion among several factors.

Measurements of suspended-sediment load are available for a number of different river cross sections. The suspended load is shown to be an index to total load for purposes of explaining the observed average characteristics of natural channel systems.

An empiric quantitative relation among average measurements of width, depth, velocity, discharge, and suspended-sediment load is derived from data on natural rivers. This relation shows that depth and width, as well as velocity, are functions of the load transported in the channel.
In a simplified example, if the discharge is constant, the empiric relation is: At a given discharge, an increase in width at constant velocity is accompanied by a decrease in suspendedsediment load; conversely, at constant discharge and velocity, an increase in width is accompanied by an increase in bed load.

The writers, like many others, postulate that both discharge and sediment load are factors essentially independent of the stream channel and depend on the nature of the drainage basin. The typical relations between suspended-sediment load and water discharge are shown in quantitative terms. Specifically, at a given stream cross section, suspended-sediment load per unit of discharge characteristically increases rapidly with increased discharge. However, suspended load per unit volume of water tends to decrease slightly downstream.

These characteristics are important determinants of the shape of the cross section of a channel and the progressive changes in its shape downstream. The empiric relation between hydraulic characteristics of the channel and suspended load provides, in semiquantitative terms, a logical explanation of the observed channel shape.

The hydraulic geometry of river channels is presented for several river systems. It is shown that similar equations apply both to rivers and to stable ("regime") irrigation canals which neither scour nor aggrade their beds. The analogy demonstrates that the average river channel-system tends to develop in a way to produce an approximate equilibrium between the channel and the water and sediment it must transport. This approximate equilibrium appears to exist even in headward ungraded tributaries and in a given cross section for all discharges up to the bankful stage.

\section{GENERAL STATEMENT}

Geomorphology, that branch of geology dealing with land forms, their genesis and history, has been classically treated almost exclusively in a qualitative manner. William Morris Davis, for pedagogic reasons, invented words and contrived similes which were descriptive and easy to remember, but were supported by intricately developed general argument rather than by field data. The qualitative approach to geomorphology has indeed been constructive, but it would be desirable to analyze sone of the concepts quantitatively.

There is available a mass of data on streamflow collected over a period of seventy years representing rivers all over the United States. The field procedure used by engineers to measure the rate of water discharge in a river furnishes concurrent measurements of mean velocity,width, shape and area of the cross section, as well as discharge. Moreover, in the last decade 
the systematic collection of data on suspended sediment has begun though the number of stations collecting is as yet few.

The present paper reports on analyses of some of these data, keeping in mind possible application to geomorphic problems. The available data are not necessarily the best type for an analysis of stream processes. The parameters measured are perhaps not the most meaningful for such analysis. Nevertheless, the available data do provide some generalized relations of interest to the geomorphologist.

The plan of the paper is as follows:

The characteristics of channel shape in certain river cross sections are examined. At a given cross section, the width and depth of the channel and, therefore, the velocity change with the amount of water flowing in the cross section. The changes in width, depth, and velocity in response to changes in discharge are observed to have certain characteristics which apply to many natural river cross sections, and these similarities are described in the first part of the paper.

These same characteristics are then examined downstream along the length of natural channels in order to determine how they change there. Changes in slope and roughness, which help determine the observed variations, are reserved for later discussion.

The data used are those collected at regular river measurement stations for purposes of determining river discharge. Such data are obtained for purposes other than a study of fluvial morphology and are, for the writers' purposes, incomplete. Particularly, data on river slope and bed roughness are meager but some useful ideas may be obtained even from the incomplete operational data.

In the next part of the paper, the river-channel characteristics including slope and roughness are discussed in relation to observational data on suspended-sediment load. It is recognized at the outset that the unmeasured bed load is of importance and that its omission from the available data is a limitation to the conclusions which may be drawn. Yet some interesting relations may be obtained by the use of data on suspended load alone. These relations provide some picture of the interaction of the hydraulic characteristics related to channel shape and a segment of the stream's sediment load and therefore seem to be potentially useful tools for the study of fluvial processes.

The relations between observed channel characteristics and suspended-sediment load involve the process of adjustment between channel shape and sediment load. Because the mechanism of adjustment between the capacity of a stream to carry a sediment load and available load is important to the understanding of the graded river, any advance in knowledge of this mechanism leads toward an improved understanding of river grading.
There are two possible levels at which this mechanism of adjustment of river-to-load may be dis?ussed. The more detailed way would lie in the realm of hydrodynamics and would concern the mechanics of sediment transport. A second and more general approach is through the consideration of river hydraulics but without a detailed treatment of the hydrodynamics. The second approach is the one used in the present paper, in part because it lends itself hotter to an understanding of the relation of hydraulies to geomorphology, and in part because it lies within the field of experience of the authors.

The last part of the paper is an attempt to explore in a preliminary way how the relations among the hydraulic variables bear on some geomorphic problems.

It is emphasized that the present study should be considered prelimimary in character. Data on streamgaging and suspended load discussed here are clearly imperfect measures of the variables of specific interest to the geomorphologist. Moreover, the present analysis deals primarily with general trends in the relations among measured variables, and much further work is necessary to explain the deviations from these trends. And finally, the suspended-load data $\varepsilon$ vailable are primarily derived from Western streams. Comparable data on streams in humid areas are most meager. These many restrictions are recognized by the authors who attempt continuously to keep before the mind of the reader the limitations of the data, while emphasizing the general trends rather than the innumerable individual variations.

Explanation of these individual variations and refinement of the general concepts must $\varepsilon$ wait further work.

\section{THE HYDRAULIC GEOMETRY OF STREAM CHANNELS}

\section{CONCEPT OF FREQUENCY OF DISCHARGE}

Before describing the channel characteristics at a given river cross section and how those characteristics change downstream, it appears desirable to discuss by way of definition, frequency of discharge and cumulative frequency, or flow-duration, curves. The hydrologist to whom these conceptions are everydsy tools will pardon the inclusion here of a brief discussion aimed at providing the geologist a picture of frequency relations which is essential to an understanding of what will follow.

The procedure used in making stream measurements is well described in the literature (Corbett, 1943; Linsley, Kohler, and Paulhus, 1949, pp. J82-198).

The daily mean discharge is the average of all rates for a day, and is expressed in cubic feet per second. The mean rate of discharge for each day of the year at measuring stations on many rivers is published by the U. S. Geological Survey in the annual WaterSupply Papers. 
The frequency of a daily mean discharge at a given river gaging station, is determined by counting the number of occurrences of this rate throughout a period of record. In hydrologic practice the number of occurrences is usually presented in the form of a cumulative frequency, or flow-duration, curve, an example of which is presented in figure 1 (after Hembree, Colby, Swenson, and Davis, 1952, fig. 30). To construct such a curve, a number of categories of rates of discharge are arbitrarily chosen. The number of days on which the measured daily mean discharge fell in each category is determined by tallying the data. The numbers in each category are then accumulated from the largest discharge category to the smallest, and each cumulative figure is divided by the total number of days of record. The resultant quotients represent the percent of time given discharges are equalled or exceeded at the station.

These figures representing percent of time are then plotted against discharge to provide the flow-duration curve of which figure 1 is a sample. On it a discharge of $1,000 \mathrm{cfs}$ or more occurs about 8 percent of the time. This means that through a long period, 8 percent of the days, or on the average 8 days in every 100 , experienced a discharge of $1,000 \mathrm{cfs}$ or more.

The cumulative frequency, or duration, of a given daily discharge is expressed as the percent of time that this rate is equalled or exceeded. Discharge rates of the same cumulative frequency may differ, depending on the streams being considered. For example, a point

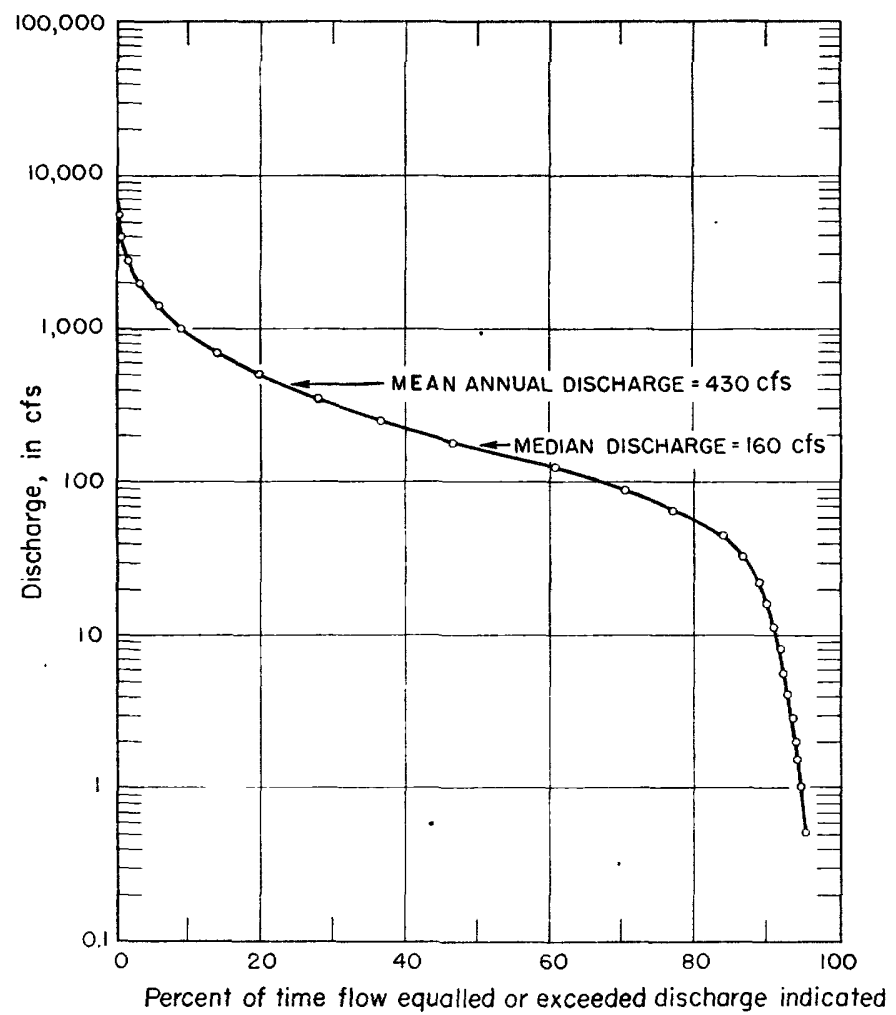

Figure 1.-Cumulative frequency, or flow-duration, curve for Powder River at Arvada, W yo., 1917-50. on a large trunk river and a point on a small tributary may have discharge rates of the same cumulative frequency -or frequency, as it is ordinarily expressed; but discharge in the tributary may be only a few cubic feet per second, and in the trunk river it may be thousands of cubic feet per second.

The median discharge is that discharge which is equalled or exceeded 50 percent of the time; that is, half the days have flow greater than the median, and half less. At Arvada the median flow is about $160 \mathrm{cfs}$. The mean annual discharge, or the arithmetic mean of the flow of all individual days at Arvada is about $430 \mathrm{cfs}$, or almost three times the median. Mean annual discharge is generally greater than median, and the mean rate of discharge is equalled or exceeded on somewhat less than half the number of days at most points on a river.

As a rough generalization, it may be stated that the mean annual rates of discharge at all points on a large number of rivers are equalled or exceeded about the same percent of time.

The values of average annual discharge at measuring stations on many rivers in the United States are readily available in the Water-Supply Papers of the U. S. Geological Survey. For example, the average discharge for the Powder River at Arvada, Wyo., for the period 1916-47 is published with the description of the station in Water-Supply Paper 1086 (1950) on page 237.

For purposes of definition the conception of a varying discharge at a given river cross section and downstream will now be explained. In figure 2 cross sections $A$ and $B$ represent two points on a river at low discharge; $\mathrm{C}$ and $\mathrm{D}$ are the same sections at higher discharge. These sections are shown at the right, as $A, B, C$, and $D$, in their relation to the full Jength of the river and to its watershed at both low and high discharge. Though the highest discharge may flow over bank, this paper is not concerned with discharges above bankful.

These diagrams illustrate the conception that the width and depth of the channel increase at a given river cross section with increase in discharge. Variations in discharge follow a pattern in time that is peculiar to the position of the cross section and to the river. The different discharges at a given cross section vary in frequency. Frequency is a function of the watershed and its hydrologic and physical characteristics.

Under the condition of low discharge represented by the diagram in the upper right corner of figure 2 , it is postulated that every point along the river is experiencing a discharge that is small for that point; or, if all points along a river system are experiencing a relatively low discharge, the frequency of the rate of discharge at any one point is about the same as the frequency of the rate at any other point. Of course the rate of discharge, not its frequency, will generally be much

$219627-52-2$ 


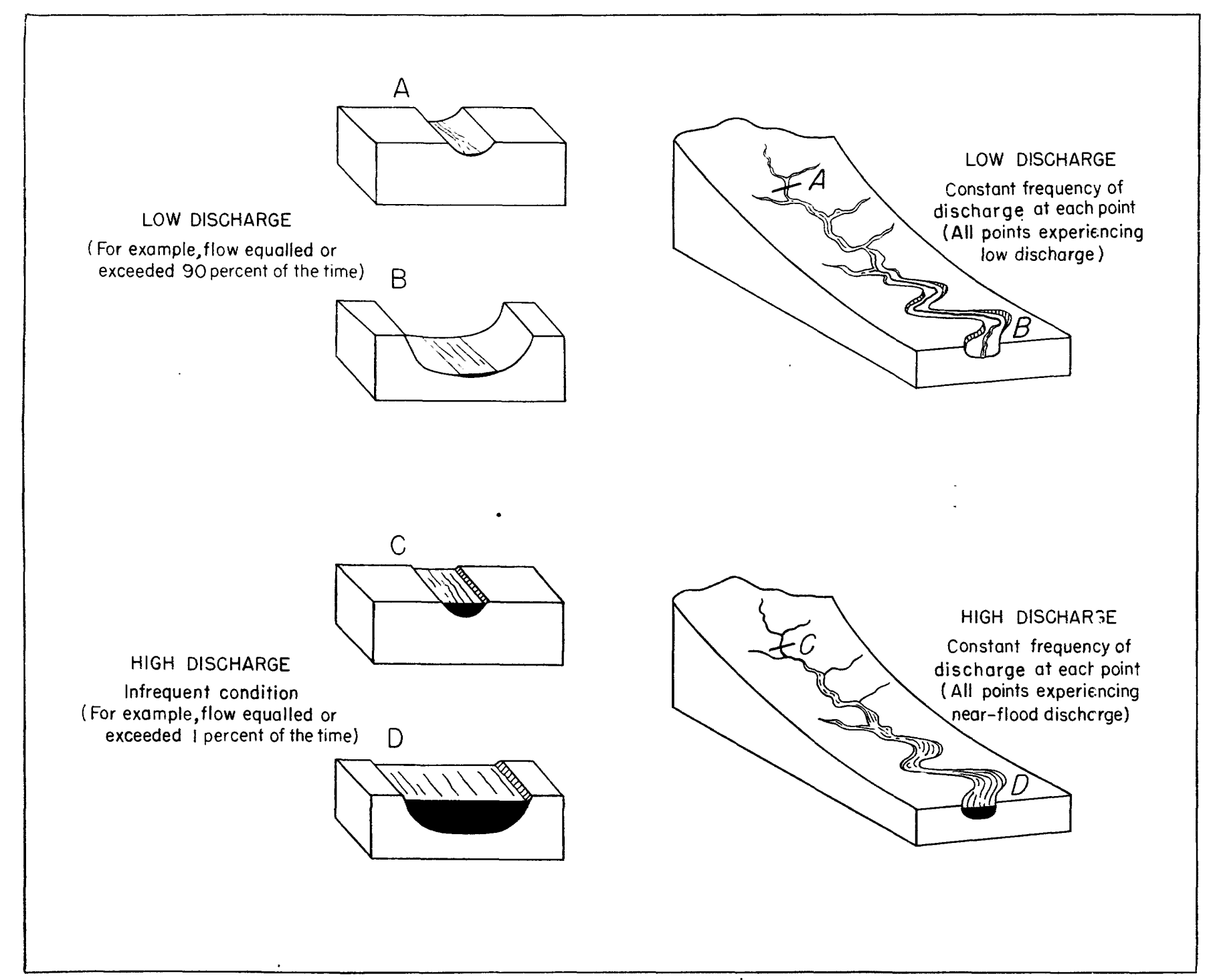

Figure 2.-Comparison of different rates of discharge at a given river eross section and at points downstream.

greater near the mouth of a river draining a large area than at some headwater point. The same postulation is made for the condition of high discharge, as represented by the diagram in the lower right.

The two diagrams of the watershed are introduced to emphasize the points, first, that at a given cross section different discharges have different frequencies; and second, that at cross sections situated at various points along the stream the rates of discharge are usually different, one from another. Comparison of the various cross sections along a stream is made in this paper only under the assumed condition that they are experiencing equal frequency of discharge.

The term "at a station" is used in this paper to mean at a given cross section, and the term "in a downstream direction" refers to cross sections situated along the length of a stream. "Change of discharge downstream" means different discharges of the same frequency at. cross sections situated along the length of a stream.

The differences in discharge both at a station and in a downstream direction are associated with differences in width, depth, and velocity, as will be shown later.

\section{VARIATION OF HYDRAULIC CHARACTERIFTICS IN A PARTICULAR CROSS SECTION OF A JPIVER}

Changes in velocity, depth, and width of flowing water take place as the discharge increases at a particular cross section of a river. Because river cross sections tend to be roughly semielliptical, trapezoidal, or triangular, increasing discharge results in an incresse of each of the other three factors. Typical relations of width, depth, and velocity to discharge will be show'n for various points on different rivers. 'These relations will show that these three factors generally increase with increasing discharge as simple power functions.

In figure $3 A$ a number of variables are esch plotted against river stage. Stage, or gage height, is the elevation of the water surface above some arbitrary datum, and is the quantity recorded by the water-level recorder of a stream gage. The discharge, width, and mean 
velocity are plotted against stage as ordinate. For comparison, width, depth, and velocity are plotted on logarithmic scales against discharge in figure $3 B$.

When velocity is measured by current meter at a gaging station for the purpose of computing discharge, the width of water surface and the depth and velocity at various positions in the cross section are recorded. Figure 3 and other similar figures to be discussed were constructed from current-meter measurements.

The current-meter data which include measurements of width of water surface, depth, and velocity at various points across the river measuring-section, are filed in the district offices of the U. S. Geological Survey and are available to the public for inspection and use. The original records must be used or copied in the Survey office, otherwise appropriate arrangements must be made to insure against loss of the originals.

The plot of stage (gage height) against discharge is, in engineering parlance, the rating curve of a station. Rating curves of all stream cross sections are similar in that the increase of discharge per unit increase of stage is greater for high than for low discharges. Thus the general form of the curve is typical of all open channels.

The width plotted in figure 3 is the width of the water surface at any given gage height.
In stream-gaging practice, the depth and velocity are measured at various distances from the bank. From: these depth measurements and their spacing, the crosssectional area of flowing water is determined.

In this report, the depth represents the mean depth associated with a particular rate of discharge, and was determined by dividing the measured cross-sectional area of flowing water by the corresponding width of water surface. This provides, then, a mean depth equal to the depth of a rectangular channel having the same surface width as the actual channel at the given stage and having the same cross-sectional area.

Velocity discussed in this report is the quotient of discharge divided by the area of the cross section, and is the mean velocity of the cross section as used in hydraulic practice (see Linsley, Kohler, and Paulhus, 1949 , p. 197). This mean velocity is not the most meaningful velocity parameter for discussing sediment transport but it is the only measure of velocity for which a large volume of 'data are available. Although the writers recognize its limitations, the mean velocity is used here in lieu of adequate data on a more meaningful parameter.

Figure $3 A$ demonstrates that if width and velocity are plotted against river stage, there is considerable
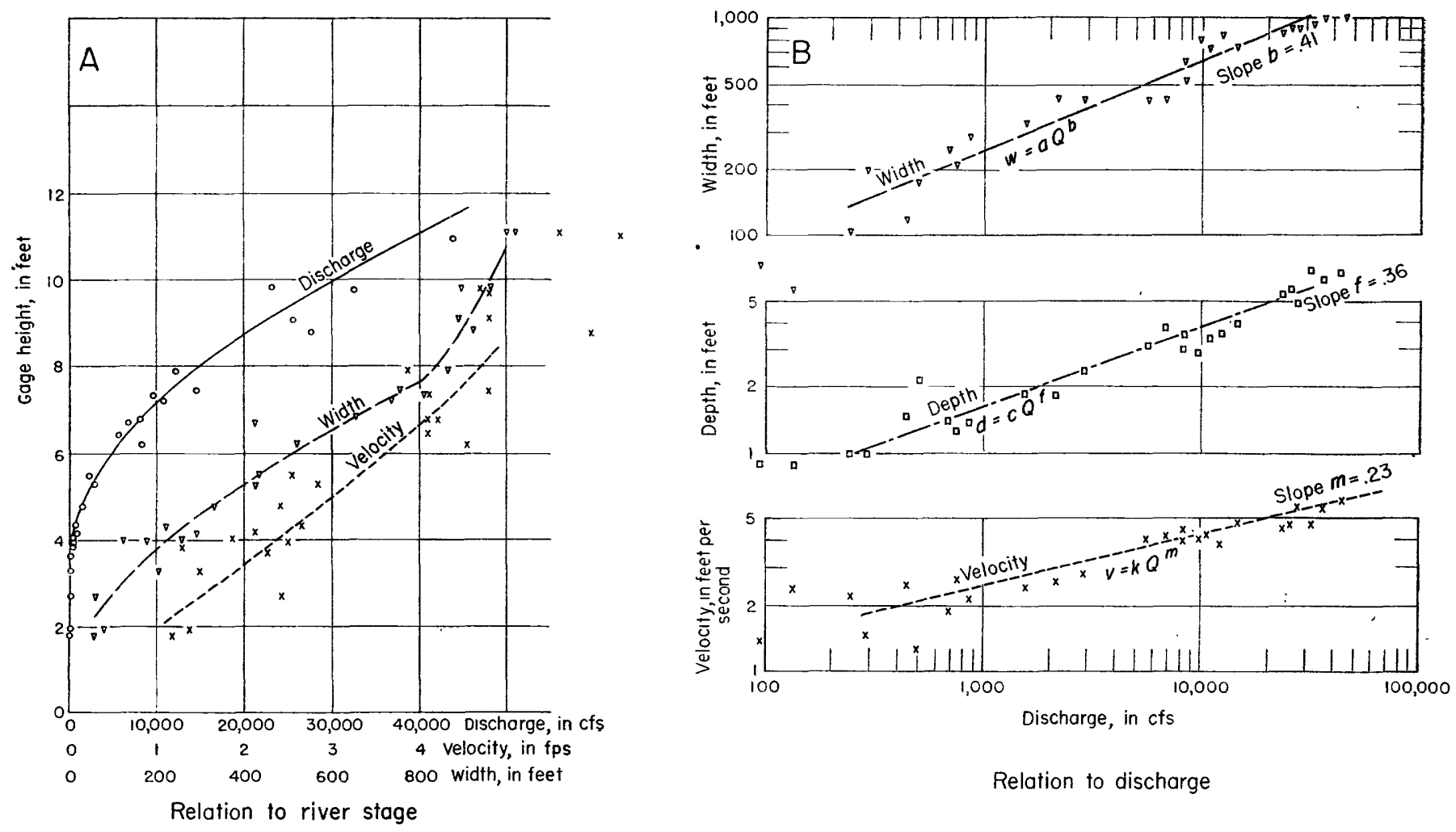

Relation to discharge

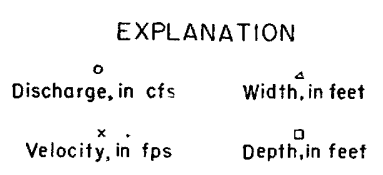




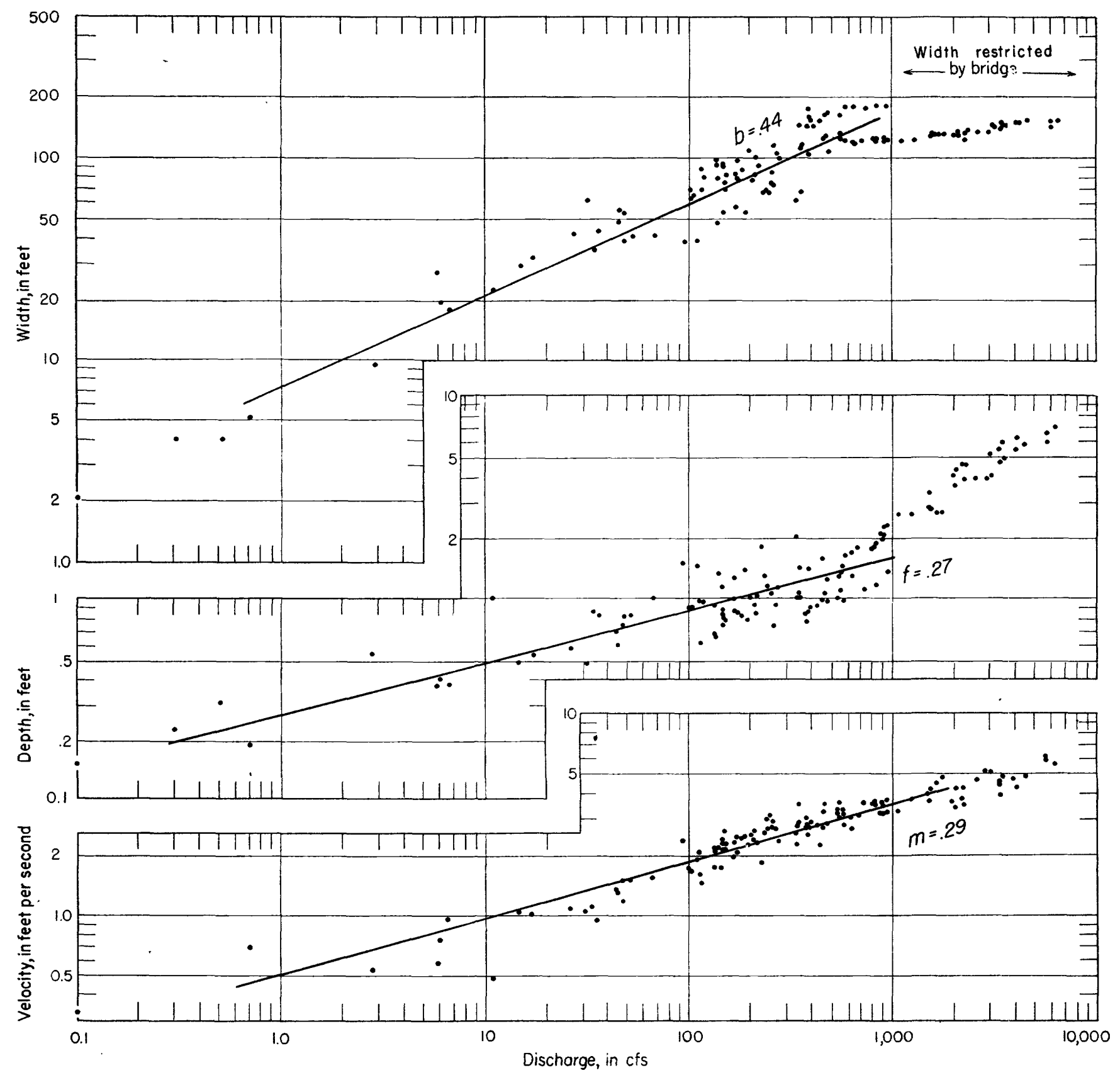

Figure 4, A.--Relation of width, depth, and velocity to discharge, Powder River at Arvada, Wyo. 


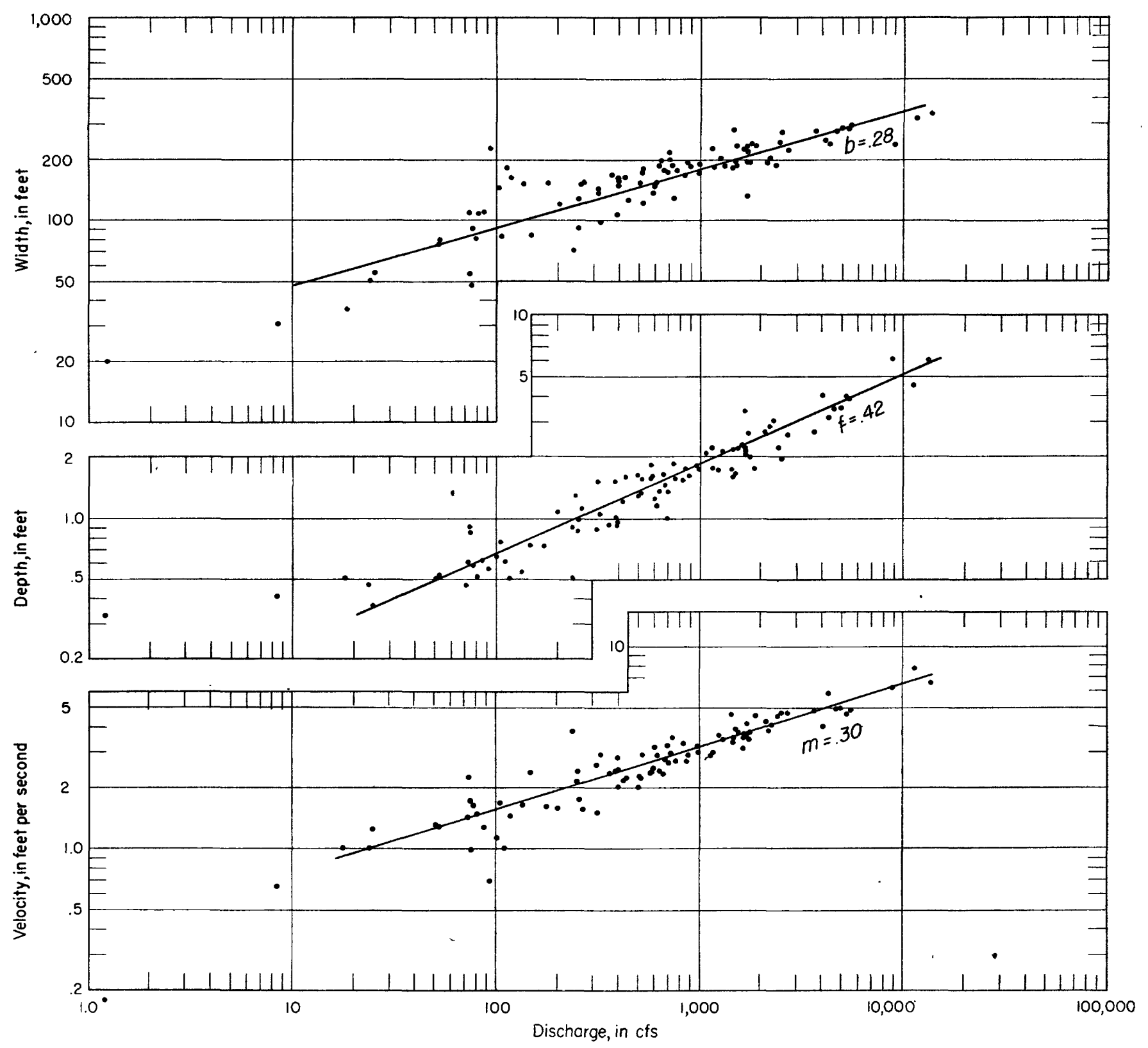

FIgURE 4, B.-Relation of width, depth, and velocity to discharge, Powder River at Locate, Mont. 
scatter of points and the curve defined is not easily expressed mathematically. If width, depth, and velocity, are plotted against discharge on logarithmic paper, their relations to discharge are expressed by nearly straight lines, as can be seen in figure $3 B$, and this may be simply expressed mathematically.

Figure $3 B$ is typical of a large number of gaging stations for which similar curves were drawn. The slopes and intercepts of the lines varied somewhat between stations but straight lines on logarithmic paper typified the relations in the data studied.

Other examples of these curves are presented in figure 4 to indicate that through a considerable range of discharge this method of plotting provides essentially straight lines on logarithmic paper. There is considerable scatter of the points on these graphs. Part of the scatter apparently results from temporary scour and fill of the stream bed. At the lower discharges measured by wading rather than from a bridge or cable, part of the scatter of points may be attributed to the fact that successive measurements are not made at exactly the same cross section. For present purposes, the general positions of the lines representing mean relations are of interest and further work will be required to study the causes and import of the scattering of the data.

In the present study every available current-metel discharge measurement was plotted for stations having . short records. For stations having long records, of which figures 3 and 4 are typical, the measurements to be plotted were chosen at random from the available data. Enough measurements were obtained to define the curve through the whole range of discharge of the - particular station.

A gaging station is installed at a river cross section where the relation of discharge to stage is as stable as possible. Specifically, a location is chosen if possible where discharge plots against gage height in a smooth curve. For this reason gages are installed either upstream from a "section control," where critical velocity (in the hydraulic sense) is attained over some outcrop or gravel bar, or in a reach of channel where the channel properties determine the stage-discharge relation. The latter, called a "channel control," merely means a relatively straight and uniform reach generally devoid of unusual riffles or bars.

In periods of low water, current-meter measurements are ordinarily made by wading. When wading is impossible, current-meter measurements are often made from bridges.

The cross section of a stream at a gaging station above a section control is not representative of an average reach of channel, particularly at high discharges. More representative sections are found at gaging stations having channel control. These stations are often equipped with a cable car from which the current meter may be operated.
In the following discussions, gaging stations having channel control and cross sections gaged from a cable car were chosen when possible. Miany stations where measurements were made from bridges were used for lack of more representative data, but these measurements were utilized only for low stages where width was still increasing with gage height; that is, stages lower than those where bridge abutments constrict the flow.

Excluding the unnatural effects introduced by constriction such as bridge abutments, the data analyzed indicate that through ranges of discharge up to the bankful stage, the relations of width, depth, and velocity to discharge in a natural stream section are in the form of simple power functions and plot as straight lines on logarithmic paper. When the river overflows its banks, of course width increases rapidly and a new relation to discharge obtains which will not be considered here.

The artificial effects introduced by atypical locations of gaging stations do not appear to invalidate the conchusion just expressed.

It can be stated that the relation of disch arge to other hydraulic factors in natural river cross sections can be described.by the expressions:

$$
\begin{aligned}
& w=a Q^{b} \\
& d=c Q^{f} \\
& v=k Q^{m}
\end{aligned}
$$

where $Q$ is discharge, $w, d$, and $v$ represent water-surface width, mean depth, and mean velocity, respectively. The letters $b, f, m, a, c$, and $k$ are numerical constants.

Because width, depth, and velocity are each a function of discharge as described by the formulas above, the three equations can immediately be related to one another through the identity

$$
Q \equiv \text { area } \times \text { velocity, or, } Q=w d v
$$

substituting from the above

$$
\begin{aligned}
& Q=a Q^{b} \times c Q^{s} \times k Q^{m} \\
\text { or } \quad & =a c k Q^{b+f+m}
\end{aligned}
$$

It follows therefore that

and

$$
b+f+m=1.0
$$

$$
a \times c \times k=1.0
$$

In figures $3 \mathrm{~B}$ and 4 , the constants, $b, f$, and $m$ represent the slopes of the three lines on the graph, and the sum of these slopes must equal unity. The values of the slope of the lines are indicated in the figures and their sum is indeed unity. 
The constants, $a, c$, and $k$ represent the intercepts of the lines and are respectively, values of $w, d$, and $v$ at discharge of unity. Because the values of discharge in the actual data are generally much larger than unity, the product of $a \times c \times k$ is not computed at unit discharge but might better be considered in the following light. The product of the values of width, depth, and velocity at any given discharge must equal that discharge. For example, in figure $3 \mathrm{~B}$, at $1,000 \mathrm{cfs}: w=245 \mathrm{ft}, d=1.7 \mathrm{ft}$, and $v=2.4 \mathrm{fps}$; their product $w \times d \times v$ equals 1,000 .

Because it has been stated that as a general rule equations (1), (2), and (3) characterize hydraulic relations for representative natural stream channel cross sections, it is logical to inquire how the slopes and intercepts represented by the numerical constants vary among streams, and what range of numerical values they represent. Width and depth for a given discharge vary widely from one cross section to another and, therefore, the intercept values, $a, c$, and $k$, will vary. Further work is necessary to determine the factors which govern these variations and to determine the extreme limits. However, there is some consistency in values of the slopes of the lines for different streams as will now be explained.

Average values of the exponents $b, f$, and $m$ have been computed for 20 river cross sections representing a large variety of rivers in the Great Plains and the Southwest. Though these particular averages are biased toward semiarid conditions, they nevertheless provide some indication of the order of magnitude of typical values. These averages are

$$
\begin{aligned}
& b=0.26 \\
& f=0.40 \\
& m=0.34
\end{aligned}
$$

The appendix includes a summary of some of the data from which the above values were derived. For each station, graphs similar to figure $3 B$ were plotted from current-meter measurements, and a straight line was drawn by eye through the points. No statisticalfitting procedure was used in drawing the line because the use to which the data are to be put did not appear to justify such accuracy. The slope of each line was measured directly from the graph.

That the values of the exponents $m, b$, and $f$ were averaged for the 20 river cross sections does not imply any expectation that the values should be closely similar. The mean values are presented so that the relative order of magnitude of the three exponents can be visualized. In a later section a partial and tentative explanation of the variability of these exponents among various rivers will be given.

For present purposes it is sufficient to note that at most river cross sections, depth increases with discharge somewhat faster than does width $(f>b)$. The ratio of width to depth decreases with increasing flow through the channel.

The relative rates of increase of width and depth are functions of channel shape. It can easily be shown thet a channel of triangular shape is the only channel $\mathrm{fc}^{\text {r }}$ which the width-to-depth ratio remains constant with changing discharge. Trapezoidal and elliptical charnels are characterized by a decrease of the width-todepth ratio, and in rectangular channels the width-tcdepth ratio decreases with increasing discharge at a rate even faster than in trapezoidal sections.

In summary, relations of width, depth, and velocity to discharge in the natural river cross sections studied are in the form of simple power functions. The relative rates of increase of width, depth, and velocity are determined by the shape of the channel, the slope of the water surface, and by the roughness of the wetter perimeter. It is emphasized again that the foregoing discussion is merely a description of natural river cross sections. The discussion of how width, depth, velc.city, discharge, slope, and roughness interact to provide the observed relations is reserved until after the descriptive presentation is completed.

The aspect of the above discussion which is different from relations discussed in the voluminous literature on open-channel hydraulics is the plotting of width, depth, and velocity against discharge on logarithmis paper. A straight-line relation between gage height and discharge on logarithmic paper is widely known and is used in many offices of the Geological Survey in the construction of rating curves for river sections having a shifting control.

\section{VARIATION OF HYDRAULIC CHARACTERISTICS IT A DOWNSTREAM DIRECTION}

Frequency of discharge is especially important in an understanding of the hydraulic geometry of riven systems and how the width, depth, and velocity of natural rivers change in a downstream direction.

As already emphasized, comparison of various cross sections along the length of a river is valid only under the condition of constant frequency of discharge at all cross sections.

The mean annual discharge is equalled or exceeded about the same percent of time on a large number of rivers. It represents roughly the discharge equalled or exceeded 1 day in every 4 over a long period. Though exactly the mean annual discharge may not occur at all points on any given day of record, it is closely approximated for a large number of days each year.

The data forming the basis of the discussion which follows are again current-meter measurements made, at gaging stations of the Geological Survey.

The width, depth, and velocity corresponding to the mean discharge are plotted against mean discharge in igure 5 for all the gaging stations on all tributaries tc 


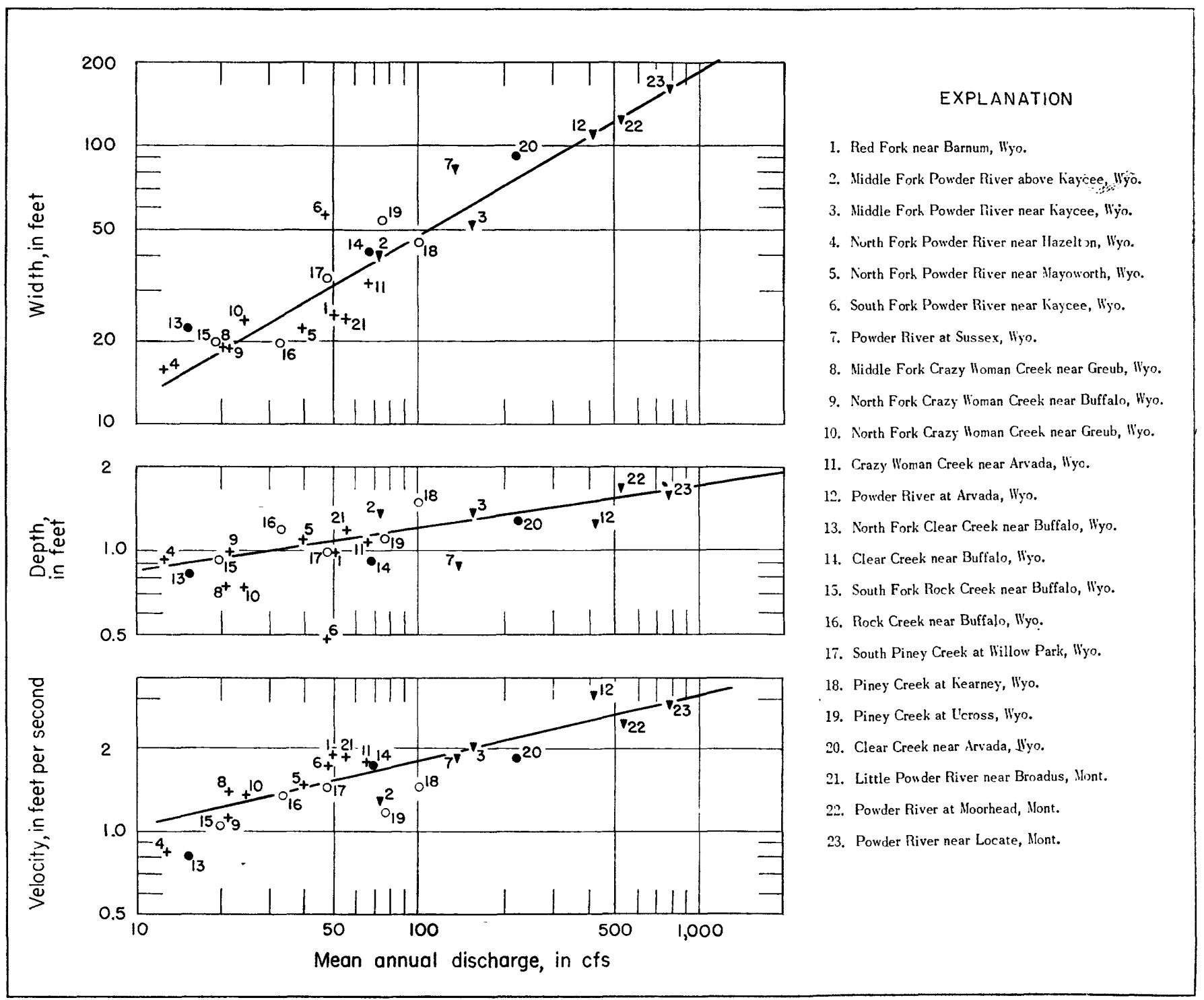

FI, TRE 5.-Width, depth, and velocity in relation to mean annual discharge as discharge increases downstream, Powder River and tributaries, Wyoming and Montana.

the Powder River in Wyoming and Montana for which adequate data were available. Each gaging station provides one point in each of the plotted diagrams. Throughout the figure the abscissa value for each gaging station is its mean annual discharge.

For purposes of comparison, similar graphs representing the change of width, depth, and velocity with average annual discharge downstream are presented in figures 6-8. These represent the Bighorn River and tributaries in Wyoming and Montana, the Arikaree, Republican, Smoky Hill, and Kansas Rivers in the Kansas-Nebraska region, and gaging stations along the main trunk of the Missouri and lower Mississippi Rivers.

Proceeding downstream in a given river, the discharge tends to increase because of the progressively increasing drainage area, though of course there are some streams in which discharge decreases downstream, particularly in arid areas. It can be seen that for all the rivers plotted, the depth, width, and velocity tend to increase progressively as power functions of discharge. There is again considerable scatter of points in the graphs. There are reaches of the rivers represented in figures $5-8$ on which either widtl, or depth, or velocity decreases downstream. The present paper, however, is concerned with the general trends and further work will be necessary to explain the details of deviations from these trends.

The graphs of figures 5-8 are referred to as the changes in width, depth, and velocity with increasing discharge in the downstream direction. It will be understood that a small tributary having a relatively low mean annual discharge may enter the main trunk far downstream, but its plotted position on the abscissa scale will be determined by its mean discharge.

Strictly speaking, the "downstream" grephs in figures 5-8 show how width, depth, and velocity change with discharges of equal frequency. Discharges of 


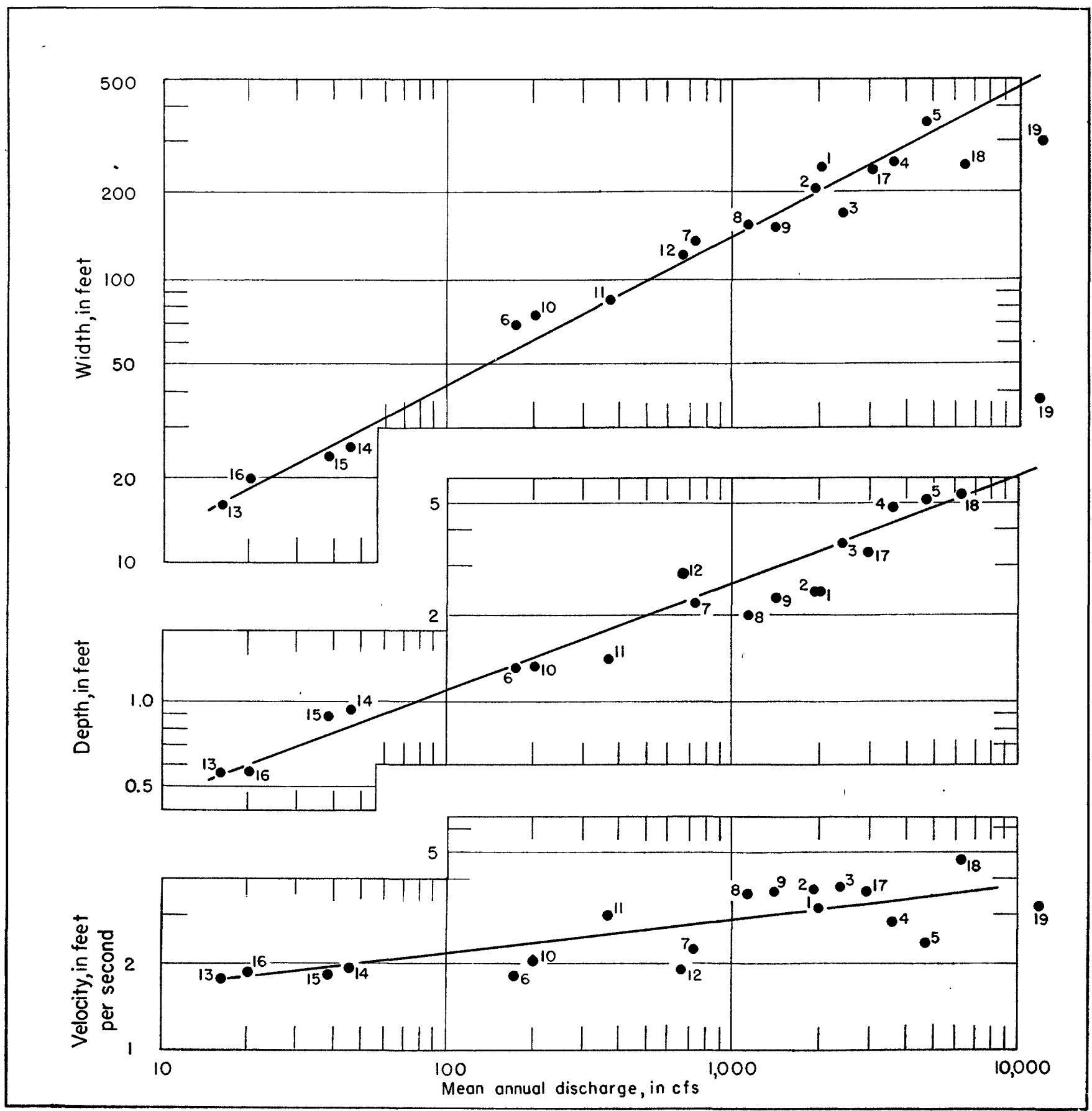

FrGURE 6.-Width, depth, and velocity in relation to mean annual discharge as discharge increases downstream, Bighorn River and tributaries, Wyoming, and Montana, and Yellowstone River, Montana.

\section{EXPLANATION}

1. Bighorn River at Manderson, Wyo.

2. Bighorn River at Thermopolis, Wyo.

3. Bighorn River at Kane, Wyo.

4. Bighorn River St. Xavier, Wyo.

5. Bighorn River near Custer (Hardin), Mont.

6. Wind River near Dubois, Wyo.

7. Wind River near Burris, Wyo.
8. Wind River at Riverton, Wyo.

9. Wind River near Crowheart, Wyo.

10. Greybull River near Basin, Wyo.

11. Greybull River at Meeteetsee, Wyo.

12. Popo Agie River near Riverton, Wuo.

13. North Fork Owl Creek near Anchor, Wyo.

14. Owl Creek near Thermopolis, Wyo.
15. Medicine Lodge Creek near Hyattville, Wyo.

16. Gooseberry Creek near Grass Creek, Wyo.

17. Yellowstone River at Corwin Springs, Mont.

18. Yellowstone River at Billings, Mont.

19. Yellowstone River near Sidney, Mont. 

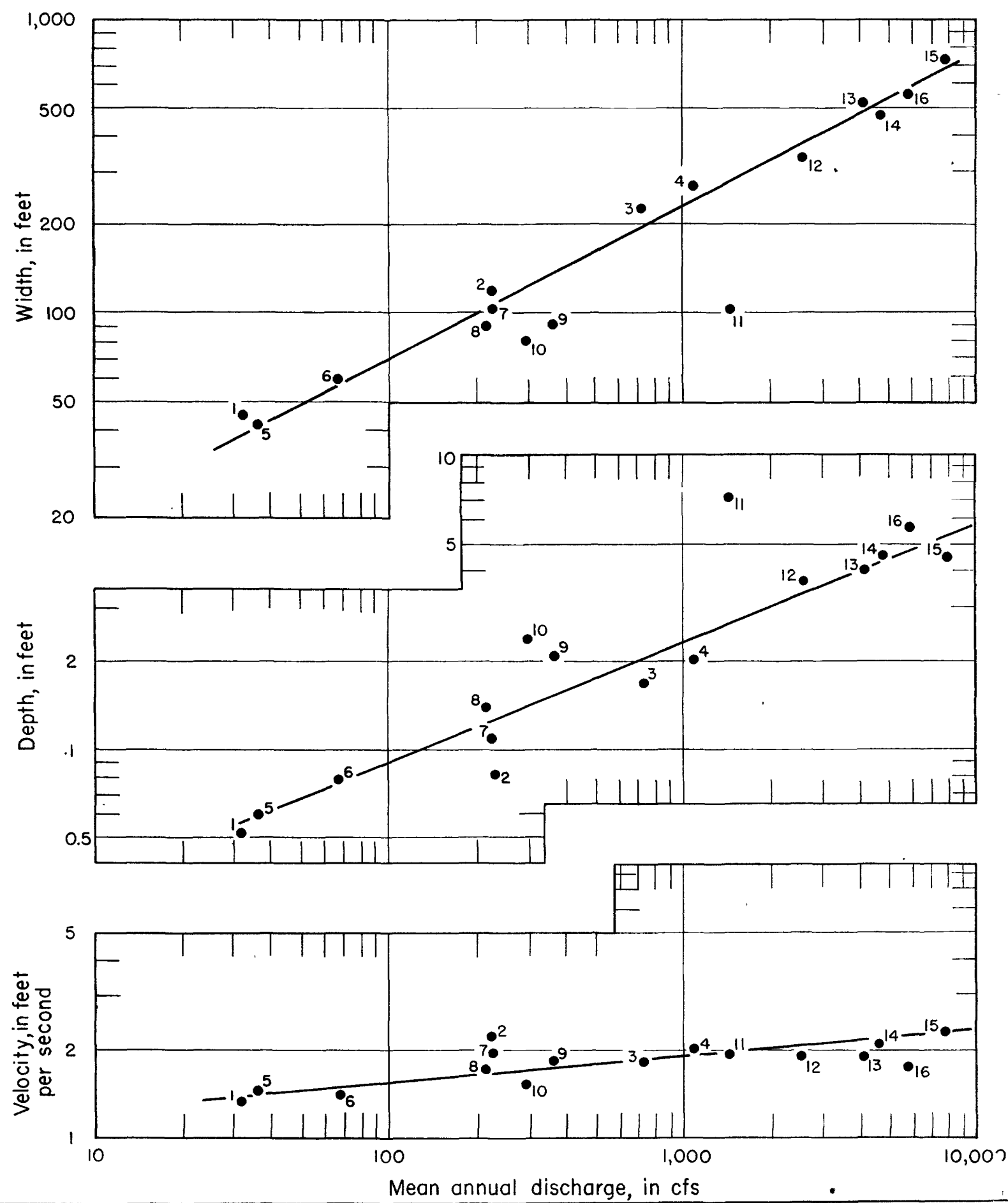

FIGURE 7.-Width, depth, and velocity in relation to mean annual discharge as discharge increases downstream, Arikaree, Republican, Smoky Hill, and Kansas Rivers in the Kansas River system, Kansas and Nebraska.

\section{EXPLANATION}

1. Arikaree River at Haigler, Nebr.

2. Republican River at Culbertson, Nebr.

3. Republican River near Bloomington, Nebr.

4. Republican River at Clay Center, Kans.

5. Smoky Hill River at Elkader, Kans.

6. Smoky Hill River at Ellis, Kans.
7. Smoky Hill River at Russell, Kans.

8. Smoky Hill River at Ellsworth, Kans.

9. Smoky Hill River near Langley, Kans.

10. Smoky Hill River at Linsborg, Kans.

11. Smoky Hill River at Enterprise, Kans.

12. Kansas River at Ogden, Kans.
13. Kansas River at Wamego, Kans.

14. Kansas River at Topeka, Kans.

15. Kansas River at Lecompton, Kans.

16. Kansas River at Bonner Springs, Kans. 


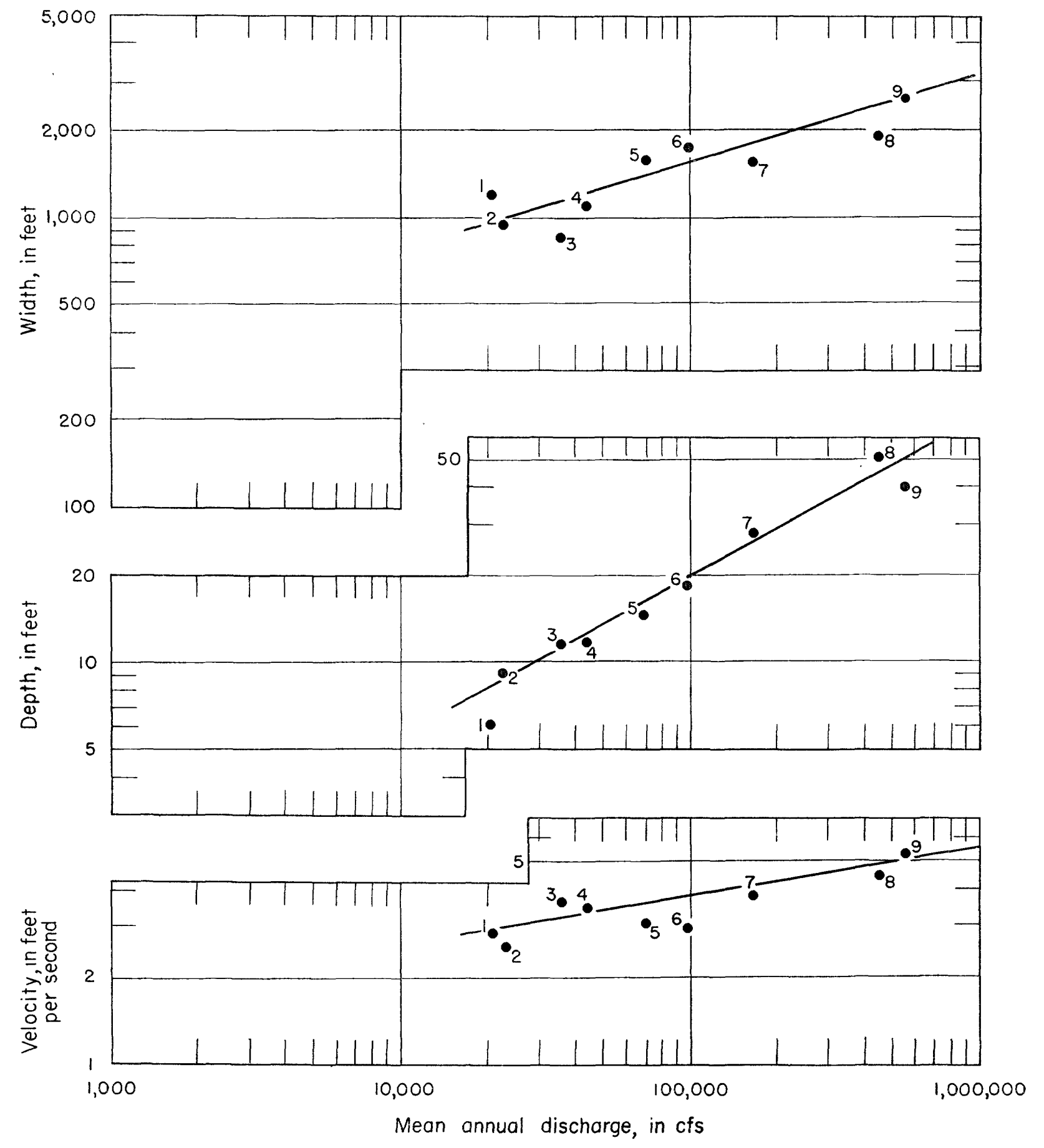

FIGURE 8.-Width, depth, and velocity in relation to mean annual discharge as discharge increases downstream, main trunk of Missouri and lower Mississippi Rivers. EXPLANATION

1. Missouri River at Bismarck, N. Dak.

2. Missouri River at Pierre, S. Dak.

3. Missouri River at St. Joseph, Mo.
4. Missouri River at Kansas City, Mo.

5. Missouri River at Hermann, Mo.

6. Mississippi River at Alton, Ill.
7. Mississippi River at St. Louis, Mo.

8. Mississippi River at Memphis, Tenn.

9. Mississippi River near Vicksburg, Miss. 
equal frequency tend to increase downstream with.increasing drainage area. The phrase "in the downstream direction" is merely used as a short designation for this conception.

By use of the graph, tributaries can be compared directly with the trunk stream. On figure 5 the gaging stations on the main trunk of the Powder River (as an example, point 7) and a single large headwater fork (Middle Fork, point 2) are designated by the solid triangles. Stations on a single tributary, Clear Creek (point 14), and its headwater tributary, North Fork of Clear Creek (point 13), are designated by solid circles. Each of these two sets of points describe a single river stem and are downstream graphs uncomplicated by tributaries. It can be seen that were lines to be drawn through those two sets of points, separately, there would be a difference from the lines on the graphs representing the Powder River basin as a whole. Yet the difference is astonishingly small.

The general alinement of points on the downstream graphs indicates that in a given river basin where all cross sections are experiencing the same frequency of discharge, the corresponding values of depth, width, and velocity at different cross sections having the same discharge tend to be similar, regardless of where in the watershed or on what tributary the cross sections may be.

The graphs presented are examples chosen from a large number drawn for various river systems in the United States. Figure 9, with the plotted points through which the mean lines were drawn eliminated, presents similar graphs for selected river basins. Rivers were chosen to represent a diversity of geographic location, and physiographic and geologic types. The basins are also considerably different in size. To indicate this diversity of size of drainage area, the stations used to represent the Tombigbee River in Alabama have mean annual discharges from 700 to $35,000 \mathrm{cfs}$, whereas the Belle Fourche basin in Wyoming has mean annual discharges ranging from 40 to $600 \mathrm{cfs}$.

The mean lines through the points representing individual gaging stations (figures 5-8 are examples) were fitted by eye. There is considerable scatter of points about the respective mean lines. Moreover, as discussed previously, the points on the graphs represent values of depth, width, and velocity at stream-gaging stations situated at positions not uniformly representative of the average river cross sections. Despite the possible variations that might be introduced by these considerations, there is a tendency toward parallelism of the lines on the graphs in figure 9 . As a rough generalization, it may be stated that in a downstream direction the rates of increase in width, depth, and velocity relative to discharge are of the same order of magnitude for rivers of different sized drainage basins and of widely different physiographic settings.

Some river basins studied have too small a range of mean annual discharge between small tributaries and the main stem to allow determination of the slope of the lines. A few river systems studied proride lines with slopes quite different from the majority. Figure 9 includes one such anomaly, the Loup River system, in order to demonstrate the range of slopes of lines found in the data studied. In the example of the Loup River, the ground-water contribution from the sand hills at the headwaters is believed to be partl'? responsible for its anomalous behavior.

The streams chosen to be included in figuro 9 differ markedly in physiographic setting. The Tombigbee River of Alabama is a coastal-plain stream, narrow and deep. At a discharge of 1,000 efs its depth is about 7.5 $\mathrm{ft}$ and its width $110 \mathrm{ft}$. The Republican and Kansas Rivers are typical streams of the Great Plains. They are relatively wide and shallow. At 1,000 cfs the lines representing these streams indicate a mean depth of $2.3 \mathrm{ft}$ and a width of about $250 \mathrm{ft}$. In other words, the intercepts of the graphs on figure 9 differ greatly among rivers but the slopes of the lines are similar in magnitude. The rates of increase in depth, width, and velocity with discharge downstream may bs similar among rivers despite marked differences in the width to depth ratio at any particular discharge.

From the data in figure 9 and other similar data it. appears that the velocity tends to increase with mean annual discharge downstream in all the rivers studied. It must be remembered that this generalization is restricted to the situation in which discharre at all points along the river is of similar frequency.

Most geomorphologists are under the impression that the velocity of a stream is greater in the herdwaters than in the lower reaches. The appeararce of a mountain stream, of course, gives the impression of greater kineticity than that observed in a large river downstream. The impression of greater velocity upstream stems in part from a consideration of river slopes which obviously are steeper in the upper than in the lower reaches. It will be recalled, however, that velocity depends on depth as well as on slope, as shown in the Manning equation

$$
v=\frac{1.5}{n} d^{\frac{2}{2} s^{\frac{1}{2}}}
$$

where depth, $d$, is approximately equal to hydraulic radius for natural river sections, $v$ is mean velocity, $n$ is channel roughness, and $s$ is slope. It is recogrized that slope, $s$, in equation (4) is the slope of the energy grade line: For practical purposes throughout mo $* t$ of the discussion in the present paper, slope of the river profile sufficiently approximates the energy gradient for equation (4) to be used as if the slopes were identical.

The fact that velocity increases downstream with mean annual discharge in the rivers studied indicates that the increase in depth overcompensates for the decreasing river slope. The magnitude of this rate of 


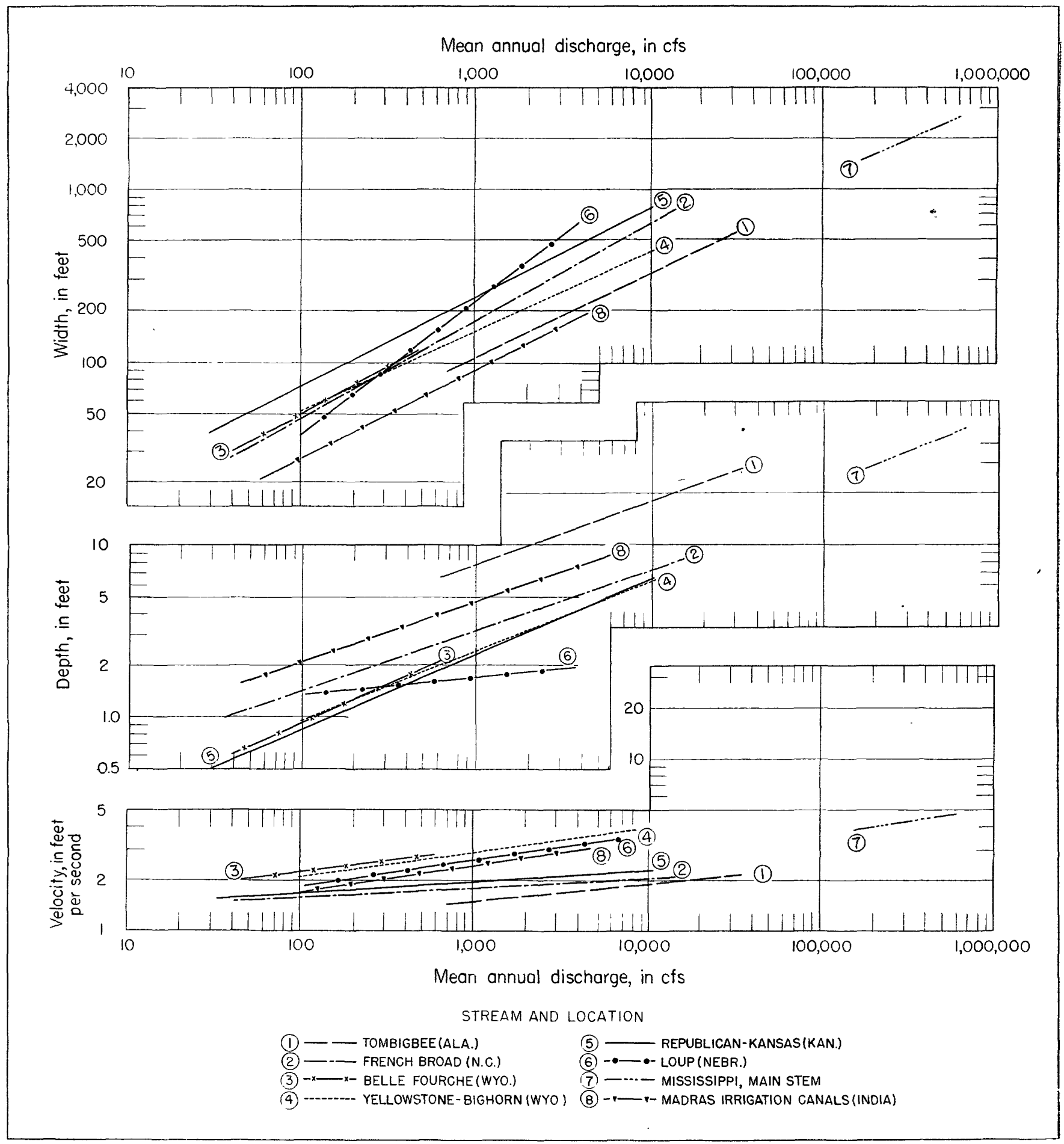

FIGURE 9.-Width, depth, and velocity in relation to mean annual discharge as discharge increases downstream in various river systems.

change becomes clear by comparison of the exponents of depth and slope. In equation (4) the velocity depends on depth to the power $\frac{2}{3}$ and on slope to the power $\frac{1}{2}$. Increasing depth tends to increase velocity in a downstream direction. A variation of roughness in the downstream direction will also affect the rate of change of velocity and will be discussed later.
In summary, the rate of increase of depth downstream tends to overcompensate for the decreasing slope and tends to provide a net increase of velocity at mean annual discharge in the downstream direction of a river.

The straight-line relations on logarithmic paper show, just as they do for a particular river cross section, th at 
width, depth, and velocity increase downstream with discharge in the form of simple power functions,

$$
\begin{aligned}
& w=a Q^{b} \\
& d=c Q^{f} \\
& r=k Q^{m}
\end{aligned}
$$

The coefficients and exponents are assigned the same letters as for a given cross section of a river, but the values will be different for points in a downstream direction from those for the given section. Average values of the exponents for river basins studied are

$$
\begin{aligned}
b & =0.5 \\
f & =0.4 \\
m & =0.1
\end{aligned}
$$

To recapitulate, both at a given river cross section and in the downstream direction at mean annual discharge, width, depth, and velocity increase with discharge. The functions representing these relations are similar but involve different exponents and numerical constants.

\section{RELATION OF CHANNEL SHAPE TO FREQUENCY OF DISCHARGE}

Thus far the changes in hydraulic characteristics downstream in a river system have been considered only for a discharge equal to the mean annual rate at each point. Comparison of the data already presented will now be made with similar data for infrequent flows.

Computation of the frequencies of various discharges at a gaging station has been discussed. The computation is a somewhat laborious task. Complete cumulative frequency (flow-duration) curves for all streamgaging stations in a watershed are available for only a few localities; one of the best collections of such data is that by Cross and Bernhagen (1949) for Ohio.

It was desired to avoid choosing streams regulated by many reservoirs, and the Maumee and Scioto River basins were selected as being freer of regulation than most major river systems in Ohio. Duration (cumulative frequency) curves were available for 19 gaging stations in these two watersheds. Though the Maumee River flows northeast into Lake Erie and the Scioto south into the Ohio River, the two basins have a common divide, and study of the data showed no significant differences in the hydraulic characteristics for the purposes of this paper.

At each gaging station discharges that were equalled or exceeded $1,4,10,30$, and 50 percent of the time, as well as the mean annual discharge, were selected for study. For each of these discharges, the corresponding velocity, depth, and width were determined by analysis of current-meter data, as explained for figure 3. For each discharge frequency, curves were plotted representing the change of hydraulic factors with discharge in the downstream direction. Figure 10 presents the individual plots of six curves in order to demonstrate the relative goodness of fit. It will be seen that the gaging stations available for the Maumee and Scioto basins did not represent so large a range in discharges as did some of the rivers discussed earlier, and that the points did not fall in so good alinement as in some other basins studied. The width-to-discharge relations are the best; more scatter of points appears on the depth and velocity curves.

For the Maumee and Scioto basins combined the curves of discharge in relation to width, depth, and velocity for each of five frequencies are shown in figure 11.

There is a general parallelism within each family of curves, but this is somewhat more consistert in the width-to-discharge than in the velocity-to-discharge relation. In these data it appears that, with less frequent discharges (flood flows), the velocity increases somewhat faster with discharge downstream than it does in low flows. A similar study made for flood flows in some tributaries to the Yellowstone River in Wyoming showed that velocity remained nearly constant downstream despite a rapid decrease in slope.

It can be seen that there is a pattern of interrelationship of stream characteristics which includes relative frequency of discharge, and it is now possible to define important aspects of the hydraulic geometry of stream channels. An understanding of this geometrir is basic to consideration of the adjustment of channel shape to carry the sediment load supplied to the streams. The relation of at-a-station characteristics to the downstream characteristics will now be discussed.

In basin $\mathrm{A}$ of figure 12 the line $\mathrm{A}-\mathrm{C}$ shows the increase of width with increase of discharge at an individual gaging station near the headwaters of a stream, and B-D shows the same relationship for a downstream station. If the discharge $A$ is of the same cumulative frequency (say 50 percent of the time) at the headwater gage as discharge $B$ at the downstream gage, then the line $A-B$ is the increase of width with discharge downstream, corresponding to a cumulative frequency of 50 percent. Also if $\mathrm{C}$ and $\mathrm{D}$ have the same cumulative frequency (1 percent of the time), then line $C-D$ is the increase of width downstream at a discharge frequency of 1 percent. Similarly then, E-G is the increase of depth with discharge at the upstream gage, and $\mathrm{E}-\mathrm{F}$ is the increase of depth downstream for a frequency of 50 percent. In the example under discussion, the curves are drawn so that at any frequency the widthto-depth ratio remains constant downstream; that is, $A-B$ is parallel to $\mathrm{E}-\mathrm{F}$.

It was noted earlier that because

$$
Q \equiv w d v
$$

and $w=a Q^{b}, d=c Q^{f}$, and $v=k Q^{m}$, then $b+f+m=1.0$ 


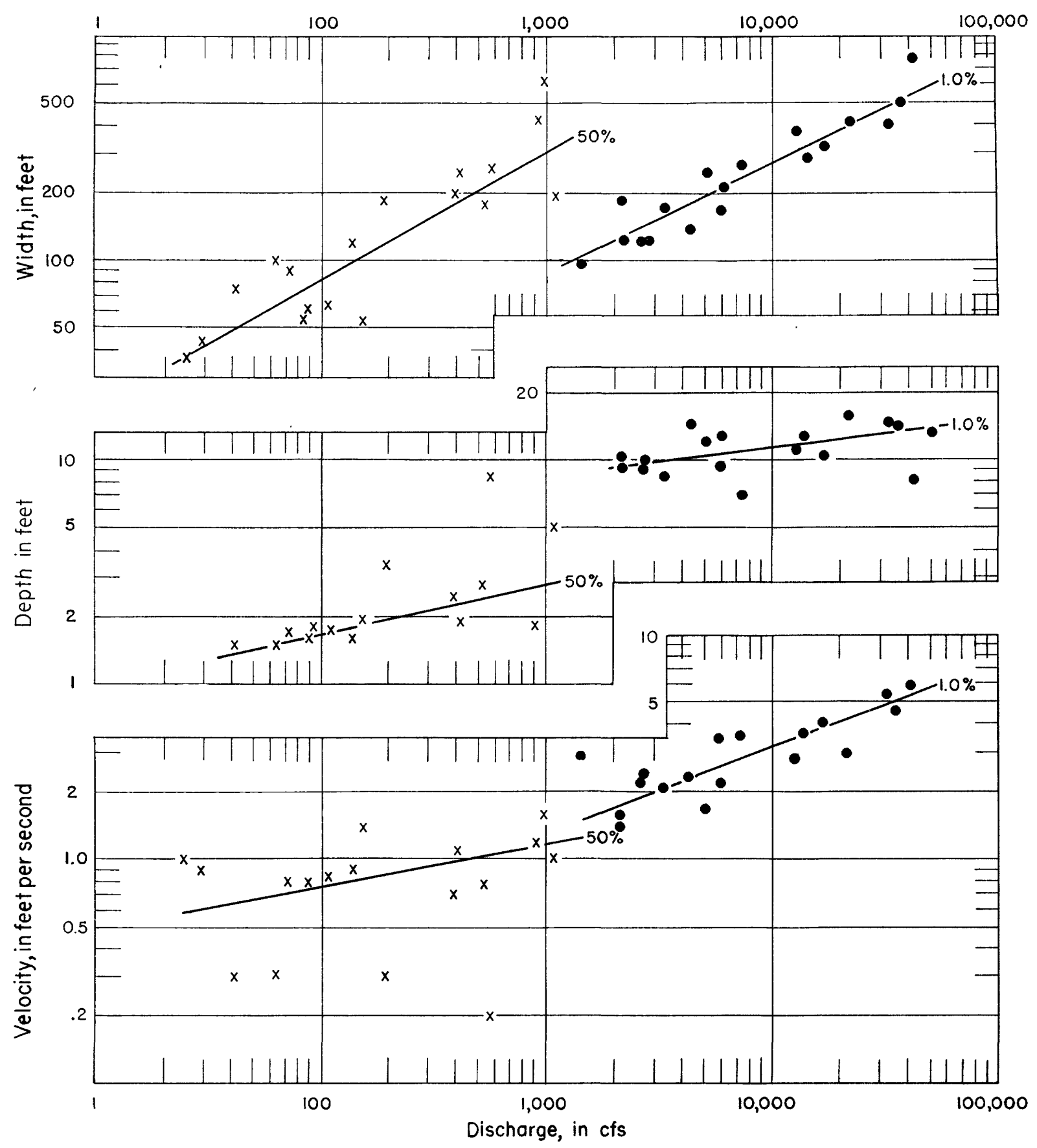

EXPLANATION :- PERCENT OF TIME DISCHARGE EQUALLED OR EXCEEDED : $\left\{\begin{array}{lr}\bullet ; & 1 . \text { OPERCENT } \\ x ; & 50.0 \text { PERCENT }\end{array}\right.$

FIGURE 10.-Width, depth, and velocity in relation to discharges representing two frequencies, Maumee and Scioto River Basins, Ohio.

If the slope of the width-discharge curve for a given frequency is 0.5 (exponent $b=0.5$ ), a typical value for many rivers, and if $\mathrm{A}-\mathrm{B}$ parallels $\mathrm{E}-\mathrm{F}$ (as in fig. 12, basin $A$ ), then the slope of the velocity-discharge curve $\mathrm{J}-\mathrm{K}$, corresponding to the discharge occurring 50 percent of the time, must be zero $(m=0)$. At that fre- quency the velocity does not change downstream. T e line $\mathrm{J}-\mathrm{L}$ is the increase of velocity with discharge at the upstream gage, and $\mathrm{K}-\mathrm{M}$ at the downstream gage. It is clear that at the 1 percent frequency, the velocity is higher at both stations than at the more frequent discharge but does not change downstream. 


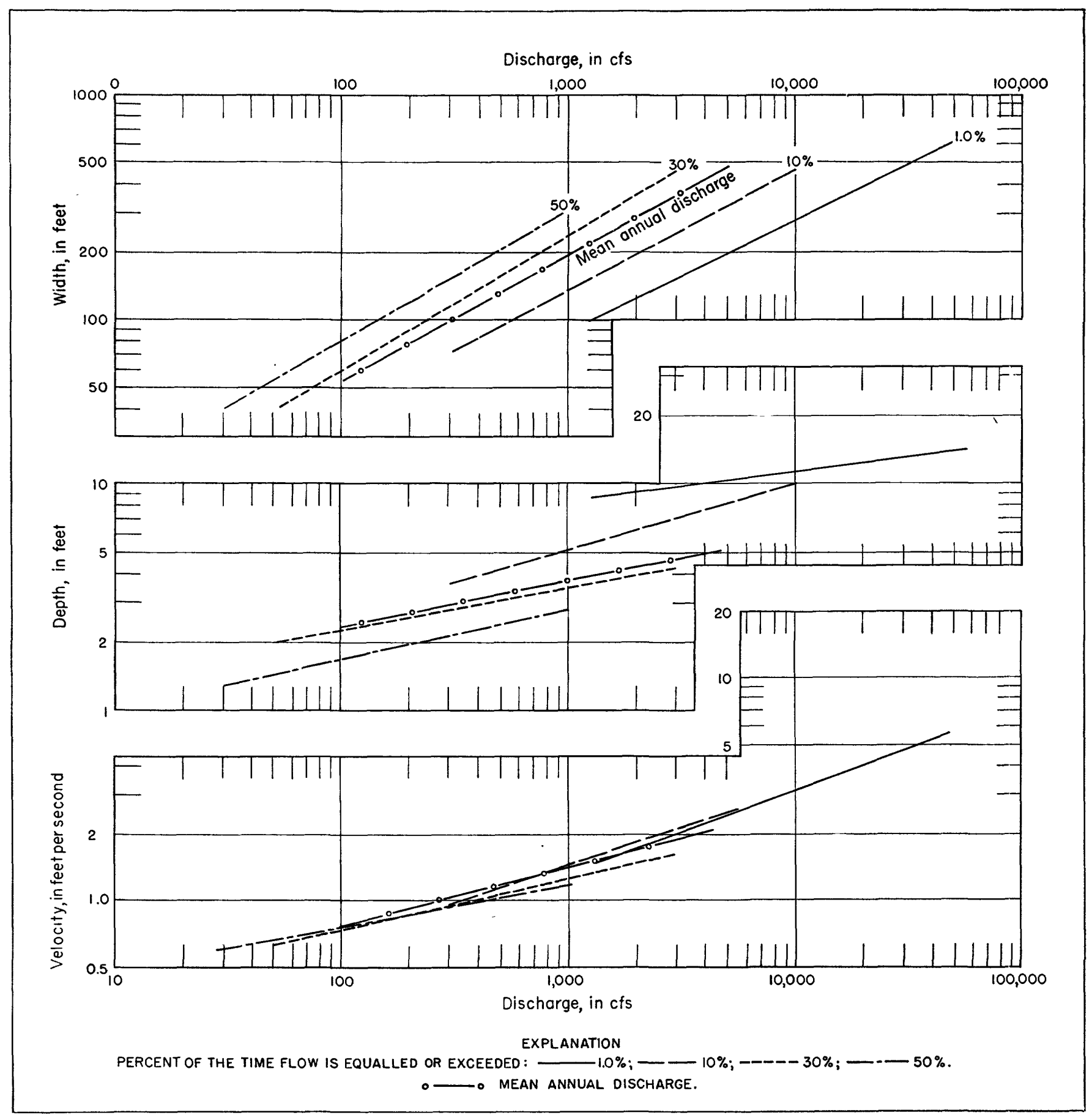

Fraure 11.-Width, depth, and velocity in relation to discharge of various frequencies, Maumee and Scioto River basins, Ohio.

In figure 12 , basin $\mathrm{B}$, the width-to-depth ratio increases downstream at any frequency. This increase is shown by the fact that $\mathrm{A}^{\prime}-\mathrm{B}^{\prime}$ slopes more steeply than $\mathrm{E}^{\prime}-\mathrm{F}^{\prime}$. If the slope of $\mathrm{A}^{\prime}-\mathrm{B}^{\prime}$ is again 0.5 , the steepening of the slope of $\mathrm{J}^{\prime}-\mathrm{K}^{\prime}$ makes the points $J^{\prime}, K^{\prime}, L^{\prime}$, and $M^{\prime}$ fall nearly in a straight line. Basin $\mathrm{B}$ is nearly identical in its geometry with the comparable curves for the Maumee-Scioto basin (fig. 11), and basin A with the Bighorn basin, presented in figure 6 .

The slopes of the width-discharge curves in a downstream direction were made the same in both diagrams.
This is in accord with the data which indicate that the slope of the width-discharge curve downstream is, between basins, somewhat more consistent than the other relations.

The channel characteristics of natural rivers are seen to constitute, then, an interdependent system which can be described by a series of graphs having simple geometric form. The geometric form of the graphs describing these interactions suggests the term "hydraulic geometry." Channel characteristics of a particular river system can be described in terrss of the 


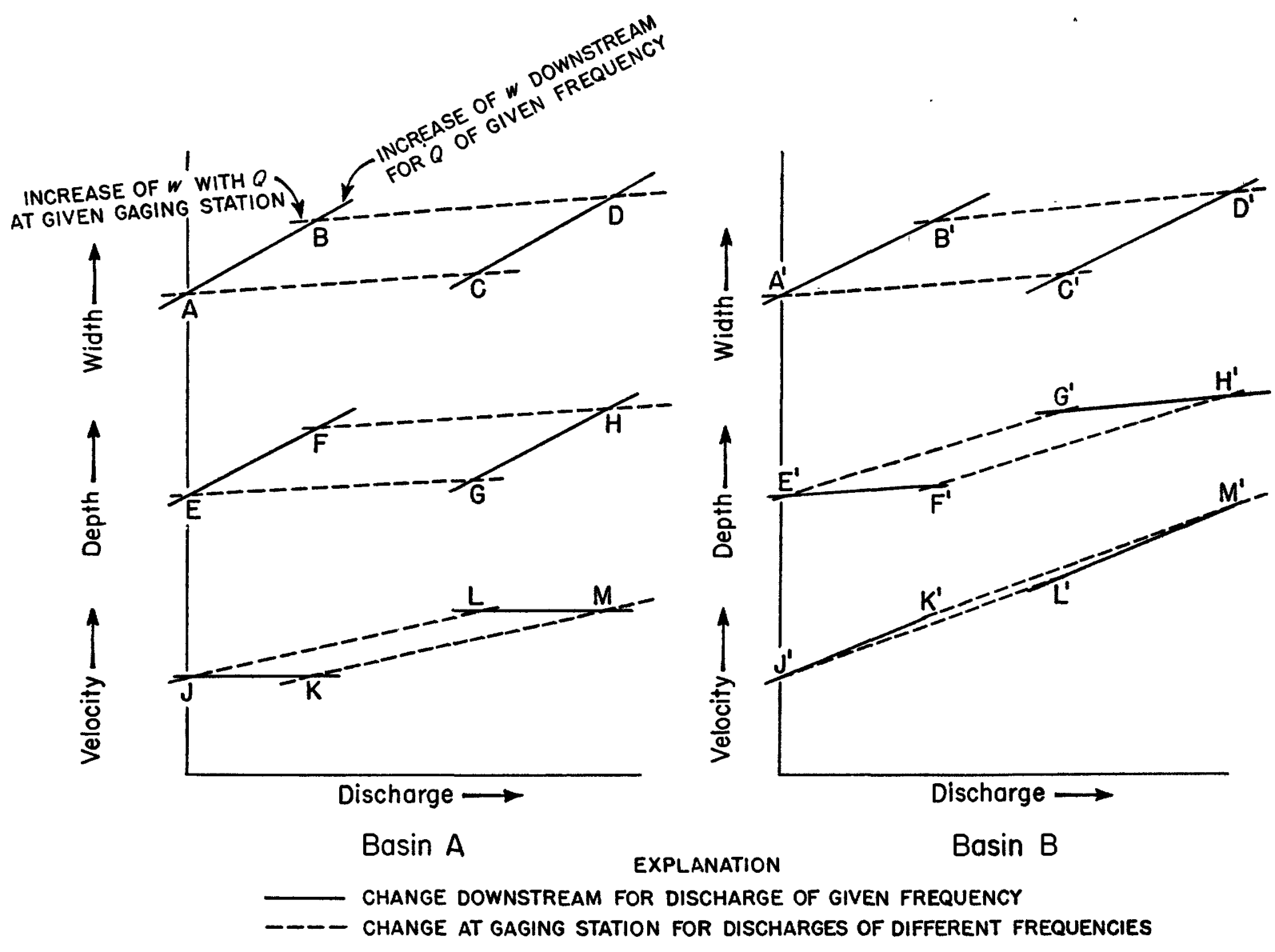

FIGURE 12.-Diagrammatic relations of width, depth, and velocity to discharge at a station and downstream.

slopes and intercepts of the lines in the geometric patterns discussed in figure 12. Though the listing of slopes and intercepts of these lines may not provide any visual picture of a river basin, comparison of the values of these factors among rivers has useful aspects which will be discussed.

Thus far, no consideration has been given to either river slope or bed roughness. The importance of these factors is recognized by the authors. However, discussion thus far is, of necessity, descriptive in nature. Because comparable data for slope and roughness are not available in so great a quantity as data on width, depth, velocity, and discharge, the particular data available for analysis make it desirable to organize the paper in its present form.

The observed relations of width, depth, and velocity to discharge in natural rivers have been described. In the next part the observed relation of width, depth, velocity, and discharge to measured suspended load will be presented. Then, the effect of slope and roughness will be discussed in an attempt to provide a partial explanation for the relations observed in the other quantities.

\section{THE HYDRAULIC GEOMETRY OF STREAM CHANNE'S IN RELATION TO SEDIMENT LOAD}

\section{SUSPENDED SEDIMENT AND DISCHARGE IN PARTICULAR CROSS SECTION}

This second part of the present paper describes the interrelations of measured sediment with the other hydraulic variables. Following a description of the changes in suspended-sediment load at a station and then downstream, hydraulic and physiographic interpretation of the observed relationships will be explored.

Sedinient transported by a stream may conveniently be divided into suspended load and bed load, but it must be understood that, depending on the flow conditions, sediment may at one time be part of the suspended load and at another time part of the bod load. Moreover, the capacity of a channel to carry sediment of one size is at least partially independent of its capacity to carry another size. For this reason Einstein (1950, p. 4) prefers to differentiate betwe?n "wash load" consisting of particles finer than those making up the stream bed, and "bed-material load."

No simple and satisfactory method of sampling bad load of a natural stream is in use at present. Any 
sampler placed on the stream bed provides an obstruction to the natural flow and tends to set up turbulent eddies in the immediate vicinity which so change the transport near the bed that the resulting sample becomes nonrepresentative. The data available for analysis, therefore, consist of suspended sediment sampled by use of the improved depth-integrating samplers. The sampled load is made up of particles moving outside the bed layer. The measured suspended load does not present a fixed percentage of the total load in motion but varies with a number of factors, as proposed by Maddock and discussed by Lane and Borland (1951).

The student of fluvial processes may at this point seriously question the general applicability of relations derived only from data on suspended load. An attempt will now be made to demonstrate that relations between suspended-sediment load and channel characteristics which can be derived from the available quantitative data justify the use made here of the data on suspended load.

Again for purpose of definition, it is desirable to discuss a tool in wide use in hydrologic practice, the graph showing the relation of suspended sediment to water discharge.

The relation of suspended load to discharge (sometimes called the sediment rating curve) is usually shown as a plot on logarithmic paper of suspended sediment, in units of weight per unit of time, against discharge of the water-sediment mixture at a particular gaging station (see Linsley, Kohler, and Paulhus 1949, p. 331; Hembree, Colby, Swenson, and Davis 1952, p. 69). A typical relation of suspended load to discharge is presented in figure 13 (after Hembree, Colby, Swenson, and Davis 1952, fig. 33). The data for such a curve are obtained by daily, weekly, or other periodic sampling at the sediment station. Such stations are being installed and maintained by Federal and State agencies in increasing numbers in the United States. When their records encompass a long enough time, the growing network of stations promises a mass of basic data which will be of importance to the study of river morphology.

The sediment is sampled by a depth-integrating suspended-load sampler. No fewer than two samples are taken at various distances from the stream bank in a given river cross section. These samples are analysed in the laboratory to determine concentration of suspended sediment in parts per million by weight. The samples from a given cross section are combined to give a mean concentration which is then applied to the mean discharge for the day to provide an estimate of tons of suspended load passing the station on the given day. This figure is then plotted against the mean discharge for the day as a single point on the curve showing relation of suspended load to discharge. Each point on the curve of figure 13 was determined in this manner.

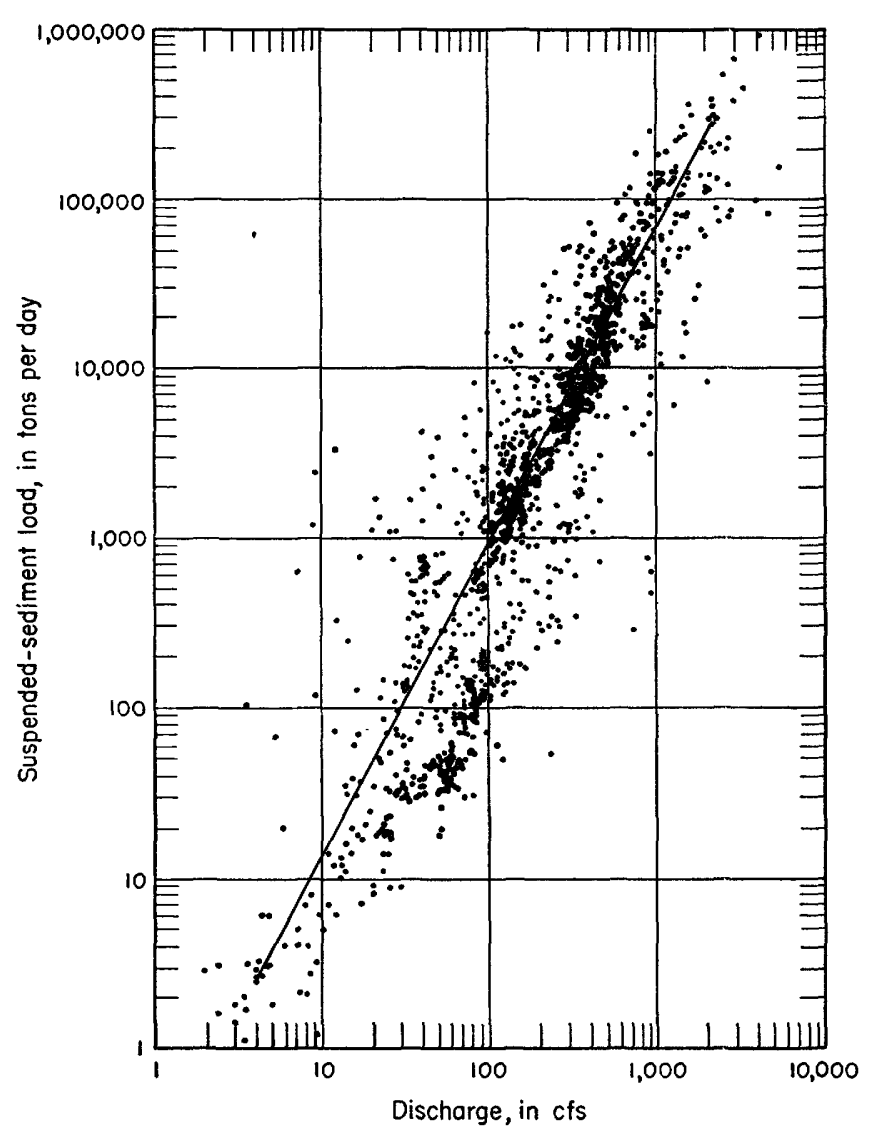

Figure 13.-Relation of suspended-sediment load to discharge, Pcwder River at Arvada, Wyo.

The basic data on suspended-sediment load used in the present study are available to the public, as already explained, in association with current-meter measurements. Data on suspended sediment will be published by the Geological Survey, but as yet there is considerable delay between collection of data and thoir publication.

It will be noted in figure 13 that the curve showing relation of suspended load to discharge contains a wide scatter of points, as is characteristic. This scatter indicates that at a given rate of discharge, the amount of suspended sediment may vary considerably from one day to another. It will be shown later that st a given discharge, increased amounts of suspended load supplied to a reach tend to promote changes in the channel characteristics leading to increased capacity to transport, particularly through adjustment of the ratio of velocity to depth. Thus, scatter of points above and below the mean line in the graph of suspended load and discharge implies corresponding compensatory arrangements of points about the mean curves showing relations of velocity to discharge and depth to discharge.

A straight line has been drawn through the points on the curve in figure 13. The points are so scattered on some graphs of suspended load and discharge that a smooth curve drawn to represent them has little meaning. When the record is sufficiently long, as it 
is in figure 13 and in the data for 20 stations analysed in this report and summarized in the appendix, a straight line on logarithmic paper is a usable approximation. Many graphs of suspended load and discharge may be represented by straight lines in the middle range of discharge, but by curves or lines of different slopes in the extremely low and high discharge ranges.

It is typical that the line approximating the data on a graph of this type slopes steeply, as in figure 13. At a station suspended load usually increases more rapidly than does water discharge. It will be noted that if water and suspended sediment increase at equal rates, the sediment concentration is constant. Constant concentration of suspended sediment would be represented in figure 13 by a line sloping upward to the right at $45^{\circ}$. The fact that the line slopes more steeply indicates that suspended-sediment concentration increases rapidly with discharge at a station.

This usual rapid increase of suspended load with discharge is interpreted by the authors as indicating that conditions of rainfall and run-off on the watershed combine to furnish to the major stream channels a large increment of debris for each increment of water. In other words, it is believed that the slope of the curve showing the relation of suspended sediment to discharge is the result of the process of sheet, rill, and gully erosion on the watershed and represents sediment imposed on the major stream channels which must carry it away.

No detailed hydraulic theory is available to explain why sediment increases at a faster rate than discharge at a given station. However, a number of widely known facts make this relation seem logical. Large discharges imply greater rainfalls than small ones. Great rains are characterized by a larger percentage of surface run-off than small rains, for many reasons. Three reasons are:

First, the initial rain must fill surface detention and depression storage before surface run-off can begin. Infiltration rate decreases rapidly during the initial period of a rainstorm.

Second, as the soil surface becomes wetted, areas poorly protected by vegetation are subjected to the churning effect of raindrop impact (Ellison, 1944) which increases with rainfall intensity. Puddling of the soil surface, if it occurs, probably increases with the duration and intensity of rainfall.

Third, moreover, large runoff rates imply greater depths and velocities of water flowing in eroding rills. These factors tend toward a greater efficiency of erosion with the increase in duration and intensity of rain. Thus, it might be expected that at a given river cross section sediment production increases faster than discharge.

It might be presumed that because the bed of an alluvial river tends to be scoured during high discharges, the observed increase of suspended-sediment concentration with increased discharge results from the suspension of the additional material scoured out of the bed by concomitant high velocity.

It will be shown later that at certain river measurirg stations deposition on the bed occurs under the conditions of high velocities accompanying the rapidly increasing suspended loads of flood rises. Thers velocities are higher than those accompanying scour of the bed during the decreasing suspended loads of flood recessions.

This occurrence is sufficiently common to support the contention that the changes in velocity and depth during a flood passage are caused by changes in concentration of suspended sediment introduced into the particular reach. Suspended-sediment concentration may generally be considered an independent variable, with velocity and depth dependent.

It is observed that the relation of suspended sediment to discharge at a given river cross section may ke approximated, through at least a major part of the range of discharge, by a straight line on logarithmic paper. Such a line is defined by the expression

$$
L=p Q^{s}
$$

in which $L$ is sediment load in tons per day, $p$ and $j$ are numerical constants. In the data analyzed, there is a tendency for the suspended sediment at a station to increase faster than discharge, or the slope, $j$, of the suspended sediment-discharge curve is greater than unity. Values of $j$ typically lie in the range 2.0 to 3.0.

In summary, it is typical at a given cross section of an alluvial stream for the suspended-sediment load to increase with increase in discharge, and at a more rapid rate. That is, the concentration of suspended sediment increases with discharge. Consideration of the physical characteristics of surface run-off and observe,tions of bed scour lead to the tentative conclusion the $t$ the observed increase in sediment concentration results primarily from erosion of the watershed rather than from scour of the bed of the main stream in the reach where the measurement is made.

\section{RELATIONS OF SUSPENDED SEDIMENT TO DISCHARGE IN A DOWNSTREAM DIRECTION}

Stations where suspended sediment is sampled are still too few to provide data for a direct analysis of change in the concentration of suspended sediment in a downstream direction, as was done for the other hydraulic factors.

In long reaches of a river through more or less homcgeneous topography the entrance of various tributaries does not appear to the eye to have any great effect on the turbidity of the water. Even over great distancer the changes in sediment concentration downstream are are not sufficient to be distinguished without acturl sampling. 
The change in sediment concentration downstream through homogeneous topography and lithology would seem to be small. However, the percentage of area of lesser surface slope increases with drainage area. Areas of little slope probably contribute less sediment per unit of water run-off than areas of steep slope. Groundwater contributes a larger percentage of flow to a stream draining a large area than to one draining a small area.

Inasmuch as the percent of land not contributing sediment and, therefore, the percent of sediment-free water tend to increase somewhat with drainage area, it would be logical to suppose that the average sediment concentration should decrease slightly in the downstream direction. Rubey (1933, p. 505) reached the same general conclusion. It should be understood, however, that individual rivers may differ in this respect (Mackin, 1948, p. 480).

Strong support for this conclusion is provided by the observation that the average annual production of sediment per square mile of drainage area decreases with increasing drainage area. In other words, sediment production per unit of area is greater for small than for large drainage areas. This conclusion has been reached by the study of erosion of sample upland areas and valley cross sections in Illinois (Brune, 1950), by the analysis of sediment trapped in small reservoirs in Wyoming (Hadley, in preparation, and open file), and from similar data on reservoirs in Iowa and Nebraska (Glymph, 1951, p. 6). If sediment contribution per unit of area decreases with increasing area, on the average there should be a tendency toward smaller concentrations of suspended sediment downstream.

The relation of suspended sediment to discharge both at a station and downstream can now be considered in the hydraulic geometry of stream channels. In figure 14 the curves of width, depth, and velocity in relation to discharge are similar to those discussed in figure 12 . In the diagrammatic plotting of suspended-sediment load against discharge in figure 14, the dotted line $\mathrm{A}_{3}-\mathrm{C}_{3}$ is the curve showing the relation of suspended sediment to discharge for an upstream station, for which the at-a-station width, depth, and velocity curves are respectively $A_{0}-C_{0}, A_{1}-C_{1}$, and $A_{2}-C_{2}$. The curves for a downstream station are, respectively, $\mathrm{B}_{0}-\mathrm{D}_{0}, \mathrm{~B}_{1}$ and $\mathrm{D}_{1}$, and $\mathrm{B}_{2}-\mathrm{D}_{2}$; and curve $\mathrm{B}_{3}-\mathrm{D}_{3}$ shows the relation of suspended load to discharge.

The small number of suspended-sediment stations arranged along the length of a given river precludes the construction of curves representing the change of suspended-sediment load downstream, but such a curve is a necessary part of the hydraulic geometry. The general argument in the preceding paragraphs appears to support the hypothesis that concentration of suspended sediment usually decreases somewhat downstream with discharge of equal frequency. As in the suspended load-discharge curve of figure 13 , equal concentration downstream would be represented by a

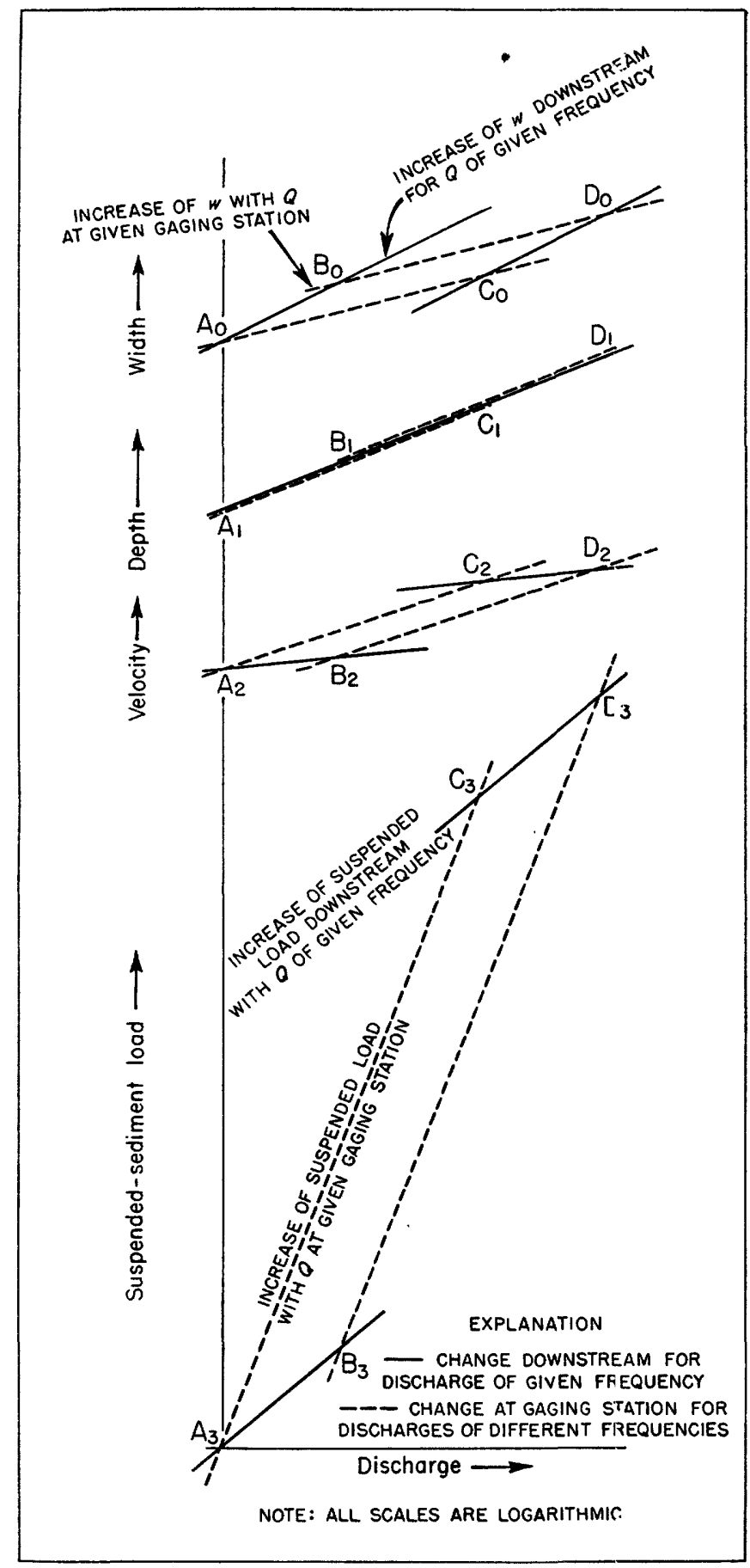

FIGURE 14.- Typical relations in the hydraulic geometry of natural channel systems, showing width, depth, velocity, and suspended-sedimert load plat ted against discharge both at a station and downstream.

line sloping upward to the right at $45^{\circ}$. The probable relation is therefore shown on figure 14 as the solid lines $\mathrm{A}_{3}-\mathrm{B}_{3}$ and $\mathrm{C}_{3}-\mathrm{D}_{3}$ which slope slightly less steeply than $45^{\circ}$.

A brief summary will explain the purpose of the next step in the analysis. The shape of the cross-section at any point on a river may be described by tha observed increase of width, depth, and velocity with increase of discharge. Considering the river system from head- 
waters downstream, if discharge at all points is comparable in percentage of time this discharge is equalled or exceeded, the width, depth, and velocity are observed to increase downstream with increased discharge. These at-a-station and downstream relations can be expressed by simple graphs having a geometric pattern. This geometric pattern is an expression of the interrelationship of width, depth, velocity, and discharge expressed by the identity

\section{Discharge $\equiv$ width $\times$ depth $\times$ velocity}

This identity, however, must be only one of a number of equations which determine the observed relationships. There probably is a relation between the characteristics of the channel shape and the measured suspendedsediment load. The purpose of the next sections is to define, at least qualitatively, how the suspended load is observed to vary in different rivers having different width, depth, and velocity relationships. The analysis will first be attempted for a given discharge, and then will be extended to include different discharges.

\section{WIDTH, DEPTH, VELOCITY, AND SUSPENDED SEDI- MENT AT A GIVEN DISCHARGE}

Certain aspects of the effect of suspended sediment on channel shape are best exemplified by consideration of the condition of constant discharge. The following discussion concerns the analysis of measured sediment load at various gaging stations when the discharge at the stations is equal.

Data for 20 sediment measuring stations were used in this study. The data consisted of curves showing relation of suspended sediment to discharge; these are summarized in tabular form in the appendix of this report. Sediment measurements are being made at many more stations but insufficient length of record or absence of simultaneous current-meter discharge measurements precluded their use. A fow records were discarded because of unnatural cross sections. Particularly, data obtained at dams or in sections where the channel walls were confined were deemed unsuitable.
For each station, current-meter measurement data were used to construct curves relating discharge to width, depth, and velocity, as shown in figures 3 and 4 . From these data and curves showing the general relation of suspended sediment and discharge, values of these four factors corresponding to a discharge of $500 \mathrm{cfs}$ were tabulated.

For each station, width was plotted against suspended load in figure 15 , and at each point the corresponding velocity was entered. Isopleths of velocity were then drawn; these are the lines slanting steeply downward to the right in the figure.

Because the graph represents data for a fixed discharge, every point in the width-velocity field defines a particular depth inasmuch as

$$
Q \equiv w d v=\text { constant }
$$

Thus isopleths of depth can be drawn which are the lines slanting gently downward to the right.

Figure 15, therefore, is a field showing the relation of corresponding values of width, suspended load, velocit?', and depth. The graph has many limitations but it is nevertheless a useful tool for some qualitative analyses. Among its limitations are, first, the fact that the velocity field is only roughly defined by the values in the available data. Second, only the suspended part of the load is being considered. Third, the scatter of points on any average curve showing relation of suspended sediment to discharge is large.

Nevertheless, certain general conclusions of apparert significance may be drawn from figure 15 and they will be tested against observed changes in the characteristics of river channels.

If a constant discharge is assumed, at constant width of channel an increase in velocity is accompanied by an increase in suspended sediment. This requires, a.t constant discharge, a decrease in depth.

Conversely, if velocity is constant, an increase in width is accompanied by a decrease of suspended load. This is also associated with a decrease in depth.

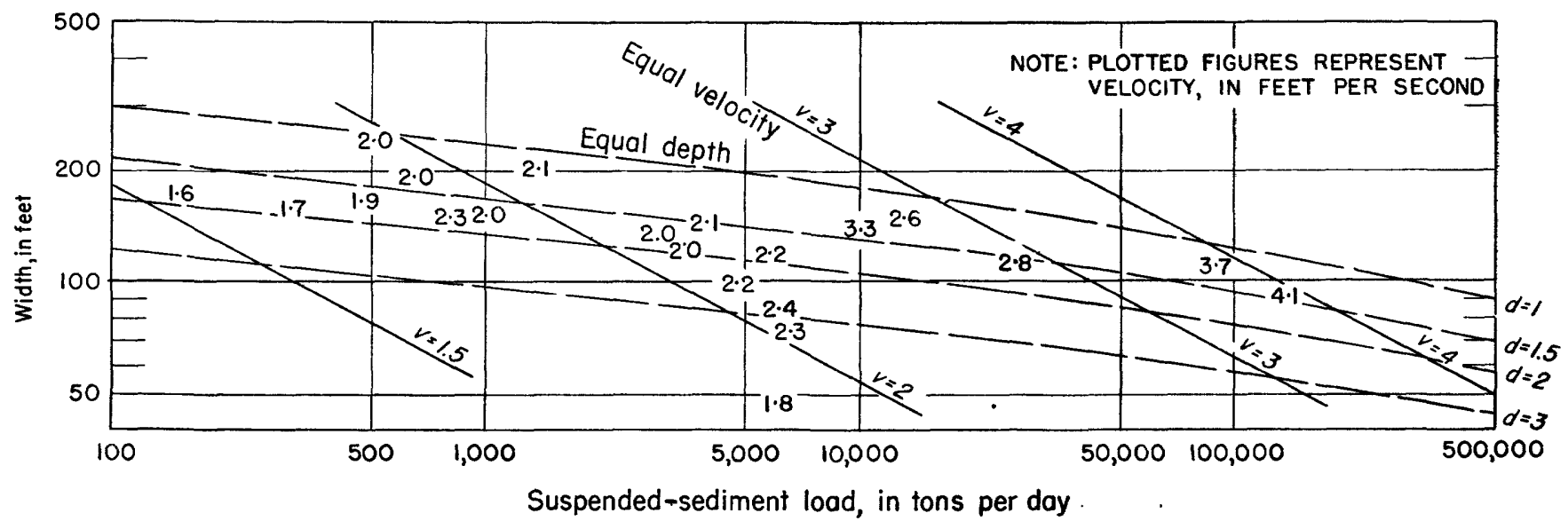

Figure 15.-A verage relation of suspended sediment-load to channel-shape factors at a constant discharge of 500 efs (from river data in appendix). 
In summary, decreasing width at constant velocity or increasing velocity at constant width each results in increased capacity for suspended load at constant discharge.

These relationships should be reviewed here in terms of the basic data from which they were derived. The basic data consist of 20 cross sections of different rivers (see appendix). The rivers include the Loup, Rio Grande, Bighorn, Smoky Hill, Powder, Moreau, Republican--in other words, rivers in the Great Plains, Colorado Plateaus, and Rocky Mountain areas. The data are therefore biased toward Western conditions, yet the rivers are rather diverse in general appearance. A station on each river was considered under conditions when $500 \mathrm{cfs}$ was flowing in the channel. At that particular discharge, some of the river sections are wide, others narrow, some shallow, others deep. The observed suspended load at that discharge has been correlated with the concurrent width, depth, and velocity at the particular discharge.

The graphical relation shows that a wide river having a particular velocity is observed to carry a smaller suspended load than a narrow river having the same velocity and discharge.

It shows also that if two rivers have equal width at the same discharge, the one which is flowing at the higher velocity is carrying a larger suspended load.

These, are empiric relations observed in the available river data. Nothing has been said regarding why one river is wide and another narrow, or one is deep and another shallow. Clearly these features depend on such factors as slope, roughness, and particle size which have not yet been considered.

In the analysis, the rivers were compared at equal discharge. It is now logical to examine the same relations at different discharges.
WIDTH, DEPTH, VELOCITY, AND SUSPENDED LOAD AT A VARIABLE DISCHARGE

Relations similar to those examined at constant discharge will now be discussed for three other discharge rates. Using the same 20 suspended-sediment sampling stations, measurements of depth, width, velccity, and suspended load were plotted for discharges of 250 , 1,000 , and $2,000 \mathrm{cfs}$ in a manner similar to that used for figure 15. The mean isopleths of velocity for the four discharges were replotted in figure 16 , with the actual velocity values shown on figure 15 eliminated for the sake of clarity.

As in figure 15, when discharge, width, and velocity are specified, depth also is specified. In other words, a particular point in the graph of figure 16 specifies width, depth, and velocity for any of the four discharges.

Any arbitrary straight line drawn on figure 16 will cross the respective fields of velocity for the four discharges. Any point on that arbitrary line vill represent simul taneous values of width and of velocity in one of the four velocity fields. The line may ka drawn, then, to represent any chosen width-to-discharge relation and a chosen velocity-to-discharge relation. A corresponding suspended load-discharge relation becomes thereby determined.

An example will help clarify this idea. If one follows the horizontal line in figure 16 representing a width of $100 \mathrm{ft}$ to the 2 -fps velocity line representing a discharge of $250 \mathrm{cfs}$, he will see that the point of intersection represents a suspended load of roughly 1,500 tons per day. The 2 -fps velocity line for $500 \mathrm{cfs}$ intersects the same horizontal line at a point equal to a load of 3,000 tons per day. The 2 -fps velocity line for $1,000 \mathrm{cfs}$ intersects at 6,500 tons per day, and the same line for a discharge of 2,000 efs at 15,000 tons per day. It will

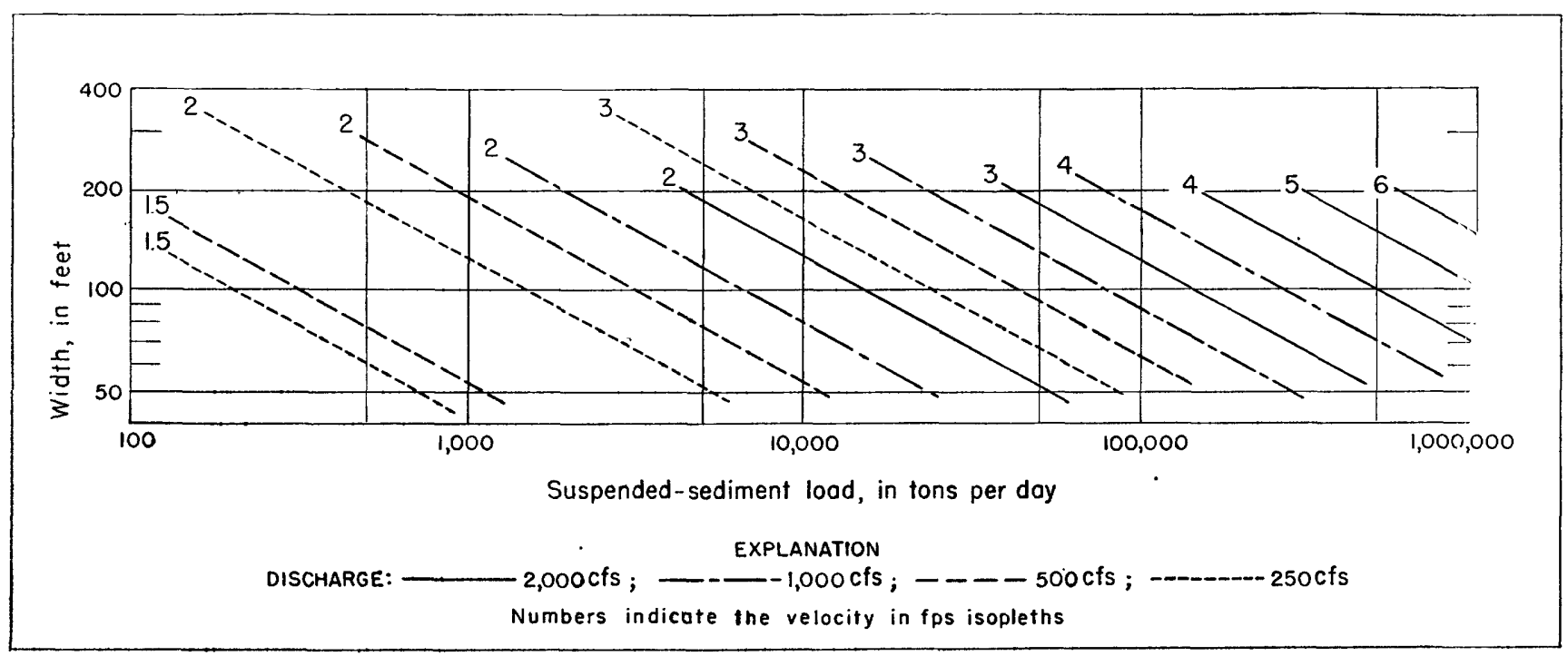

FIGURe 16.-A verage relation of suspended-sediment load to channel-shape factors at four discharge rates (from river data in appendix). 
be noted that these corresponding values of discharge, velocity, and suspended load could be used to define relations between discharge and the separate factors of velocity and suspended load. These relations have been plotted in figure 17. This suspended sedimentdischarge curve would represent the mean suspended sediment-discharge relation for a channel of constant width. In this hypothetical channel, various discharges would have the same mean velocity, $2 \mathrm{fps}$. Because for each of the four discharge points, velocity and width are specified, depth also would be specified. Therefore the relation of width, depth, and velocity to discharge can also be plotted, and these plots also are shown on figure 17 .

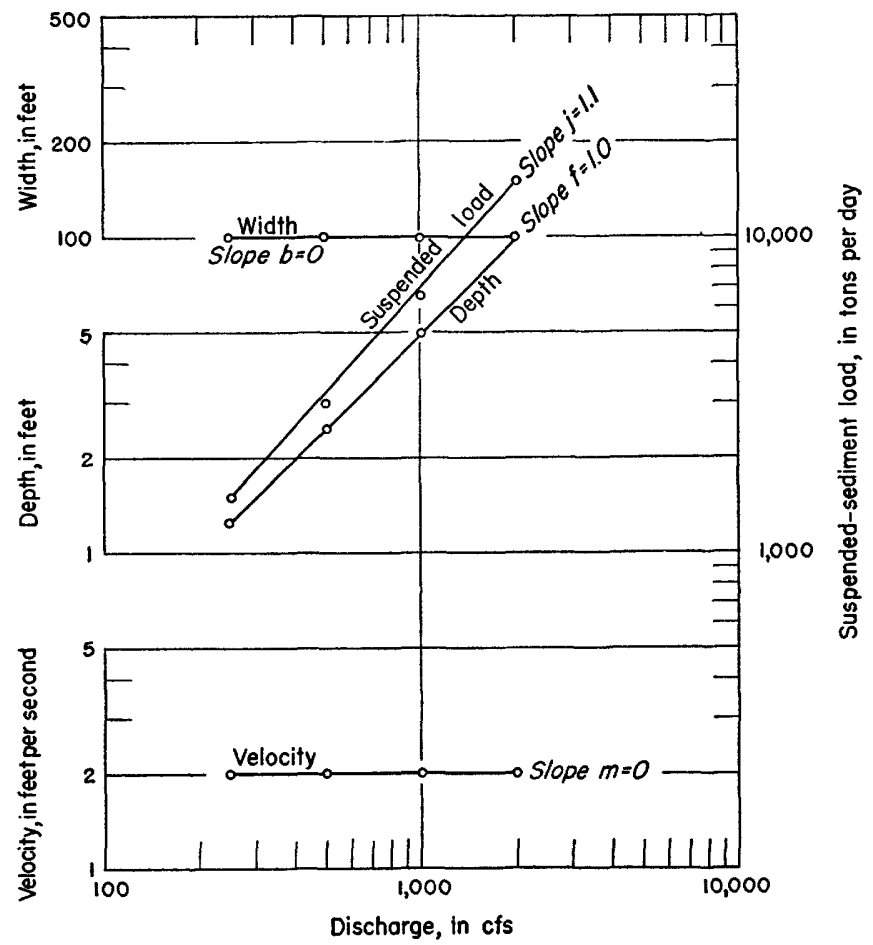

Figure 17.-Example of the relation of suspended-sediment load and water depth to discharge for specified relations of width to discharge and velocity to discharge (constructed from fig. 16).

In accordance with the procedure used in the example, any straight line drawn on the width-suspended loadvelocity field of figure 16 defines the rates of increase of two variables with discharge. The rate of increase of the other two variables with discharge must be given. In the previous example, the rate of increase of width with discharge and the rate of increase of velocity with discharge were specified. Then the rates of increase of depth and suspended load with discharge became known. The slopes of these lines can be measured and are the exponents $b, m, f$, and $j$ in the equations

$$
\begin{aligned}
& w=a Q^{b} \\
& d=c Q^{s} \\
& v=k Q^{m} \\
& L=p Q^{s}
\end{aligned}
$$

where the symbols are as defined previously. In the graphs of figure 17 it will be noted that

$$
b+f+m=0+1.0+0=1.0
$$

as is required by the identity

$$
Q \equiv w d v
$$

By analogy to the example plotted in figure 17, it can be visualized that for any given assumption of $b$ (the rate of increase of width with discharge), the slope $j$ of the curve relating suspended load to discharge will depend on the rate of increase of velocity with discharze defined by the exponent $m$. And because $b+m+f=1$, when $b$ and $m$ are specified, $f$ is also specified. If the ratio of $m$ to $f$ is known and the value of $b$ is knov'n then values of $m$ and $f$ are known. For example, assume arbitrary straight lines on the field of figure 16 and find the slope $j$ of the suspended load-discharre relation for various values of $b$ and the ratio $m$ to $f$. The results are plotted in figure 18. Each point in the figure represents a given straight line drawn in the graph of figure 16. These lines were drawn in such a way that various values of $b$ were represented. The resulting relation of velocity and load with discharge were plotted just as in figure 17, the slopes of the lines representing values of $m$ and $f$ were measured, and the ratio of $m$ to $f$ was computed. Values of $j$ and this ratio of $m$ to $f$ were then plotted in figure 18 .

From figure 18 a number of useful concepts may be inferred. The first concerns the interaction of velocity, depth, and the suspended-sediment load. For any given rate of increase of width with discharge - that is,

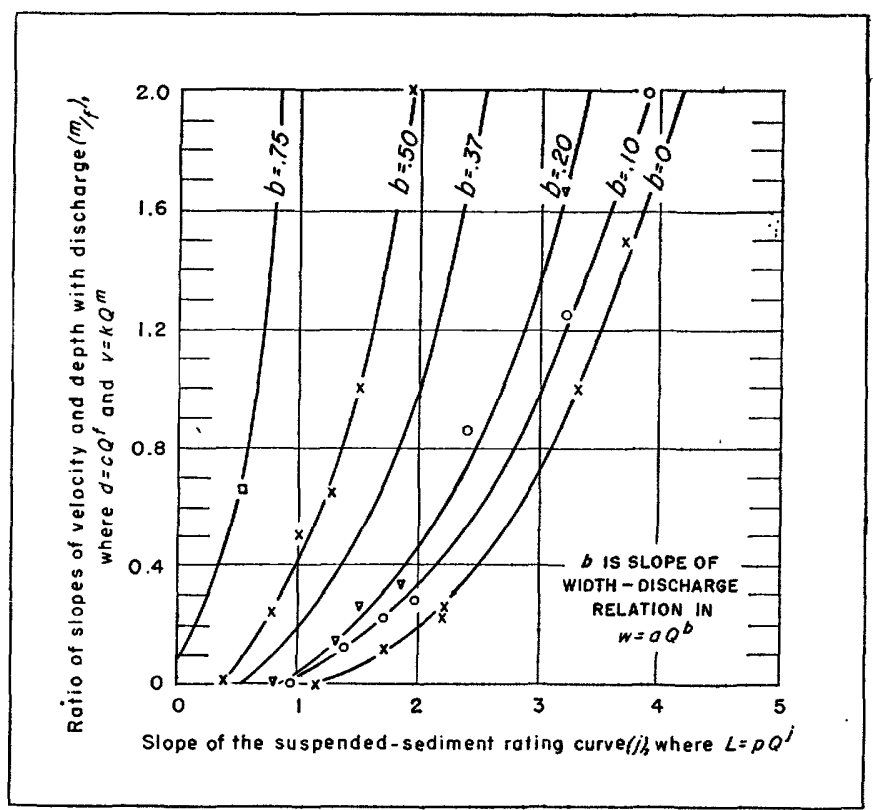

FIGURE 18.-Relation of rates of increase of width, depth, velocity, and suspende 1 load to increasing discharge, expressed by values of $b, \frac{m}{f}$, and $j$ (constructed from fig. 16). 
for any given value of $b$-the diagram indicates that the value of $j$ increases with an increase in the $m$ to $f$ ratio. That is, the rate of increase of suspended-sediment load with discharge is a function of the ratio:

$$
\frac{\text { rate of increase of velocity with discharge }}{\text { rate of increase of depth with discharge }}
$$

Slopes of the lines representing depth, width, and velocity respectively, in relation to discharge are, according to the implications contained in figure 18, functions of the slope of the line representing the relation of suspended sediment to discharge. For a given value of $b$, the steeper the slope of the suspended sediment-discharge line, the greater will be the slope of the velocity-discharge line.

It is also possible to observe in figure 18 the points, or zones, which represent the average river conditions. The average values of the rates of increase of width, depth, and velocity with discharge have been listed separately, and are summarized here.

$$
\begin{array}{cc}
\text { At a station } & \text { Downstream } \\
b=.26 & b=.5 \\
f=.40 & f=.4 \\
m=.34 & m=.1
\end{array}
$$

The suspended sediment-discharge relations providing the basic data from which figure 18 was derived, represent a number of different stations. Earlier discussion of typical relations of suspended sediment to discharge brought out the fact that the slope, $j$, of typical curves is of the order of 2.0 to 3.0. As previously indicated, at a typical river cross section, width increases only slightly with discharge until the bankful stage is reached. This rate of increase is described by the average value $b$ which is provided by the available data, $b=.26$. For the average cross section (at a station) $\frac{m}{f}=.85$. In figure 18 where $\frac{m}{f}=.85$, and $b=.26, j=2.3$. Thus the value read on the curves of figure 18 compares favorably with the observed average slope of suspended sediment-discharge curves.

It was brought out in the discussion of the relations of suspended sediment to successive points in the downstream direction that suspended-sediment concentration should decrease slightly downstream. A value of $j=1.0$ means that suspended load is increasing at the same rate as discharge and represents equal sediment concentration. It is to be expected, therefore, that the observed value for rivers should be somewhat less than 1.0. Referring to the mean values of $m, f$, and $b$ in the downstream direction where $b=.5$, and $\frac{m}{f}=.25$, it can be seen on figure 18 that $j=0.8$. Thus figure 18 indicates that concentration of suspended sediment decreases slightly in a downstream direction for a given frequency of discharge, as the earlier argument indicated.
Figure 18 appears to apply to average conditions both at a station and downstream. For any particular cross section of a given river or for any particular flood hydrograph, it should not be expected that figure 18 would define the relations because it will be recalled that figure 15, from which type of data figur? 18 was derived, represents a series of smooth lines drawn through data having considerable scatter in the plot. Nevertheless, figure 18 is a useful guide in summarizing a large volume of data on suspended load of rivers.

It is presumed that as additional data on suspended load become available, it will be possible to refine the graph of figure 16 by adjustment of the slope and position of the velocity isopleths. From available data, the relations in figure 16 may be summarized as follows: When cross sections of different rivers having different channel characteristics are compared, the observed suspended-sediment load will vary directly as a function of the velocity, directly as a function of the depth, and inversely as a function of the width of water surface. The suspended load varies $\varepsilon . s$ a large power of velocity, and as small powers of depth and width.

The preceding discussion may now be summarized by indicating the relation which the curves of figure 18 bear to the hydraulic geometry of river systems characterized by figure 14 . To facilitate reading, figtre 14 has been reproduced in essentially the same form in figure 19 with the addition of simple block diagrams to allow easy visualization of the at-a-station and dornstream relations constituting the hydraulic geometry.

Figure 19 summarizes the average conditions observed in the numerous rivers studied. Cross section A represents the conditions at a headwater station during low flow. Its position will be noted in the upper physiographic diagram of a watershed in which low flow prevails. Cross section $C$ represents the same headwater station under conditions of high discharge. Similarly, B is a downstream section at low flow, and D the same section at high discharge.

The slopes of the lines in the graphs of figure 19 represent the average conditions observed in rivers. In the width-discharge graph, line $A_{0}-B_{0}$ has a slope upward to the right equal to 0.5 , or in the expression $w=a Q^{b}, b=0.5$, which is representative of the increase of width with discharge downstream.

Similarly, in the width-discharge graph, the line $\mathrm{A}_{0}-\mathrm{C}_{0}$ represents the increase of width with discharge at a station and has a slope $b=0.26$.

In the depth-discharge graph line, $A_{1}-B_{1}$ has a slope $f=0.4$, and $A_{1}-C_{1}$ has a slope $f=0.4$. In the velocitydischarge graph, line $m=0.1$ for the downstream direction, and $m=0.34$ at a station.

Lines in the suspended load-discharge grephs also have slopes equal to average values for rivens, $j=0.8$ downstream (line $\mathrm{A}_{3}-\mathrm{B}_{3}$ ) and $j=2.5$ at a station (line $\mathrm{A}_{3}-\mathrm{C}_{3}$ ). 


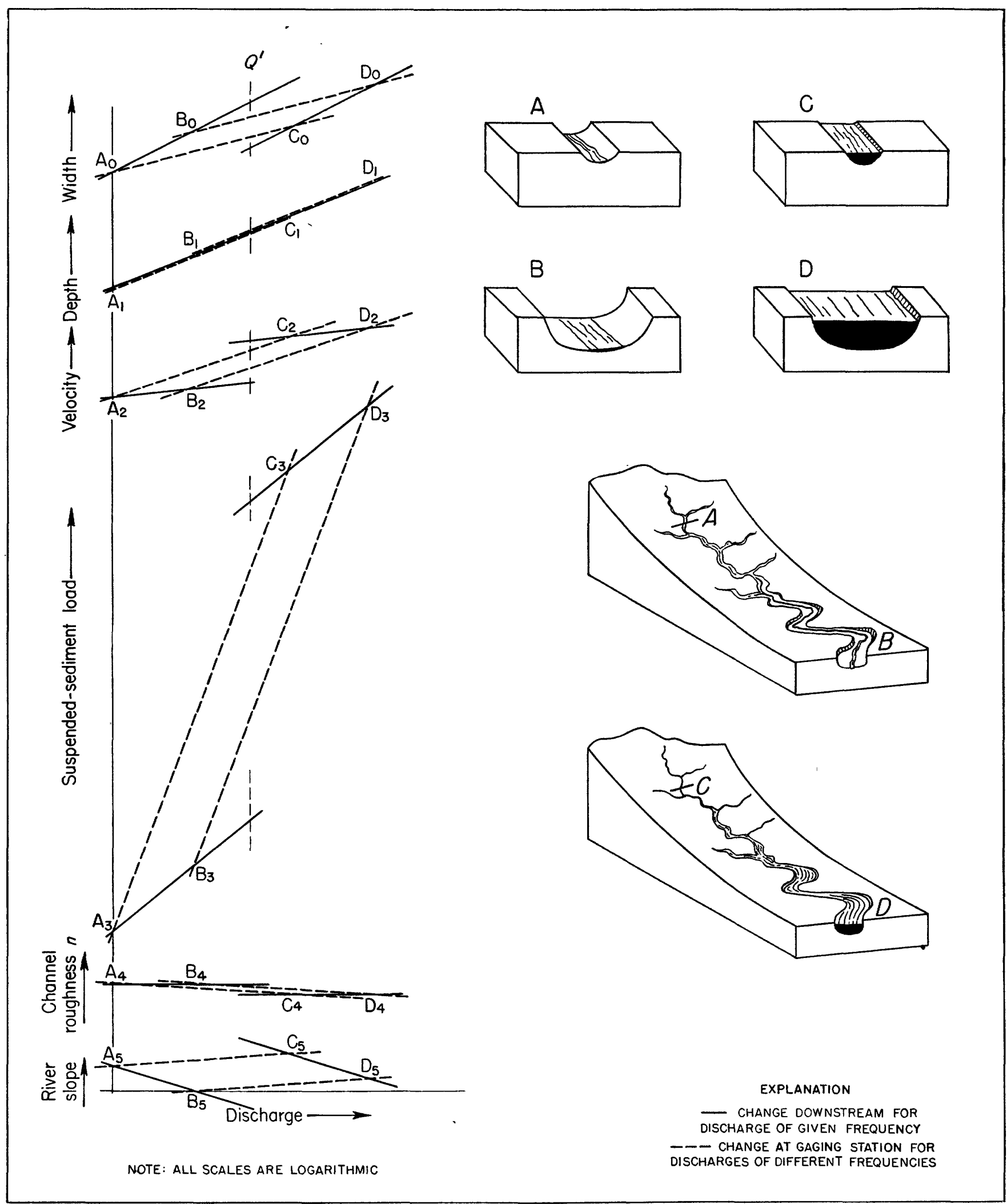

FigURE 19.-A verage hydraulic geometry of river channels expressed by relations of width, depth, velocity, suspended-sediment load, roughness, and slope to discharge at a station and downstream. 
It is now possible to interpret the relation between $\frac{m}{f}, b$, and $j$ shown in figure 18 and the diagrams in figure 19. Figure 18 shows the observed relationship between suspended load in rivers and the channelshape factors. The figure shows that for a given value of $b$, the value $j$ increases with the ratio $\frac{m}{f}$. The river data indicate that for given a rate of increase of width with discharge (a given slope of line $A_{0}-B_{0}$ ), the steeper the slope of the suspended load-discharge line $A_{3}-B_{3}$, the steeper must be the slope of the velocity-discharge line $A_{2}-B_{2}$. This would require a smaller slope of the depth-discharge line $A_{1}-B_{1}$ in order to preserve the relation of slopes required by

$$
b+f+m=1.0
$$

Another way to look at the geometry of figure 19 would be as follows: For a given width, and at a given discharge, an increase in suspended sediment requires an increase in velocity and a reduction in depth. Exactly this interpretation was drawn from figure 15 .

This set of interrelationships provides a visual picture of how the channel system of a river is carved to carry the water and sediment provided by the drainage basin. The at-a-station and downstream relations between discharge and suspended load shown by the geometrical pattern $\mathrm{A}_{3} \mathrm{~B}_{3} \mathrm{C}_{3} \mathrm{D}_{3}$ may be considered essentially independent of the channel system, but are functions of the drainage basin. The relations of width, depth, and velocity to discharge tend to be adjusted to conform to the load-discharge function according to the principles just outlined.

The geometrical relations describe another typical relationship in rivers - that of the upstream and downstream station at a given discharge, represented along a given vertical line in figure 19. As an example, a particular discharge is represented by the dashed vertical line representing the discharge $Q^{\prime}$. The $A-C$ lines represent changes at the upstream station and the B-D lines at the downstream station. At the same discharge, ' $Q$ ', note that the suspended load at the downstream station (ordinate where $B_{3}-D_{3}$ crosses the dashed line) is less than the suspended load at the upstream station (ordinate where $\mathrm{A}_{3}-\mathrm{C}_{3}$ crosses the dashed line). This is reasonable because a given discharge at the downstream station may represent a frequent flow or a low flow condition, whereas to attain that same discharge the upstream station must experience a flood flow. A given discharge is equalled or exceeded more often at a downstream than at an upstream station, and common experience teaches that the frequent, or low, flow is likely to carry a small concentration of suspended sediment, and a flood flow a large concentration. The given discharge, then, seldom occurs in nature simultaneously at the headwater and downstream station.
It may now be asked how the channels at tl e various stations are shaped to promote the equilibrium required by this comparison. At that given discharge, the downstream station has a larger width and a lower velocity, as can be seen in the diagram. This is exactly what figure 15 suggests; that is, at a given discharge, a smaller suspended-sediment load requires for equilibrium a larger width or lower velocity or both.

Inasmuch as the diagrammatic relations in figure 19 show the actual average slopes of the various lines derived from river data, the comparison at constant discharge again confirms the principles of channelshape adjustment postulated.

The diagram also includes observed averege variations of roughness and slope which will be discussed later.

It is emphasized that these relations are those derived by comparing a large number of river data. The relations are those existing in natural rivers. Flumes could be constructed in which relations of slope, roughness, and the channel-shape factors are different from those existing in rivers. In such flumes the relations described above would not necessarily hold.

It is now desirable to observe what kinds of similar relations seem to hold for bed load.

\section{INTERRELATIONS OF WIDTH, DEPTH, VITOCITY, AND BED LOAD AT A GIVEN DISCHARGE}

The experimental flume data of Gilbert (1914) have an advantage, for present purposes, over a ny other comparable experimental data. Gilbert used flumes of various widths under conditions of constant discharge. These data allow an analysis, therefore, of the relation of width, velocity, and load at constant discharge. The Gilbert sands were such that the load was carried primarily near the bed, and for present purposes his results may be considered to represent primarily the transport of sediment as bed losd.

The Gilbert data used here were taken from the summary by Johnson (1943, pp. 59-63), in which the data are presented in centimeter-gram-second units.

For "sand B" of Gilbert, four widths of flume were used at a discharge of $15,433 \mathrm{cu} \mathrm{cm}$ per sec and five widths at a discharge of $5,154 \mathrm{cu} \mathrm{cm}$ per sec.

Figure 20 presents the relation of the bed load carried in the full width of the flume to width and observed mean velocity at constant discharge. Thus the graphs of figure 20 are for bed load and are analogous to figure 15 for measured suspended load in natural rivers. Isopleths of velocity are drawn through the observed velocity values appearing in the graph.

It is clear that the isopleths of velocity slope upward to the right in contrast to those in figure 15 which slope upward to the left. These graphs provide, then, the following tentative interpretation, which, if sustained by further work, may provide important assistance in the understanding of fluvial morphology. 
At constant discharge, an increased velocity at constant width is associated with an increase of both suspended load and bed load in transport. At constant velocity and discharge, an increase in width is associated with a decrease of suspended load and an increase in bed load in transport.

It is unfortunate that the lack of data on bed load for rivers dictates reliance on flume observations. However, some general arguments and observation support the conclusions reached by analysis of flume data. Lane (1937 p. 138) observes,

If a channel is supplied with a heavy bed load, in order to be stable it must move this load along. *** To be stable, the channel carrying bed loads, therefore, should have a higher velocity along the bed, but the same velocity along the banks, and this could only occur with a wider, shallower section.

This statement by Lane is significant because it applies to the interpretation of river channels as they are observed to exist. That is, an alluvial river channel which is relatively wide and shallow probably carries a relatively large bed load.

Griffith $(1927$, p. 246$)$ notes that the $" * * *$ large rivers flowing through the alluvial plains of India, which in flood are heavily charged with silt, have in all cases a tendency to adopt a broad, shallow section * * *." Mackin (1948, p. 484) concludes from the British and Indian literature that "*** the broad, shallow channel is the type of cross section best adapted for the transportation of heavy bed load."

Though these general observations are of interest in this paper, they imply rather than assert that a constant

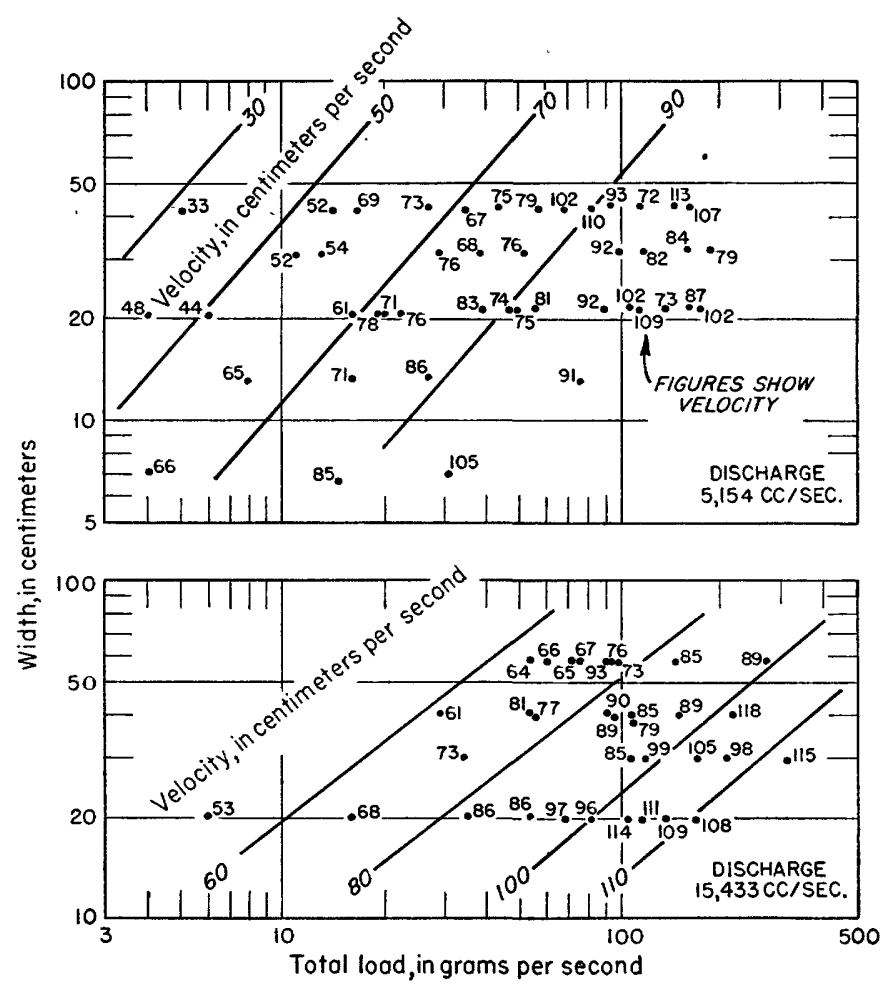

FIGURE 20.-Relation of bed load to channel-shape factors at constant discharge showing two discharges, same sediment material (sand B), from Gilbert data. discharge is assumed. A constant discharge and constant velocity are specified in the present discussion of the effect of width on bed load and suspended load.

Further indication of the effect of width on bed load is provided by computations made using the Einstein (1950) equation. In a study for the Bureau of Reclamation, Lara and Miller (1951) computed by the Einstein equation the bed load which would be transported in a channel of variable width, under different conditions of discharge. The computations involved in the equation require that a value be assumed for river slope and bed-material size. Computations were made $\mathrm{ky}$ Lara and Miller for different sized fractions of the load separately, and combined to provide the computed bed load having a size distribution characteristic of Rio Grande sediments. Lara and Miller assumed slope comparable to that of the Rio Grande.

The computed values of bed load for a constant di charge of 500 cfs were plotted by the writers against width and mean velocity provided by the computation, in a manner similar to figures 15 and 20 . In the graph, not included here, isopleths of velocity sloped upward to the right as in figure 20. Thus, bed load computed by the Einstein equation appears to increase with increased width at constant discharge and velocity - at least for the assumptions of slope and sediment size made by Lara and Miller.

In the preceding sections some relations have been developed among suspended load, bed load, and channel characteristics. By far the majority of data available on sediment load are restricted to measurements of suspended load only, and further detailed analysis of necessity depends on the measured fraction. Mackin (1948, p. 469) emphasizes that the size-distribution of the load of a given segment of a stream depends $c \eta$ "*** thre lithologic characteristics, relief, ard erosional processes in its drainage basin, and on prosesses in operation within the stream itself (as sorting.)" The sizes and quantities of available load determine, in part, whether the stream carries the load as suspended or as bed load.

A large part of the total sediment transported $\mathrm{ky}$ natural rivers is carried as suspended load. This is recognized by some geologists (Mackin, 1948, p. 468), but because bed load measurements are few, the relative proportions of bed and suspended load in natural rivers are not generally known:

Both suspended and bed load are being measured in the Niobrara River near Cody, Nebr. (Serr, 1950). The data already published show that for discharges between 200 and 1,000 efs bed load constitutes an average of about 50 percent of the total load. Tre percentage of the total carried as bed load varied from 24 to 68 percent. No significant correlation existed between this percentage and either the water discharge or the rate of sediment transport (Serr, 1950, p. 15). 
This comparison of bed load and suspended load in the measurements of the Niobrara River led the Bureau of Reclamation and the Geological Survey to begin a joint investigation for the purpose of extending this experimental work (Serr, 1951). The Middle Loup River has a sandy bed and the water appears clear and free of suspended load. The engineers of these agencies selected the Middle Loup River near Dunning as an example of a stream which carried most of its load as bed load. The junior author, at that time head of the Sedimentation Section, Bureau of Reclamation, represented that Bureau in the studies which led to the establishment of the measurement program on the Middle Loup River.

The measurements showed, however, that the bed load constituted an average of only 55 per cent of the total load even on the Middle Loup River (Vice and Serr, 1950, fig. 14).

Before regulation of the Colorado River by Boulder Dam, measurements were made in the overflow nappe on the spillway of Laguna Dam where presumably the total sediment would be caught by a suspended-load sampler. These measurements, when compared with suspended-load data at a normal section, indicated that before regulation and, at least at low flow, the Colorado River in the lower reaches transported almost all of its sediment load in suspension (Lane 1937, p. 190).

The 1948 survey of the sediment deposition in Lake Mead showed that 49 per cent by weight (978 million tons) of the total sediment deposited in the reservoir consisted of material fine enough to be transported in density currents (Gould, 1951, p. 48).

It might be argued, however, that despite a large suspended load in a river only the bed load is of real significance in fluvial morphology assuming it places the greatest tax on the energy of the stream.

It is possible that owing to the influence of the engineer, one may tend to place too much emphasis on bed load and to underrate the role of suspended load in determining the observed characteristics of natural streams. In the present discussion, an attempt is made to demonstrate that data on suspended load may provide an insight into the mechanisms by which river characteristics are determined.

The following detailed consideration of the effect of suspended load on river channel characteristics does not deny the importance of bed load. But if the measurements of suspended load allow the development of a meaningful picture of river channel characteristics, the importance of the suspended load in fluvial morphology can hardly be denied.

\section{CHANNEL-SHAPE ADJUSTMENT DURING INDIVIDUAL FLOODS}

It is known that during the passage of a flood, the channel of an alluvial stream is scoured and filled with considerable rapidity. Though such changes may be fortuitous, the foregoing discussion implies that there might be a definite pattern of channel changes directly related to the suspended-sediment load provided to the river by the drainage basin. If this were true, these changes should be of the type required by the frinciples derived from a study of figures 15 and 16 .

The gaging station on the San Juan River at Bluff, Utah, might first be considered. This river generally has a bed consisting of sand, silt, and some gravel, which characteristically shifts during a flood. At high stages the stream at the Bluff station is confined by ronk walls, but some changes in width are possible at low stages. The control at the station is a reach of gravel and boulders downstream from the gaging section, and this control is subject to shift under flood conditions. Current-meter measurements are made from a cable car.

Daily current-meter data and daily suspended load samples are available for a few years. These daily data are used in figure 21 to show the changes that occurred during a river rise between Septembar 9 and December 9, 1941. A measurement on a particular day is indicated in figure 21 by a point in each of six graphs. For example, during the first day of the rising stage the discharge was $635 \mathrm{cfs}$, width $171 \mathrm{ft}$, depth $1.20 \mathrm{ft}$, velocity $3.08 \mathrm{fps}$, and suspended lord 2,140 tons per day. To simplify the picture, an intermediate rise and fall in discharge between September 16 and 29 are omitted.

The rising discharge was accompanied by a slight rise in width up to the peak discharge of $60,000 \mathrm{cfs}$, and the falling discharge retraces nearly the same path in the curve showing relation of width to discharge.

Suspended load, in contrast, increased at a very rapid rate as the discharge rose from 600 to $5,000 \mathrm{cfs}$, but then load increased at a less rapid rate while the discharge continued up to $60,000 \mathrm{cfs}$.

Depth rose uniformly with discharge until a discharge of about 5,000 efs was reached. Then the slore of the depth-discharge curve increased as the discharge rose from 5,000 to $60,000 \mathrm{cfs}$. In the falling stage, a new slope of the depth-discharge curve was established, which was intermediate between the two slopes in the rising stage. At a discharge of 5,000 efs, the depth was about $3.2 \mathrm{ft}$ in the rising stage and 4.4 in the falling stage.

A corresponding adjustment in the velocity-discharge curve is apparent. In the rising stage at $5,000 \mathrm{cfs}$ the velocity was $8.6 \mathrm{fps}$; at the same discharge in the falling stage it was about $6.0 \mathrm{fps}$.

The graph of stream-bed elevation in relation to discharge is shown in figure 21. Bed elevation, as plotted, is a relative value which was derived by subtracting the depth from the gage height (water-surface elevation). This difference is a satisfactory estimate of bed elevation in the examples discussed here because width varied but little with discharge. Detailed river cross sections at various intervals during the flood 


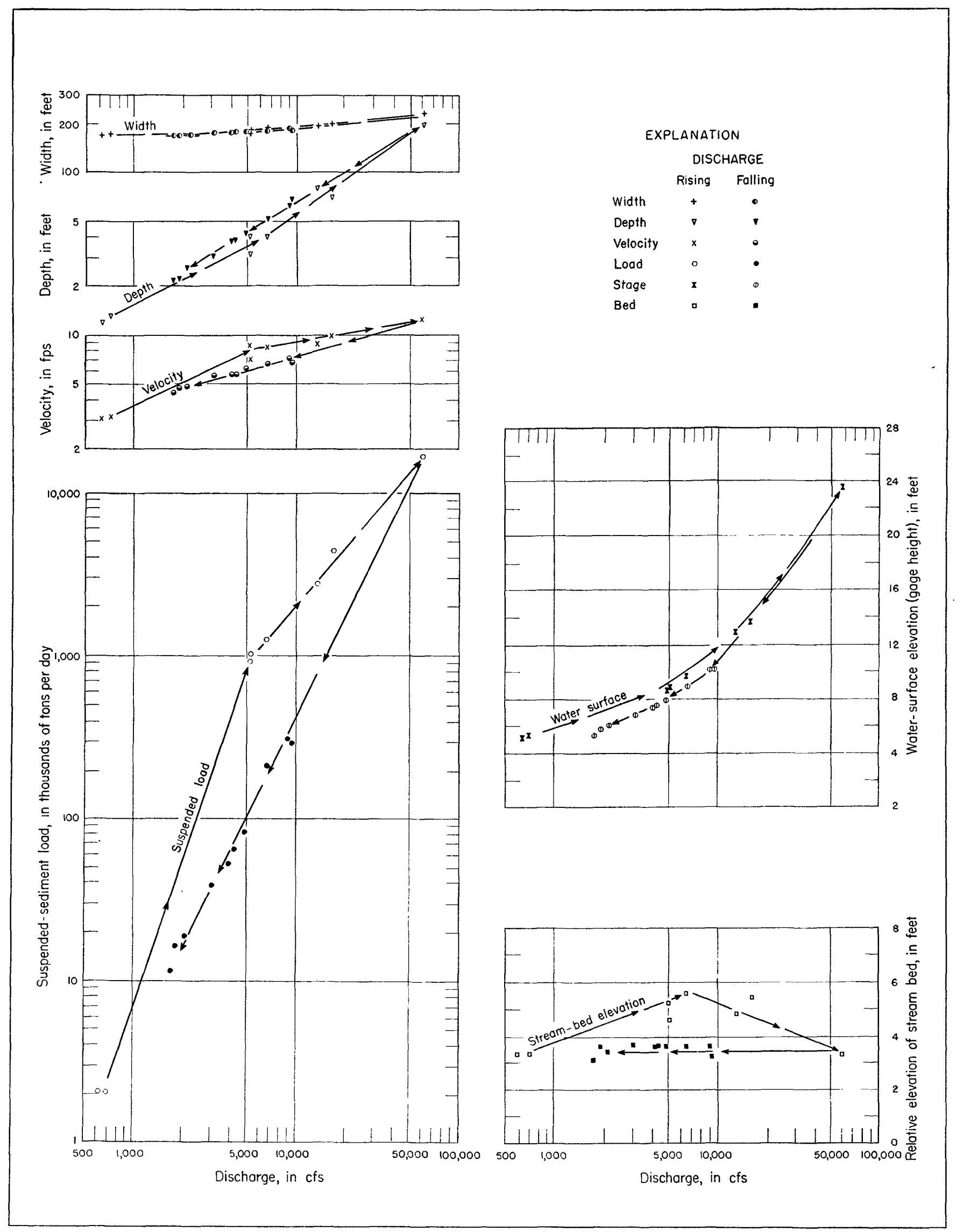

FIGURE 21.-Changes in width, depth, velocity, water-surface elevation, and stream-bed elevation with discharge during flood of September-December 1941, San Ju9n River near Bluff, Utab. 


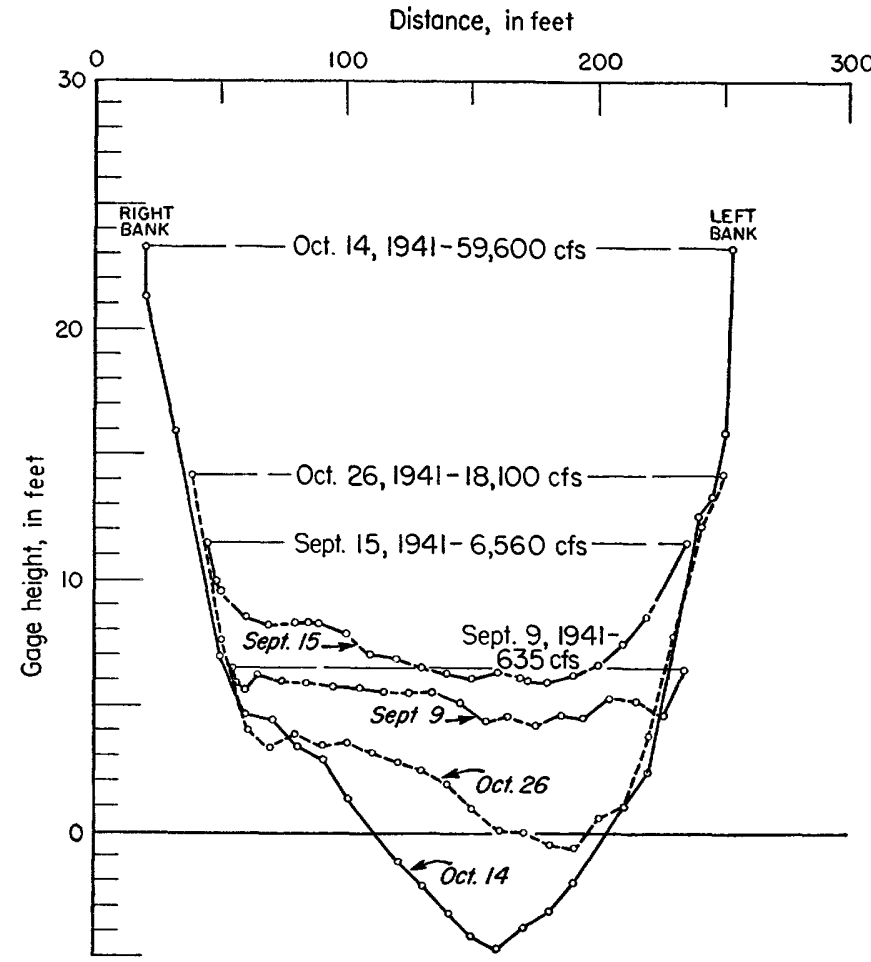

FIGURE 22.-C'hannel cross sections during progress of flood, SeptemberDecember 1941, San Juan River near Bluff, Utah.

have been plotted from original current-meter measurements.

The bed elevation rose during the first part of the flood rise. Deposition of material on the stream bed at the measuring section during the early period of the flood can be seen by comparing the cross sections in figure 22 for September 9 (635 cfs) and September 15 $(6,560 \mathrm{cfs})$. This deposition continued progressively as long as the slope of the suspended sediment-discharge curve was steep. At a discharge of about 5,000 $\mathrm{cfs}$ the suspended sediment-discharge curve assumed a different, less steep slope, and this smaller slope of the line was maintained as the discharge continued to rise to the peak flow of almost $60,000 \mathrm{cfs}$.

At discharges between roughly 5,000 and 60,000 efs the suspended-sediment concentration increased less rapidly per increment of discharge than in the range below $5,000 \mathrm{cfs}$. The smaller rate of increase of suspended-sediment concentration was associated with bed scour. After the peak flow, the falling discharge was accompanied by a stable bed elevation.

This flood is one in which the slope of the widthdischarge curve was about the same throughout the flood passage, and, therefore, the mutual adjustment among suspended load, velocity, and depth is quite evident. At 5,000 $\mathrm{cfs}$ the suspended load was about $1,000,000$ tons per day in the rising stage. In the falling stage at the same discharge and the same width
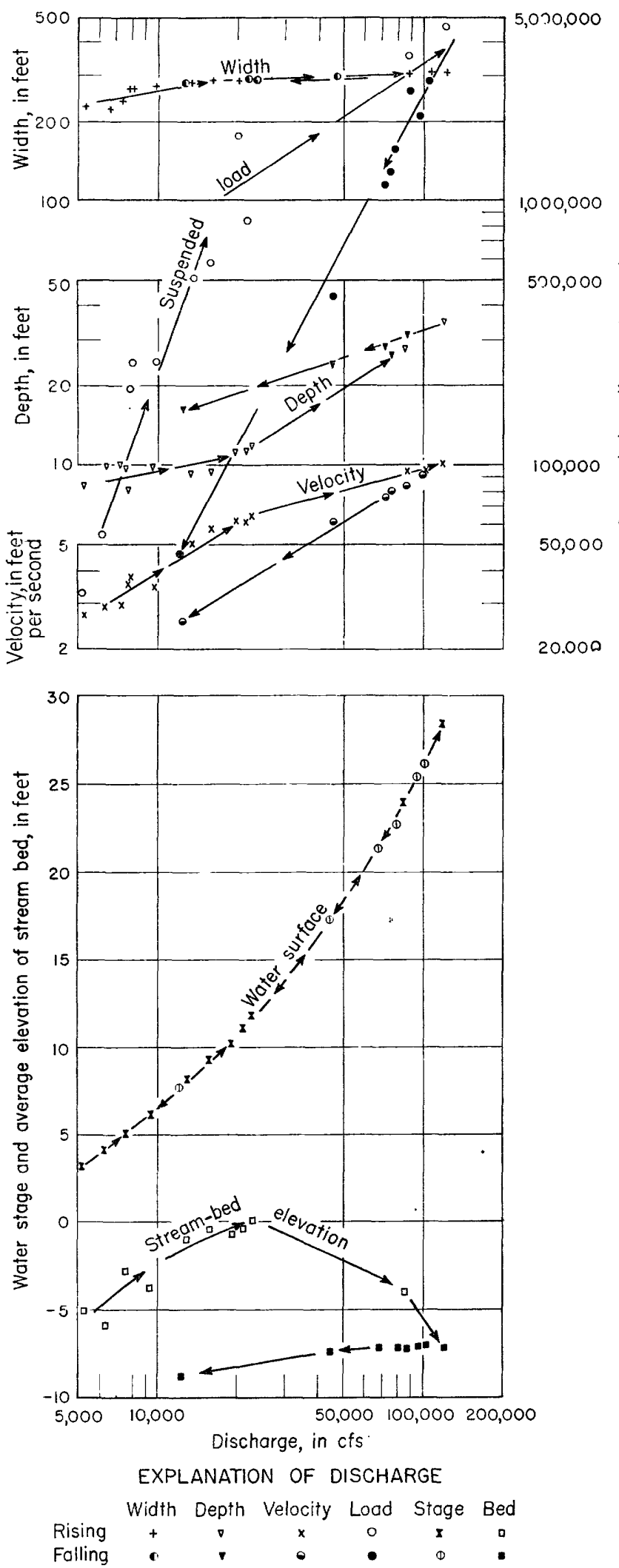

Figure 23.-Changes in width, depth, velocity, water-surface elevation, and stream-bed elevation with discharge during flood of December 1940-June 1941, Colorado River at Grand Canyon, Ariz. 
the suspended load was only 100,000 tons per day. The lower suspended load was accompanied by a lower velocity and a correspondingly higher depth. This is indeed in accord with the relation already noted in figure 15; that is, at constant discharge and width, decrease in suspended-sediment load is accompanied by a decrease in velocity and an increase in depth.

The observed relations during this flood are in accordance with the ideas explained in association with frgure 18. For the same value of $b$ (slope of the widthdischarge line), a decrease in the value of $j$ (slope of the suspended load-discharge line) is associated with a decrease in the $m$ to $f$ ratio; that is, the slope of the velocity-discharge line $(m)$ decreased while the slope of the depth-discharge line $(f)$ increased.

A second example of the day-to-day adjustments of channel shape and suspended load is the spring rise of 1941 on the Colorado River at Grand Canyon (fig. 23).

In this flood passage, at a discharge of $20,000 \mathrm{cfs}$ there is a break in the slope of the width-discharge curve, as well as in the load, velocity, and depth curves. At $20,000 \mathrm{cfs}$, in the rising stage, the load was about 1,000,000 tons per day, whereas in the falling stage the load was about 120,000 tons. This lowered load was accompanied by a definite increase in depth and lowered velocity while the width remained the same.

The bed elevation rose during the first part of the flood rise, then lowered as the discharge continued to increase toward the peak flow, it continued to lower during the falling stage. At $20,000 \mathrm{cfs}$, the bed elevation was $8.5 \mathrm{ft}$ lower on the falling than on the rising stage. The gage height, plotted against discharge, showed that the water-surface elevation was the same in both rising and falling stages at each discharge. At the measuring section, therefore, the difference in channel shape was taken care of by changes in bed, but the control downstream, a bar of heavy gravel, did not shift.

The reality of deposition on the bed during the first part of the flood rise can be observed in the successive cross sections in figure 24 . The river bed was lower on January $12,(5,210 \mathrm{cfs})$ than on March $6(23,400 \mathrm{cfs})$. These cross sections demonstrate that the bed was filled during the first part of the flood rise and then was scoured as the discharge rose above $20,000 \mathrm{cfs}$.

A further example which illustrates another type of adjustment to changing suspended load is provided by the spring rise of 1948 on the Rio Grande at Bernalillo, presented in figure 25. There was some decrease in suspended load at a discharge of $11,000 \mathrm{cfs}$ as the peak flow passed the station. The curve of bed elevation shows that the river scoured its bed during the rising stage when the sediment concentration was high and filled the bed during the falling stage when the con- centrations were lower. The San Juan at Bluff and the Colorado at Grand Canyon deposited during a part of the rising stage, then scoured during the remainder of the rise and continued to scour during the falling stage.

Figure 26 presents three cross sections of the Ri? Grande channel at the gaging station during the passage of the 1948 spring freshet. The scour of the bed was irregularly distributed across the section but on the whole, scour progressively occurred up to the peak discharge and deposition occurred during the falling stage.

The foregoing analyses of scour and fill of a river bet during flood demonstrate that the changes in the bed occurred simultaneously with changes in the rate of change of suspended-sediment concentration.

It is the thesis of this paper that the observed changes in the stream bed resulted from changes in the sedimer $t$ load brought into the measuring reach from upstream. It is postulated that the hydrodynamic factors involver tend to promote a mutual adjustment between channel shape and the sediment load carried into the reacr. The change in sediment load which results in a change of channel shape involves both bed load and suspender load. However, because only the suspended load is measured, it is necessary to use the data on the suspended fraction of the load as an index to how the totel sediment load interacts with the hydraulic variables. That the suspended fraction is a meaningful index is demonstrated by the fact that the relations between the channel-shape factors and suspended load, which are derived from measurements of a number of different rivers, appear to apply in principle to channel changes at a given station during an individual flood. Speciff-cally, with no change of channel width, a decrease of suspended load at a given discharge was accompaniet by an increase in depth by bed scour that resulted in a decrease in velocity. This is the type of change indicated by figure 15 . The decrease in velocity provides the adjustment of capacity for carrying the load of the particular size-distribution supplied by the watershed. In response to a decrease in load, the channel shape became adjusted through scour to the lower capacity required for quasi equilibrium.

In the hypothesis stated it was postulated that the changes in channel shape occurred in response to a change in sediment load brought into the reach. This postulate requires proof that the observed change in suspended-sediment load was not the result of the observed change of velocity in the reach rather than the cause. This is just the question faced by Mackin (1948, p. 471) when he observed that

As set up in an equation * * * load is a function of velocity. In answer to a query as to which is the cause, and which is the effect, the average engineer will assert that velocity 
controls or determines the load carried by a stream. $* * *$ [The equation as a] method of expression is inadequate for present purposes because the terms of an equation are transposable.

If the high suspended-sediment concentrations resulted from the scouring action of high velocities, it is implied that high velocity in a given reach scours the channel in that reach. The increase in sediment in transport resulting from the local bed scour should then account for the observed increase in sediment concen- tration. Under such an assumption, increasing velocity should be associated with bed scour and decreasing velocity with bed fill.

During the rising flood stage in both the San Juan River at Bluff (fig. 21) and in the Colorado River at Grand Canyon (fig. 23) the beds were filling during a period of rapidly increasing velocity concomitant with a rapidly increasing suspended-sediment load. The material deposited on the bed obvio'ssly came from upstream. How far upstream is unknown. It

Distance, in feet

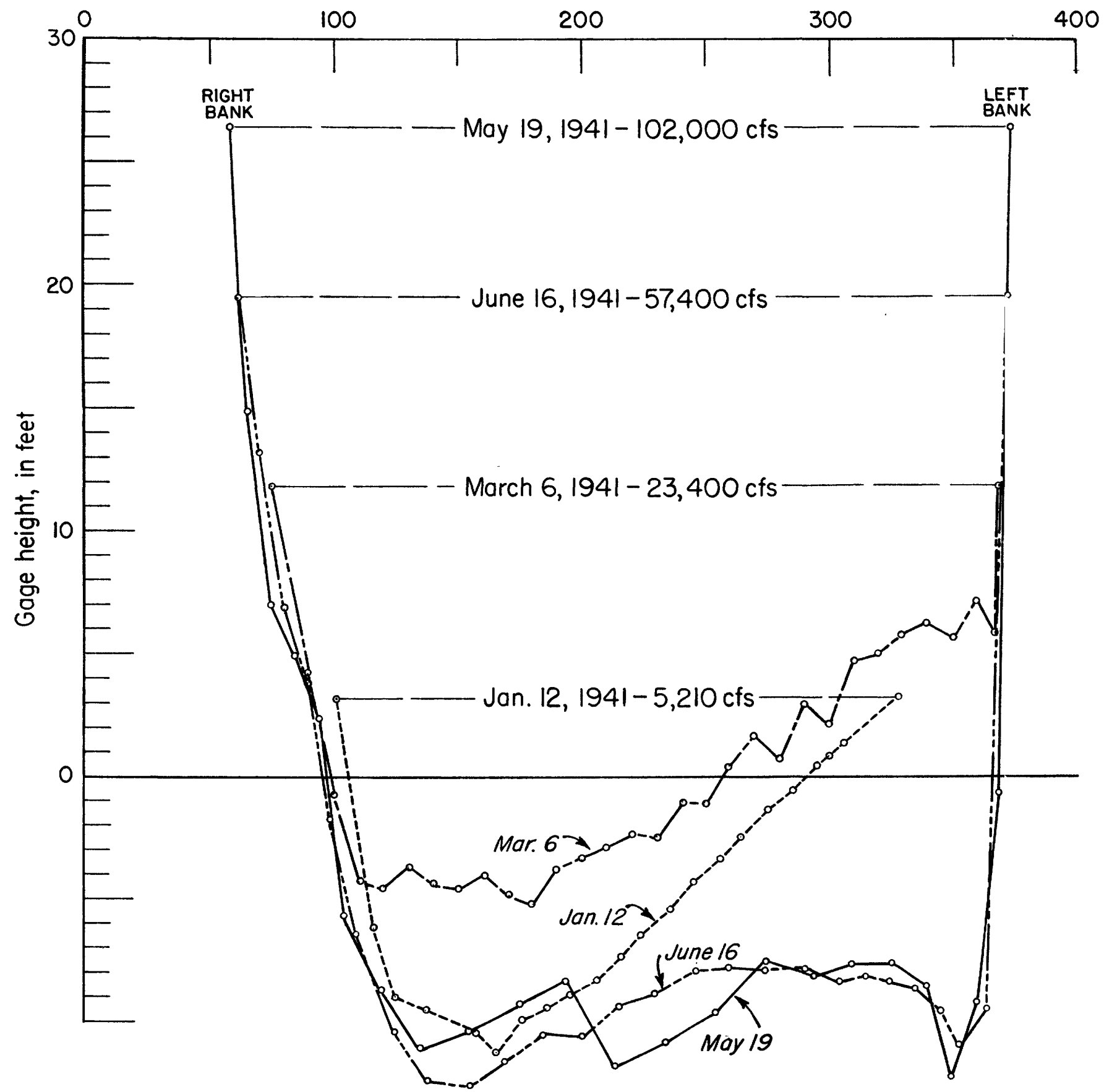

EIgure 24.-Channel cross sections during progress of flood, December 1940-June 1941, Colorado River at Grand Canyon, Ariz. 

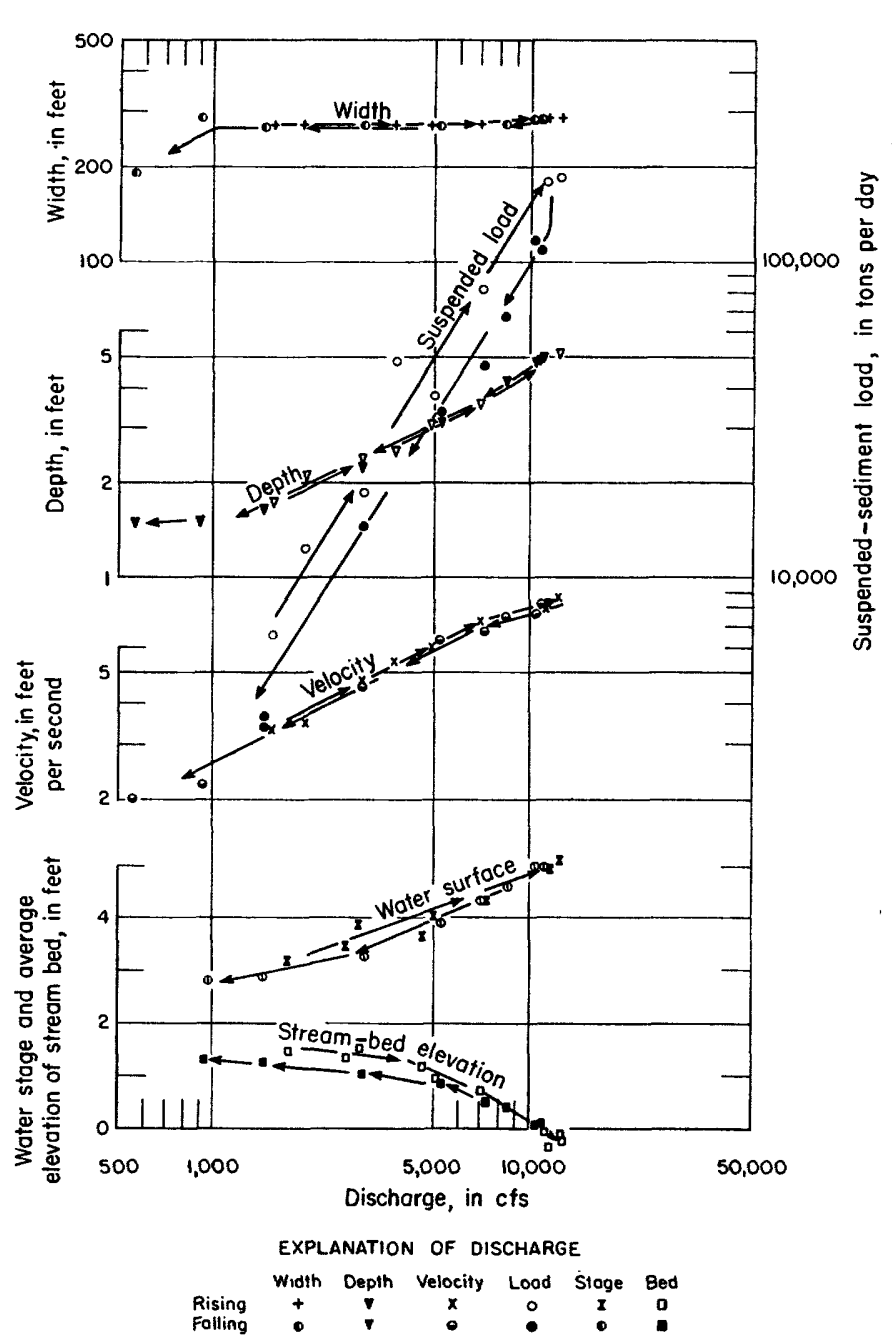

Figure 25.-Changes in width, depth, velocity, water-surface elevation, and stream-bed elevation with discharge during flood of May-June 1948, Rio Grande near Bernalillo, N. Mex.

is presumed that the bulk of the sediment carried past Bluff and Grand Canyon during spring flood was derived originally from erosion in ephemeral gullies, rills, and by sheet wash rather than from the channels of the larger perennial tributaries and trunk streams.

Concerning the seasonal sequences of scour and fill, the three rivers discussed in the preceding examples

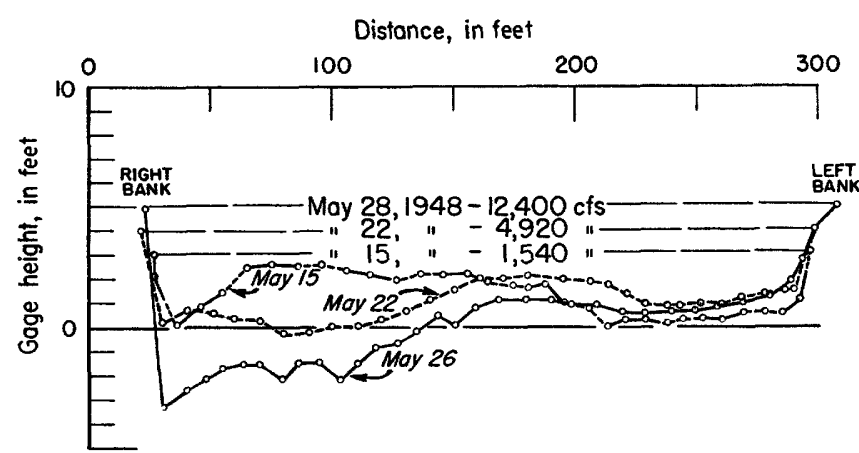

Figure 26.-Channel cross sections during progress of flood, May-June 1948, Rio Grande near Bernalillo, N. Mex. are typical of a number of streams in western United States. The spring floods are derived primarily from snow melt in the mountains. Much sediment must be carried into the major stream channels by the melt water, but this load is augmented by the transport of readily available material deposited in the channe? system during the local summer floods.

The spring flood leaves the river bed of the trunk river at a lower elevation than had obtained before the flood, but the succession of summer floods tends to aggrade the bed to the level observed preceding the spring snow melt. The succession of events appears from available data to be approximately the same each year.

It can be said in summary that the scour and fill of the bed of the main stem of an alluvial river during: flood appears to be an adjustment of channel shape in response to a varying sediment load. The adjustment takes place rapidly. This should not be interpreted as implying a complete absence of a time lag. In the long-continued flood passages typical of spring snow-melt contribution to Western streams, the progressive adjustment of channel to load is easily observed from the data, as has been shown. However, similar graphs for small irregular changes in discharge even for the same stations show that the adjustment is not so nearly complete as this. A time lag measured in days and perhaps weeks is required for adjustments to take place, as might be expected.

\section{THE ROLE OF CHANNEL ROUGHNESS AND SLOPF IN THE ADJUSTMENT OF CHANNEL SHAPE TC SEDIMENT LOAD}

It has been shown earlier that, at constant discharge. suspended-sediment load is related to the shape factors-width, velocity, and depth. It was noted that at constant width and discharge, increased suspended-. sediment load would be associated with increased velocity. But because $P$ and $w$ are constant, then the product $v \times d$ must be constant. Any increase in velocity, therefore, must require a decrease of depth.

As the Manning formula states:

$$
v=1.5 \times d^{\frac{2}{3}} \times \frac{s^{\frac{1}{2}}}{n}
$$

in which $v=$ velocity

$$
\begin{aligned}
& d=\text { depth } \doteq \text { hydraulic radius } \\
& s=\text { slope of the energy grade line } \\
& n=\text { roughness parameter }
\end{aligned}
$$

It is clear that an increase in velocity and a decrease of depth requires an increase in the factor $\frac{s^{\frac{1}{2}}}{n}$; or, in other terms, increased velocity and decreased depth would require an increase in channel slope or a decrease of roughness or both. 
Under the condition of a varying discharge a similar result is obtained. The relations of depth and velocity to discharge have been expressed by the equations

$$
\begin{gathered}
d=c Q^{s} \\
v=k Q^{m} \\
k Q^{m}=1.5\left(c Q^{\prime}\right)^{\frac{3}{3}} \frac{s^{\frac{1}{2}}}{n}
\end{gathered}
$$

The coefficients $c$ and $k$ are numerical constants for a given set of conditions.

Thus

$$
Q^{m} \propto Q^{\frac{2}{3}} \frac{\left(s^{\frac{1}{2}}\right)}{(n)}
$$

Under the condition that $s$ and $n$ do not change with discharge, then

$$
m=\frac{2}{3} f
$$

or

$$
\frac{m}{f}=\frac{2}{3}
$$

where

$$
\frac{s^{\frac{1}{2}}}{n} \text { increases with discharge, } \frac{m}{f}>\frac{2}{3}
$$

and when

$$
\frac{s^{\frac{1}{2}}}{n} \text { decreases with discharge, } \frac{m}{f}<\frac{2}{3}
$$

The average values of $m$ and $f$ for rivers studied were shown to be

$$
\begin{array}{rlrl}
\text { At a station } & \text { Downstream } \\
m=.34 & m=.1 \\
f=.40 & f=.4 \\
\frac{m}{f}=.85 & \frac{m}{f}=.25
\end{array}
$$

It appears, then, that for the rivers studied, the factor $\frac{s^{\frac{1}{2}}}{n}$ increases with discharge at a station and decreases downstream. In the following discussion the separate effects of slope and roughness will be considered. It will be shown that slope of the water surface tends to remain about constant at a station while the increase in the concentration of suspended load with discharge is associated with a decreasing roughness. Thus, the at-a-station value of $\frac{s^{\frac{1}{2}}}{n}$ tends to increase with discharge, a fact which explains why the mean at-a-station value of $\frac{m}{f}$ exceeds $\frac{2}{3}$.

It will further be shown that in the downstream direction the value of roughness, $n$, tends to be conservative, or remain about constant, while slope de- creases. This leads to an explanation of the observed value of $\frac{m}{f}<\frac{2}{3}$.

Because the present paper deals with the suspendedsediment load of streams, the general effect of sediment load on channel roughness will be considered. Vanoni $(1941$, p. $618-619 ; 1946$, pp. 96 and 127$)$ sl owed that an increase in suspended load tends to decrease channel resistance and thus causes an increase in velocity. He explains this effect as a result of decreased turbulence. Buckley (1922) found similar results in mexsurements of the Nile River.

The effect of suspended-sediment concentration on chamnel roughness was discussed by Thomas (1946, pp. 43-45) who also concluded that increased concentration was associated with decreased values of Manning roughness factor $n$.

It should be expected, then, that when a given river cross section is considered, the large changes in suspended-sediment concentration which orcur with changes in discharge should be reflected in important changes in channel roughness. In a given cross section (at a station), an adjustment of water-surface slope does not appear adequate to account for the observed variations in the velocity-depth relations; so, important changes in roughness must occur.

During the passage of a flood through a given river cross section, the slope of the water surface dees change. In any given reach slope tends to be steeper during a flood rise than a recession. The steeper slope on the flood rise is due to the fact that the rise at a given cross section precedes the rise at any section downstream. It will be noted, however, that the normal shape of a flood hydrograph tends to make the most marked change of slope coincide closely with the passage of the flood crest in a given reach.

In the Colorado and San Juan River examples however, it is observed that there was a change in velocity-depth relations which coincided with a change in suspended load-discharge relations at a discharge well below the peak. There is no a priori reason that any change of the slope-discharge relation should have occurred at that discharge. These facts irdicate that such at-a-station adjustments in velocity-depth relations result primarily from changes in roughness associated with changes in sediment load, rather than from changes in slope of the water surface. Moreover, during the passage of a flood lasting several months, conditions approach steady flow and therefore changes in water-surface slope as a result of the passage of a flood wave are minimized.

The velocity-depth changes and their relation to suspended load observed at a single cross section in the Colorado River, Rio Grande, and San Juan River are typical of all the cross sections studied for which adequate data are available. This appears to support the idea that such changes are typical of fairly long 
reaches of channel, measured in tens of miles rather than in tens of yards.

Changes in velocity-depth relations typified by the individual floods measured at Grand Canyon, Bluff, and Bernalillo must primarily represent, therefore, changes in roughness rather than in slope. If observed changes in velocity-depth relations can be attributed to changes in roughness, then lower values of roughness are associated with larger suspended-sediment concentrations, and this is just the effect found by Vanoni, Buckley, and Thomas.

The changes which have occurred in the lower reaches of the Colorado River after the construction of Hoover Dam, appear to confirm these observations, as will now be shown. When the sediment load of the Colorado River was stored in Lake Mead, clear water released from the reservoir caused degradation in the channel reach below Hoover Dam. The main degradation occurred in the reach of about 100 miles between Hoover and Parker Dams. The gaging station at Yuma, Ariz., is about 350 miles below Hoover Dam. A record of observations before and after the construction of Hoover Dam allows a comparison to be made of the channel characteristics at Yuma between a period when the river carried a large suspended load and a period when the load was markedly reduced. The current-meter measurements for that gaging station used in the present analysis are available in the offices of the Geological Survey.

In addition to the data on width, depth, velocity, and discharge included in the current-meter data, summary data on river slopes and on suspended-sediment load at Yuma are contained in a detailed report by the Bureau of Reclamation (1949). ${ }^{1}$ These data provide the basis for the present analysis.

The Yuma gaging records are obtained from a cablecar. The river at this point flows in a flat alluvial valley bounded by low scarps probably representing pediment remnants. The channel conditions before the changes brought about by the construction of Hoover Dam were described by the Geological Survey as follows: ${ }^{2}$

Channel at all stages composed of sand and silt. Brush and trees growing on both banks. *** Channel is straight for about $1,400 \mathrm{ft}$ above and a mile below the cable.

In figure 27 the width, depth, velocity, gage height, and stream-bed elevation are plotted against discharge for the Colorado River at Yuma. The figure includes graphs of these relations for the period 1927-34 before the construction of Hoover Dam and similar graphs for 1945-46 to represent measurements after the construction of the dam. It will be noted that the relations of these factors to discharge are similar to at-a-station

\footnotetext{
1 The river-slope data used in the following paragraphs appeat in figures 5 and 9 in the Bureau of Reclamation report, and the suspended-load data are tabulated in table 8, p. 33 .

2 Contained in description of the Yuma gaging station, dated June 3, 1938, in the files of the Geological Survey, Washington, D. C.
}

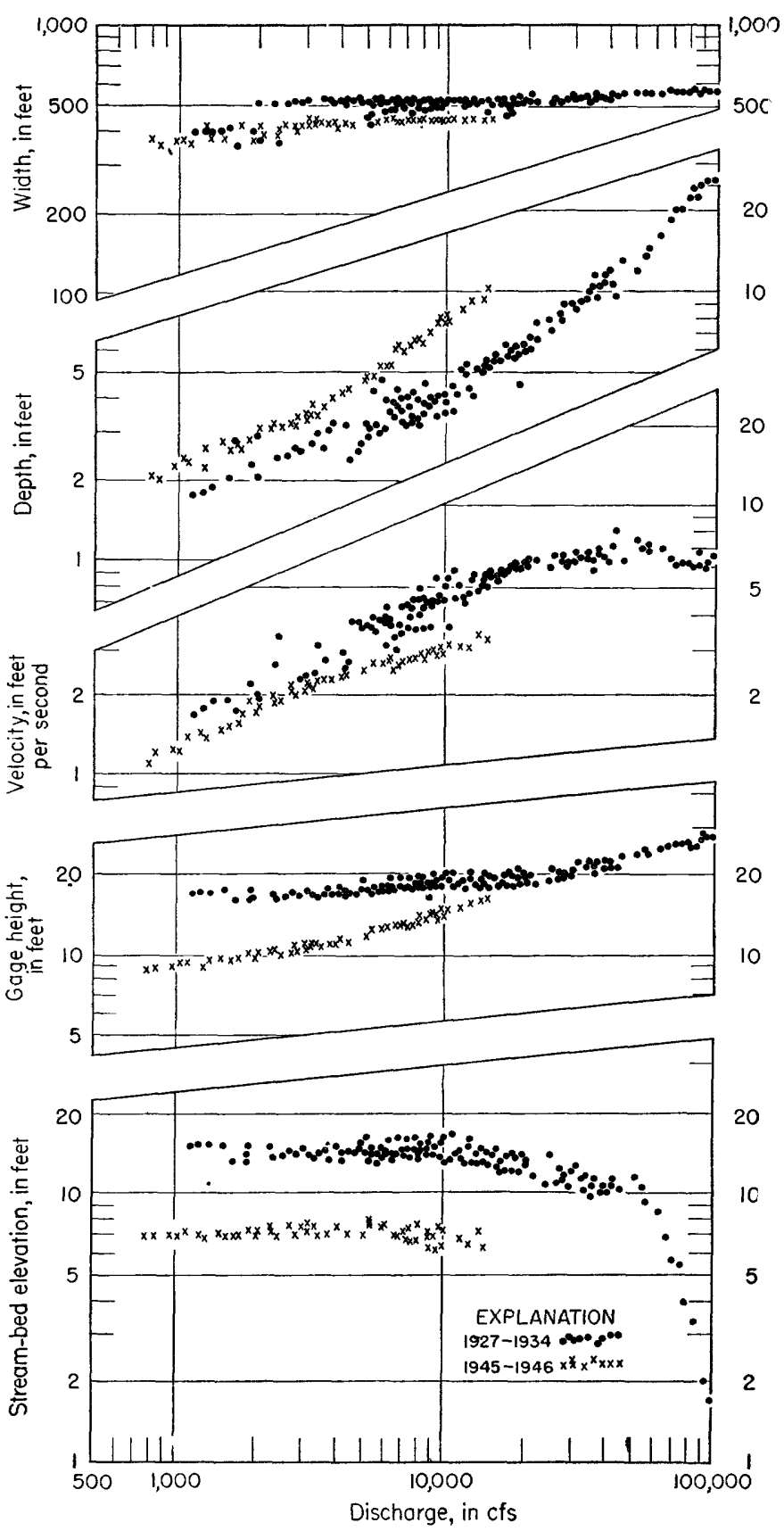

Figure 27.-Relation of width, depth, velocity, water-surface elevation, and stream-bed elevation to discharge, Colorado River at Yuma, Ariz. Sample periods before and after construction of Hoover Dam are shown.

curves presented for other river cross sections. The relations at Yuma changed, however, after construction of Hoover Dam.

Figure 28 presents the progressive change of the same factors with time. The width, depth, velocity, gage height, bed elevation, and roughness representing the average values for each of five discharges are plotted against time, in years.

Figure 28 includes the annual suspended-sediment load and annual discharge at Yuma gaging station plotted against time. Also included are graphs of the median size of bed material and river slope. Tho 
THE HYDRAULIC GEOMETRY OF STREAM CHANNELS
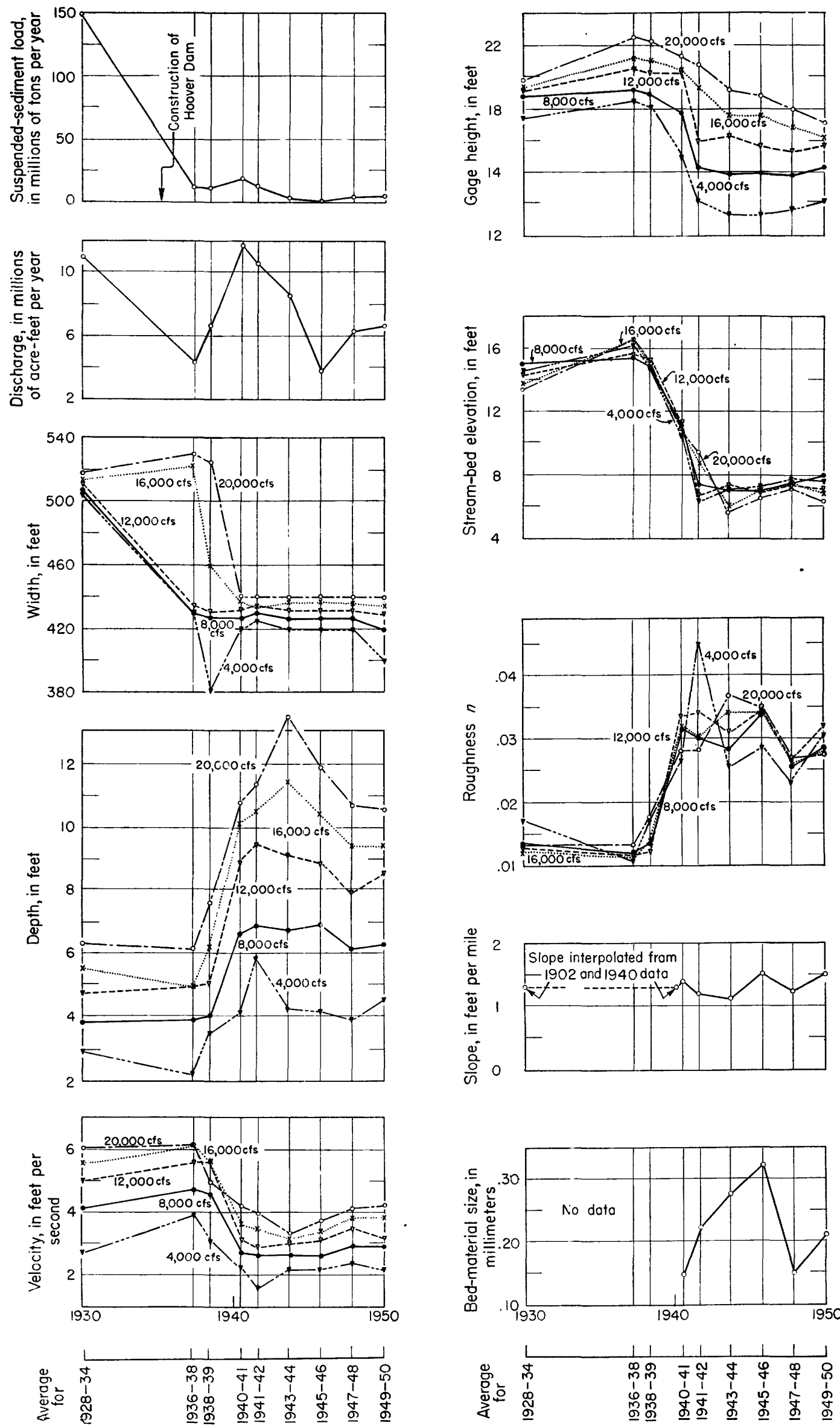
bed-material size was measured at Bureau of Reclamation section 7-S (1949, fig. 15), situated about 3 miles above Yuma. River slope was obtained as follows:

Successive measurements of particular cross sections were made by the Bureau of Reclamation to observe the degradation of the channel following building of the dam. These measurements permitted the construction of successive profiles of different reaches of the river. The profiles of the reach from Laguna Dam to the Mexican boundary, published by the Bureau of Reclamation (1949, fig. 5), are presented as figure 29 of the present report. The average slope in the 7-mile reach (Reclamation sections 7-S to 10-S) which includes Yuma gaging station, is plotted against time in figure 28.

The conclusions to be drawn from figure 28 will now be presented. Following the construction of Hoover Dan the annual suspended load passing Yuma decreased from an average of nearly 150 million tons to less than 25 million tons. The water discharge fluctuated from one period to another, depending on the releases from the dam and the contribution of tributaries entering the Colorado below the dam. In the period analyzed here there was, however, no large, consistent and sustained decrease in water passing Yuma after the dam was built.

This great decrease in suspended load supplied to the reach near Yuma caused the channel at Yuma to change markedly. Simultaneous with the reduction in suspended load, the channel at Yuma was degraded. The gage height, or water-surface elevation, decreased 5 to $6 \mathrm{ft}$ but the elevation of the river bed decreased about $9 \mathrm{ft}$. The difference represents the increase in mean depth, this increase was particularly great at high discharges. Despite a decrease in width from 510 to $430 \mathrm{ft}$ accompanying the degradation, the mean velocity decreased considerably. This decrease of velocity resulted from a considerable increase in roughness. The changes in slope were small and there was no progressive change during the period of record. The consistency in slope in the reach near Yuma can be seen in the river profiles of figure 29 .

The strong increase in bed roughness was not caused by a corresponding, consistent change in the size of bed material, at least the correlation of the roughness and the median size of bed material is poor. It appears more likely that the increase in roughness was an effect of the decreased concentration of suspended sediment.

The explanation for the decrease in channel width at Yuma probably lies in the cessation of large floods after construction of Hoover Dam. The channel was degraded. The large floods formerly characteristic of the reach had resulted in the development of a wide original channel to provide a balance among the requirements of width, depth, and velocity for transportation of the load which was supplied to the stream,

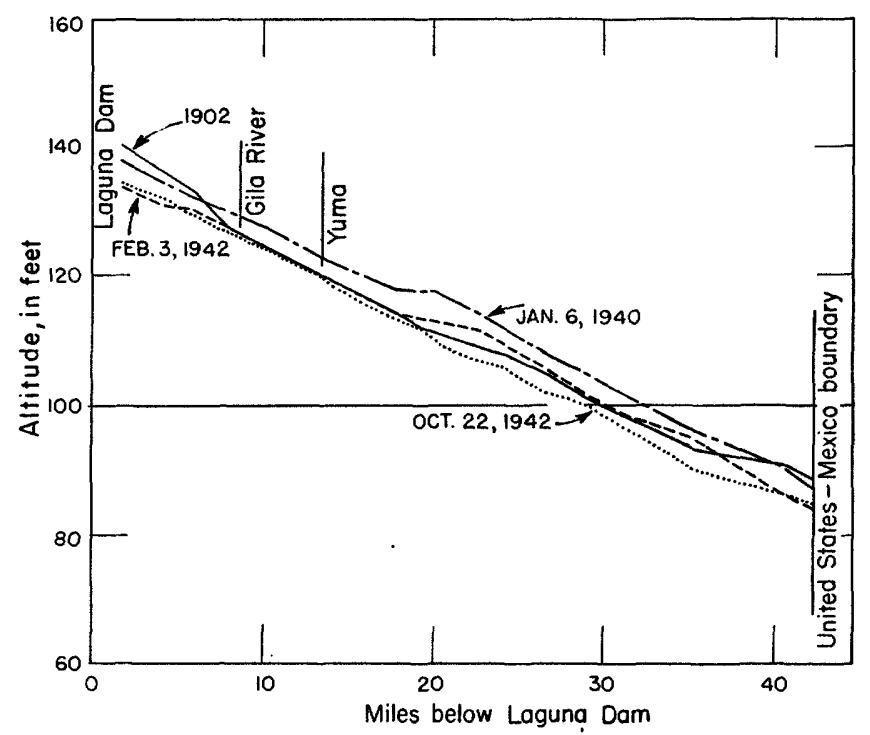

FIGURE 29,-River profiles in reach of Colorado River near Yuma, Ariz,, comparing conditions in 1902 before the construction of engineering works upstream with conditions in 194 and 1942 (after Bureau of Reclamation).

and the relative erodibility of bed and banks. The new discharge regime lacked the high floods to provide such widening, and new width-depth-velocity requirements for transportation are balanced by the relative erodibility of bed and bank now existing.

The reduction in width implies a larger capacity for suspended load at a given velocity and discharge, and a smaller capacity for bed load. However, becaus? velocity has decreased, the new channel can be considered to have a lowered capacity for both types $c^{f}$ load at a given discharge.

In summary, in this example for which considerable data are available, a decrease in sediment load-which originally, at least, was carried primarily in suspension-was accompanied by an important increase in bet roughness. Slope remained essentially constant. Undoubtedly, a different proportion of the load is carried as bed load in the present than in the original channe', and may be in part responsible for the observed increasa of roughness.

It is possible that changes in slope which have occurred in upstream reaches near the dams may in time affect the Yuma reach. In the years since tho construction upstream began, however, a quasi equilibrium has been established at Yuma by change in channel characteristics and not by changes in slope.

The example demonstrates that even during a perio $d$ of years adjustment of a channel reach in response to a change in suspended load may be made primarily by changes in channel shape through changes in roughness rather than in channel slope.

The longitudinal profile of most rivers is concave to the sky, or the slope tends to decrease downstream. The change in velocity-depth relations in the dowrstream direction, as discussed earlier, must be related, in part, to this progressive change of slope. The role 
of roughness, as compared with slope, in the maintenance of the observed $\frac{m}{f}$ ratio for the downstream direction can now be analyzed.

At least three factors affect bed roughness: the particle size, the bed configuration, and the sediment load. The effect of sediment load on roughness is in itself partly determined by particle size and is intricately related to bed movement, as well as to the suspended fraction. The Einstein equation (1950) provides a method of determining bed roughness when certain other factors are given, particularly the slope and the size distribution of bed material. The Einstein equation, however, allows width of the channel to be assumed, and therefore does not specify what widthdepth ratio will be developed under natural conditions.

The present analysis is concerned with relations among width, depth, and velocity as they are observed to exist in natural rivers and is, furthermore, restricted in dealing with sediment load to its easily measured fraction, or suspended load.

The present discussion of the effect of the three factors of size, bed configuration, and suspended load on roughness aims at a general qualitative understanding of how the values of roughness observed in rivers appear to be related to the average characteristics of rivers.

A characteristic of most natural rivers is a decrease in particle size of the bed material in the downstream direction, due primarily to abrasion. The authors are in agreement with Mackin's (1948, p. 482) rejection of the oversimplified explanation that the downstream decrease in river slope is caused directly by the decreased caliber of load downstream.

A change in caliber of load must have an effect on bed roughness and, through roughness, may affect other stream characteristics. This effect will now be examined.

In the present paper a distinction is made between roughness resulting from ripples or dunes on the channel bed and roughness due to the individual particles of bed material. A nearly identical distinction was made by Einstein and Barbarossa (1951). It is assumed in the present discussion that the roughness due to channel irregularities includes not merely semipermanent obstructions such as rocks and bars but transitory conditions of bed ripples and waves which change with discharge.

The Manning roughness factor in pipes represents a more or less permanent characteristic of the boundary surface. This is also true for certain open channels, drainage canals, and even irrigation canals where the banks and bed are fixed. However, in most sedimentladen channels the roughness is not a permanent characteristic but must change with the configuration of the bed. It is logical to suppose that when the bed of an alluvial river is smooth, the roughness as described by the Manning $n$ is different from and probably lower than that which applies to the same reach at a different discharge when the bed is molded into dunes or antidunes. This idea was clearly stated by Rubey (1952, p. 131).

In figure 30 the relation of bed roughness measured by Manning's $n$ is plotted against discharge for four sizes of sediment in transport. The data were collected by the U. S. Waterways Experiment Station and were summarized by Johnson (1943, pp. 80-84). From Johnson's summary, data for figure 30 were taken. The experiment concerned the transport of natural river sand by water in a flume.

It will be noted in figure 30 that a constant slope was maintained. When sand 1 , the coarsest of the four sizes discussed here was used, an increase of discharge was accompanied by a slightly increasing roughness. At low discharge, the roughness associated with sand 3 was only slightly higher than that for sand 1 , but when the configuration of the bed changed from a "smooth" condition to one of "general riffles" (term" used by Waterways Experiment Station), the roughness increased markedly. With further increase of discharge, roughness decreased gradually.

The importance of these relations may be summarized as follows. An increase in bed roughness is one type of change that will result in the decrease of velocity with respect to depth. Because changes in the velocitydepth relation constitute a part of the adjustment of channel shape to load, variations in roughness affect capacity for load.

Decreasing sediment size results in a decrease of roughness due to the individual particle. But in hydrodynamically rough channels, the roughness due to bed configuration may be much more important than that due to particle size, and sometimes decreased particle size may result in larger or more effective bed ripples or waves and thus in increased roughness.

It will be noted in figure 30 that the values of roughness representing "general waves" are markedly different among sizes of sand. Larger values of roughness are associated with smaller sand sizes. Thi implies, therefore, that among the four experimental runs using different sands, even when the configuration of the bed looks similar, for a given discharge and slop? the sediment particles of smaller size may arrange themselves in such a manner that effective roughness is greater than for larger particles.

At a station with a specific bed configuration, an increase in discharge may be accompanied by either a slight decrease in roughness, as in sands 3,6 , and 7 , or a slight increase. However, with increasing discharge the bed may change successively through conditions described as smooth, riffles, bars, dunes, and finally antidunes. As indicated by Langbein (1942), antidunes form when the Froude number approaches a value of 1.0, critical flow. Also, the finer the material, the lower 


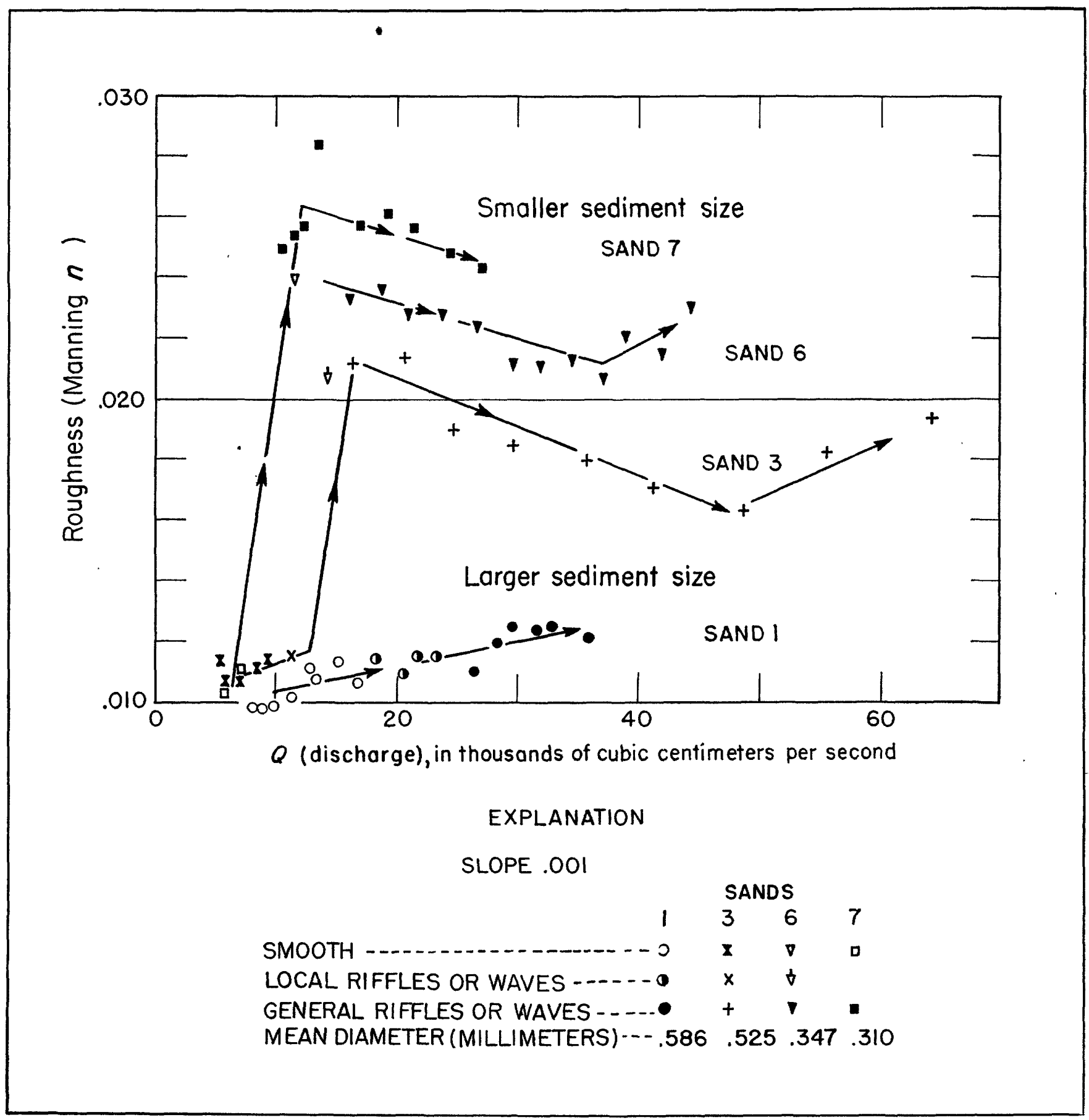

FIGURE 30.-Channel roughness (Manning $n$ ) in relation to discharge for various sizes of sediment (from flume data).

will be the value of the Froude number at which the transition occurs from a smooth bed to dunes and from dunes to antidunes.

At a given discharge, the change in bed configuration may increase the value of $n$ more than does a considerable increase in discharge during which the bed configuration remains the same.

Two general conclusions may be derived from figure 30. First, for the same slope and discharge, the effect of decreasing particle size is a tendency to increase the roughness even when the condition of the bed is observed to remain the same. Second, with no change in particle size, a change in bed configuration may violently chang: bed roughness and its effect may be of the same $o^{r}$ greater order than the effect of differences in particle size.

Headwater tributaries flowing on gravel or boulders obviously move the large bed debris only in exceptional flows. The channel roughness in such streams must b? determined by the sizes of the individual rocks or cobbles, because the bed material is not ordinarily in movement and is not thrown up into transitory ripples and waves in the sense used in describing the bed of an 
alluvial stream. The downstream decrease in the size of the gravel or pebble bed therefore results generally in a downstream decrease in the value of channel roughness. This can be seen in the data tracing the change from a headwater tributary down to the Powder River, Wyoming, listed below. The data apply to the conditions of velocity, depth, and width, prevailing at a discharge equal to the mean annual rate.

\begin{tabular}{|c|c|c|c|c|c|}
\hline & Station & $\begin{array}{c}\text { Mean } \\
\text { annual dis- } \\
\text { charge (efs) }\end{array}$ & Slope & $\underset{(n)}{\text { Roughness }}$ & Bed material \\
\hline$\downarrow_{\text {Downstream. }}^{\text {Upstream. }}$ & $\begin{array}{l}\text { Red Fork near Barnum } \\
\text { Middle Fork above Kaycee } \\
\text { Middle Fork near Kaycee } \\
\text { Powder River near Arvada. }\end{array}$ & $\begin{array}{r}50 \\
73 \\
115 \\
430\end{array}$ & $\begin{array}{r}0.0057 \\
.0038 \\
.0019 \\
.0009\end{array}$ & $\begin{array}{l}0.058 \\
.087 \\
.039 \\
.017\end{array}$ & $\begin{array}{l}\text { Gravel. } \\
\text { Gravel. } \\
\text { Sand and silt. } \\
\text { Silt. }\end{array}$ \\
\hline
\end{tabular}

The decrease in value of roughness $n$ is interpreted as the result of decreasing particle size, but may also be influenced somewhat by a downstream increase in suspended-sediment concentration in that particular reach of river.

However, in the Arikaree, Republican, and Kansas Rivers in the Kansas River system in which the bed is largely fine sand, there is a progressive diminution of slope but a nearly constant value of channel roughness. Though the particle size decreases downstr $a$ am in this river system, from coarse sand to fine sand and silt, the values of roughness are sufficiently large for it to be assumed that bed configuration rather th an size of individual particles controls the roughness.

\begin{tabular}{|c|c|c|c|c|}
\hline & Station & $\begin{array}{c}\text { Mean } \\
\text { annual dis- } \\
\text { charge (cfs) }\end{array}$ & Slope & $\underset{(n)}{\text { Roughness }}$ \\
\hline$\left.\right|_{\text {Downstream. }} ^{\downarrow}$ & $\begin{array}{l}\text { Arikaree River at Haigler } \\
\text { Republican River at Culbertson } \\
\text { Republican River at Bloomington. } \\
\text { Republican River at Clay Center } \\
\text { Kansas River at Ogden } \\
\text { Kansas River at LeCompton }\end{array}$ & $\begin{array}{r}29 \\
205 \\
670 \\
1,000 \\
2,300 \\
6,200\end{array}$ & $\begin{array}{l}0.0031 \\
.0015 \\
.0010 \\
.0004 \\
.0004 \\
.0004\end{array}$ & $\begin{array}{l}0.040 \\
.023 \\
.036 \\
.023 \\
.035 \\
.034\end{array}$ \\
\hline
\end{tabular}

Though the slope decreased downstream, the roughness showed only a modest decrease that was nearly masked by its variability.

As a generalization, it may be said that the value of channel roughness is controlled by the size of individual particles when this size is large; that is, gravel, cobbles, or even coarse sand. When the size of sediment is large, channel roughness tends to decrease downstream as the size of the particles decreases. In streams whose beds are composed primarily of fine material, there is a tendency for the bed configuration (ripples, waves or dunes) to control the channel roughness. In streams like these roughness tends to change but little in the downstream direction when discharge of equal frequency obtains along the river length.

The average changes of roughness and slope at a station and downstream are part of the hydraulic geometry of the channel system. For alluvial streams in which roughness tends to be determined by bed configuration and, therefore, decreases downstream only slightly, figure 19 indicates the average relations with discharge. The line $A_{4}-B_{4}$ representing the downstream change of roughness for a rate of discharge that occurs frequently or for a low discharge, is nearly horizontal. For flood. flow, the roughness is lower, presumably in part because of the greater suspendedsediment concentration, as indicated by the lower ordinate position of line $\mathrm{C}_{4}-\mathrm{D}_{4}$.

The river slope decreases downstream as indicated by the slant downward to the right of line $A_{5}-B_{5}$. In flood flow the river slope is probably very slightly greater than at low flow, in part, because of the tendency for the main thread of water to eliminate some of the minor contortions of the low water channel. Thus the line $A_{5}-C_{5}$ representing the at-a-station change of river slope is drawn so that it slopes slightly upward to the right.

In summary, the observed relations of velocity to depth in the downstream direction are considered to be those required for the transportation of the supplied load. It is postulated that these velocity-depth relations are provided by the concomitant change downstream of roughness and slope. Roughness is governed by the sediment size, the suspended-sediment concentration, and the bed configuration, all of which are independent of the channel or nearly so. That part of the required relation of velocity to depth not rrovided by the downstream change in roughness is provided by change in slope, because slope is the dependent factor which can be adjusted by stream processes. 
The characteristically rapid increase of suspended load with discharge at a station requires for transportation of that load a relatively rapid increase of velocity in comparison with depth, or a relatively large value of $\frac{m}{f}$. For the cross sections studied this was equal to .85 . This value, being larger than $\%$, requires that $\frac{s^{\frac{1}{2}}}{n}$ increase with increasing discharge. This is accomplished primarily by the decrease of roughness, $n$, resulting from the increase of concentration of suspended load with discharge.

In the downstream direction, however, load increases not quite so fast as discharge; this means that the concentration of suspended sediment decreases slightly downstream. The transportation of this load requires that the depth increase with discharge much faster than does the velocity, or the $\frac{m}{f}$ ratio must be small. For the rivers studied its mean value was .25 .

To provide that velocity-depth relation, $\frac{s^{\frac{1}{2}}}{n}$ must decrease downstream. Because of the nearly constant concentration of suspended sediment and the effect of bed configuration, roughness $n$ tends to remain about constant downstream. Thus the required $\frac{m}{f}$ ratio is provided primarily by the decrease of slope downstream.

\section{SOME PHYSIOGRAPHIC IMPLICATIONS}

\section{THE STABIE IRRIGATION CANAL-AN ANALOGY TO A GRADED RIVER}

An irrigation canal constructed in alluvial material tends gradually to scour or fill its bed and banks until a cross section is achieved that remains in equilibrium with the water and sediment flowing through it. Engineers designing canals to carry sediment-laden water have faced many of the same problems that face the geologist attempting to understand the grading of rivers. A large literature exists, particularly in India, on the subject of "regime" channels; that is, channels that are neither scoured nor filled.

Early work by Kennedy (1895) and Lindley (1919) laid the foundation for the research of Lacey who in two papers $(1930,1939)$ presented a detailed analysis of stable canals studied in India. Important addition to this literature have been provided by Lane (1937), Das (1950), Blench (1951a, b), and others.

In figure 31 data on regime canals published by Lacey $(1939$, pp. 41,49$)$ have been plotted in the same manner as the river data shown in figures 5-8. There is indeed considerable similarity between the graphs for regime canals and those for rivers.

Lacey utilized measurements of channel characteristics made on reaches of Indian canals that, through time, had achieved a stable cross section. He proposed a number of empirical equations that were derived from these data. From these equations, which he considered "basic," are derivable many other correlative relationships. Included in his basic equations $(1939$, p. 24) a.re

$$
\begin{aligned}
& P=2.67 Q^{\frac{1}{2}} \\
& V=1.15 F^{\frac{1}{2}} R^{\frac{1}{2}}
\end{aligned}
$$

where $P=$ wetted perimeter

$Q=$ discharge

$V=$ mean velocity

$R=$ hydraulic radius $\doteq$ mean depth

$F=$ a sediment factor

The equation relating wetted perimeter to discharge is identical in form to the relation found in the present study for river data, inasmuch as the wetted perimeter, $P$, is nearly equal to width, $w$, in wide channels. 'T comparable equations are

$$
\begin{array}{cc}
\text { Lacev } & \text { Present study } \\
w=2.67 Q^{\frac{1}{2}}-\cdots & Q^{b} \\
& \text { where } b=0.5 \text { in downstream direction }
\end{array}
$$

Lacey recogniced that his equation relating wetted perimeter to discharge applied to many natural streams, but having few river data he could not explore the limits of its applicability.

Lacey's data provided him with only a small range of intercepts, so that his width coefficients, ranging from 2.50 to 2.80 and averaging 2.6 , included a much smaller range than corresponding coefficients for American rivers. Because of the small range of intercepts in the canal data and the fact that the few individual measurements on rivers also happened to plot with nearly the same intercept as the canal data, Lacey concluded that his width-discharge equation was fundamental and that it was independent of sediment size.

The second Lacey equation expresses the relation of velocity to depth,

$$
V \propto R^{\frac{1}{2}}
$$

Because $R$, the hydraulic radius, is essentially equal to mean depth, $d$, of wide rivers this equation is directly comparable to the $\frac{m}{f}$ relation for rivers discussed earlier. Equations (2) and (3) of the present study can be combined as follows,

and

$$
d=c Q^{f}
$$

then

$$
v=k Q^{m}
$$

$$
\left(\frac{d}{c}\right)^{\frac{1}{f}}=Q=\left(\frac{v}{k}\right)^{\frac{1}{m}}
$$

or

$$
v \propto d^{\frac{m}{f}}
$$




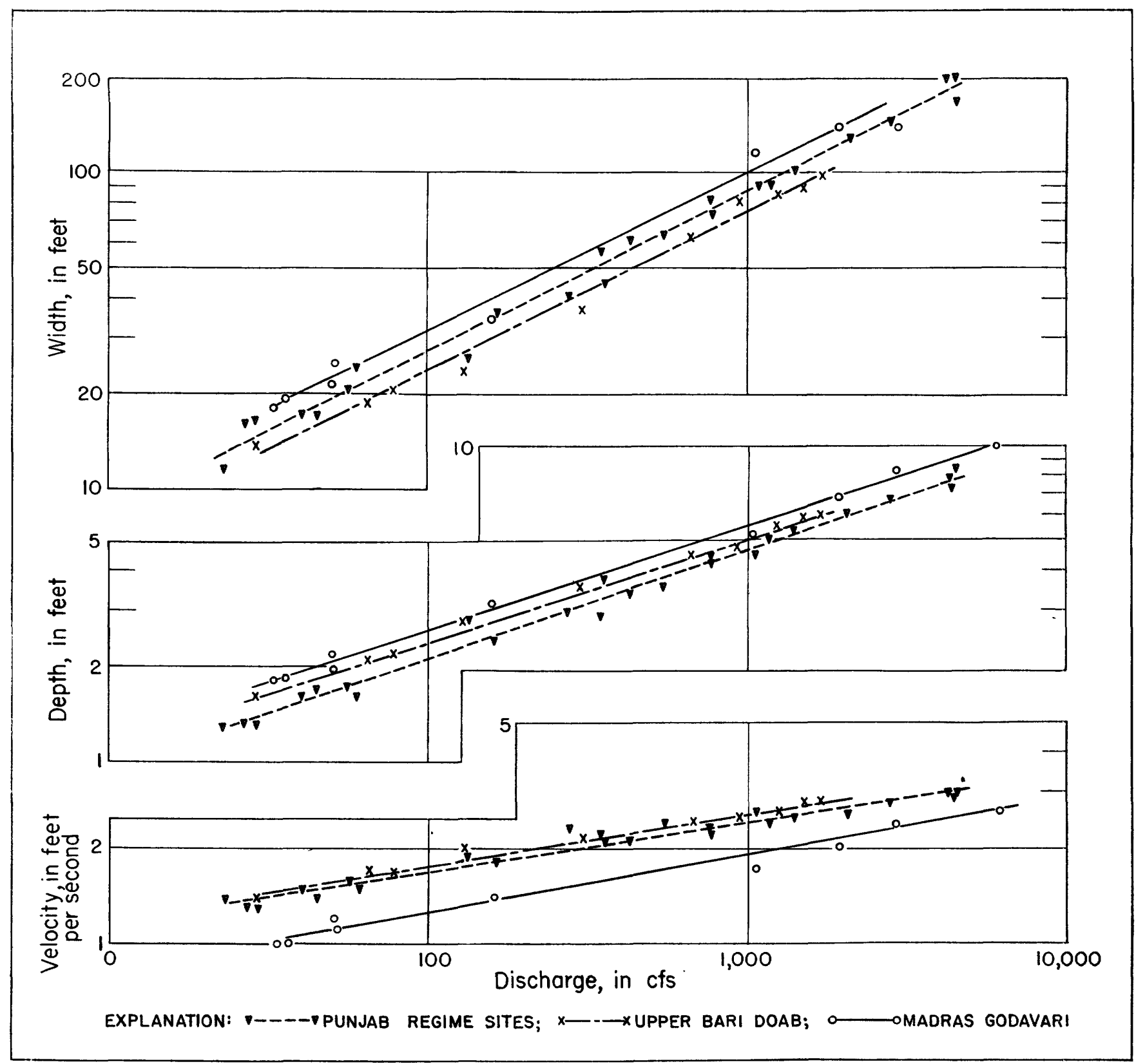

FIGURE 31.--Relation of width, depth, and velocity to discharge for stable (regime) irrigation canals in India (Lacey data).

In the downstream direction for river data $\frac{m}{f}=0.25$, whereas the comparable Lacey exponent is 0.5 . The difference between the numerical values of the exponent in these equations probably can be attributed to the difference in the downstream change in suspendedsediment concentration. It was shown in figure 18 that for any given value of $b$ (the rate of increase of width with discharge), the larger the value of the ratio $\frac{m}{f}$ the larger is the value of $j$. In terms of the comparison of the canal and river data, the regime canals show a larger $\frac{m}{f}$ value and must experience a rate of increase of suspended-sediment load with discharge along the canal length different from that of the average river in the downstream direction.

A canal system begins with the largest dis sharge at the intake where river water is diverted. Downstream the flow is gradually divided into successively smaller lateral canals. A regime canal is by definition one that neither scours nor fills its channel.

To preserve a condition of neither scour nor fill, as much sediment must be taken out of the system at the final points of diversion to the irrigated fields as was introduced at the head of the canal system. This is accomplished in practice by dividing, at each point of diversion, the sediment load in the same profortion as the water. That is, if at a given point of lateral diversion 10 percent of the flow of the mair canal is 
diverted, then 10 percent of the sediment being carried in the canal is also diverted. Blench (1951b, p. 5) implies that this is the practice in handling regimecanal systems when he says:

One [canal] exhibited serious sediment trouble on one branch but not on another because engineers did not understand regulator designs that could divide sediment suitably.

Blench makes a similar statement elsewhere (1951a, paragraph 2.17):

* * * The Lower Shelum Canal gave trouble [by progressive filling of its bed] because the regulator for the two Branches divided sediment unfairly.

Equality of division of water and sediment is tantamount to the maintenance of a constant sediment concentration throughout the regime svstem.

If the suspended-sediment concentration remains equal at all discharges, then the slope of the line representing the relation of suspended load to discharge would equal 1.0. This slope is, by definition, the value $j$. Now, in figure 18, if in the downstream direction for both canals and rivers, the exponent $b$ in the widthdischarge relation equals 0.5 as has been demonstrated, then the $\frac{m}{f}$ ratio (corresponding to $j=1.0$ in fig. 18) should apply to regime canals. The $\frac{m}{f}$ ratio at the value of $b=0.5$ and $j=1.0$ in figure 18 is seen to be about .43, or slightly less than 0.5 . Tentatively this appears to be a satisfactory agreement.

As indicated previously, the smaller value of $\frac{m}{f}$ obtained from the river data analyzed here indicates that $j<1.0$, or that the sediment concentration in the rivers studied decreases slightly in the downstream direction.

It can be seen that the general relation shown in figure 18 applies to regime canals, as well as to natural rivers. In fact, the Lacey equations for regime canals become a particular condition in the general relation involving $b, \frac{m}{f}$, and $j$. The particular condition is merely that of constant suspended-sediment concentration in the downstream direction.

The comparison of regime canals and natural rivers is valid only in the downstream direction. Canals carrying water high in sediment concentration would not normally be expected to maintain the regine condition except at the discharge for which they were designed. The lack of a varying discharge at any particular canal cross section precludes a proper comparison with the at-a-station relation of rivers. Failure to recognize this would lead to fallacious reasoning, as in a discussion by Stevens (see Lane 1937, p. 147) in which he compared the width-discharge formula of a particular river gaging station with the Lacey width-discharge formula for canals.

Another fact that demonstrates the analogy between regime canals and rivers in the downstream direction lies in a consideration of slope. In the design of canals, it has usually been found necessary to provide greater slope in the small laterals than in the large trunk canals. Thus canals in regine have a longitudinal profile convex upward because the flow is reversed as compared vrith natural rivers - that is, the discharge in a canal sys ${ }^{+} \mathrm{em}$ decreases downstream. This is analogous except for the direction of flow to the condition in natural rivers, which are steeper in the headwaters where the discharge is small than downstream where the flow is great.

The rate of increase of width with discharge is apparently independent of the size of the sediment particles. Not only is this rate similar for headwater reaches and lower reaches, but is is similar for rivers and canals which carry sediment of quite different sizes. Intercepts represented by $a, c$, and $k$, in equations (1) to (3) are probably related to sediment size. Lacey found so little variation of $a$ in Indian regime canals that he considered it to be a constant for all streams. Inspection of the large differences in intercept of the lines in figure 9 representing natural rivers indicates that the value of $a$ is not a constant. Das (1950, p. 160), reanalyzing the data on Indian canals, concluded that this coefficient is "* * * a function of the naturs of the periphery of the stream, i.e., it represents the nature of the soil surface forming the margin of the stream." He stated that values of $a$ for canals and rivers in delta areas where sediment sizes are small are less than for canals and rivers where sediment sizes are larger. It will be recognized from common experience that sandy channels are wide compared with silty or clayey channels.

A regime canal is a system in equilibrium. By definition it is a canal which over a period of years neither scours nor fills. It is a system in which slope and channel characteristics are adjusted over a period of time to carry the load supplied to it at the upstream end. In this respect a regime canal fits perfectly the definition of a graded stream (Mackin, 1948, p. 471).

Mackin's definition is:

A graded stream is one in which, over a period of years, slope is delicately adjusted to provide, with available discharge and with prevailing channel characteristies, just the velocity required for the transportation of the load supplied from the drainage basin. The graded stream is a system in equilibrium; its diagnostic characteristic is that any change in any of the contro'ling factors will cause a displacement of the equilibrium in a direction that will tend to absorb the effect of the change.

The discharge is provided to the canal system ky a source independent of the channel itself, just as Mackin visualizes a graded river. Load also is supplied by an exterior source. In the regime canal the water and s?diment are diverted into the canal system from a river, whereas in a graded stream, the load and dicharge are supplied from the watershed. In both, however, the source is independent of the stream.

The regime canal is in equilibrium. Although local 
or temporary scour and fill may occur to a minor degree, it is a diagnostic characteristic of regime that a change in any controlling factor causes a displacement of the equilibrium in a direction that will tend to absorb the effect of the change. Were this not true, local and temporary fill or scour would have an accumulative effect and the system would have, over a period of years, changed sufficiently for the term "regime" to be inapplicable.

It is logical to suppose, then, that the point in figure 18 which describes regime canals, represents values of $b, \frac{m}{f}$, and $j$ which apply to a graded channel system in the sense used by Mackin in his definition of a graded river.

It has been demonstrated by the concurrent changes in $m, f$, and $j$ during individual floods that the general relations in figure 18 define, at least in general, the mutual adjustments which occur at a station when suspended-sediment concentration changes. Because figure 18 describes relations both at a station and downstream for average values of the factors observed in rivers, and approximately fits regime canals, any point in the graph is considered by the authors to represent concurrent values of $m, f$, and $j$ required for equilibrium. It is understood, however, that the exact form and positions of the lines in figure 18 must be considered subject to adjustment as more data become available.

In practice, the suspended load-discharge relations vary within definite limits. At-a-station values of $j$ probably vary between 2 and 3 and downstream values between 0.5 and 1.3. Values of $b$ appear to remain close to 0.5 downstream and $0.1-0.3$ at a station.

Therefore, actual values of the variables occur in only a limited part of the field of values shown in figure 18 .

The conception of adjustment of the cross section of a channel in response to changes in the load-discharge relationships has not been stressed in the geologic literature. Only Mackin (1948) and Rubey (1952) give this the prominence it deserves. As shown by the Yuma data, a change in the governing factors may result in changes in channel characteristics without a change in river slope.

The present analysis adds weight to the importance of adjustment in channel cross section, and the writers would support the alternate wording of the definition of a graded river which Mackin considered but, apparently for the sake of brevity, discarded. Mackin says (1948, p. 484):

The question arises $* * *$ as to whether the foregoing definition [of a graded river] which describes the graded stream as one "in which slope is delicately adjusted," etc., should not be revised to read, "in which slope and channel characteristics are delicately adjusted," etc.

The latter phraseology would be preferred by the writers, and in principle is the conclusion reached independently by Rubey (1952, p. 130).

Because the data in figure 31 represent canal sections chosen as examples of regime conditions, the figure may be considered to represent the relations of width, depth, and velocity to discharge in a channel system graded in the sense used by Mackin. The graded channel system represented in the graph is a spenific one in that the graphs apply only to the conditions of sediment size and constitution of bed and bank existing in those canals. It has been noted, however, that the intercepts of these lines are the factors whicl would change with the type of sediment.

The relative slopes of the depth-discharge and velocity-discharge lines are considered to be functions of suspended-sediment concentration at differ $ə n t$ discharge.

There might be some logic in postulating, that if data from a particular river plotted with as little scatter of points on these graphs as do the data on regime canals, the river could be considered in regime and therefore graded. River data discussed in this report plot in graphs similar to those for regime canals, and the differences in slope and intercept appear to be explicable by differences in sediment size and in sediment concentration.

In practical terms, however, a particular graded reach of a stream is generally too short to include a large enough number of gaging stations to allow a development of graphs adequate to describe in definitive manner the slope and intercepts of the downstream relations. Moreover, the slopes of the graphs depend for clear definition on a considerable range in discharge in the downstream direction. A stream segment may be graded when there is no increase in discharge downstream.

The downstream graphs presented in figures 5-8 do not necessarily represent river systems which are graded throughout their length. For example, if two graded reaches are separated by a canyon reach within which the river flows in a rock-lined gc"ge, the canyon section may be steep and may include waterfalls and would obviously not be called graded. If the gaging stations available for analysis were all located in the two graded reaches, it is possible that downstream graphs comparable to figure $5-8$ could be plotted in which there might be a very good alinement of points. Figure 6 representing the Bighorn River system includes two canyon sections, the Wind River Canyon through the Owl Creek Mountain, in the reach between Riverton and Thermopolis, and the Bighorn Canyon between St. Xavier and Custer. Figure 6 shows a considerable scatter of points about the mean line and at least part of this scatter is due to the nongraded conditions of some of the reaches where gaging stations are located. 
Figure 5 presents data for the Powder River system. The Powder River, at least in the reach from Kaycee, Wyo., to Locate, Mont., has many of the characteristics used by Mackin (1948, p. 472-474) to support his choice of specific reaches of certain streams as examples of graded reaches. Terrace remnants indicate that the Powder River once flowed at a high level. The terrace surfaces exhibit smooth, longitudinal profiles concaveupward, similar to the profile of the present flood-plain. As in Mackin's Columbia River example, downcutting during a period of planation was not prevented by bedrock resistance. The underlying material in the Powder River Valley is unconsolidated alluvium.

This graded reach is represented in figure 5 by the six solid triangles labeled points $2,3,7,12,22$, and 23 . These points have considerable alinement, and deviate from the mean lines drawn on the graph very little more than the scatter seen in the regime canal data of figure 31. But the recognition of the graded reach from the alinement of points would obviously be impossible.

It appears that the available data do not allow identification of a graded reach from reaches which are not definitely known to be graded. It follows that the gaging-station data taken at points distributed over a drainage system without regard to the existence of or lack of grade, define a change of width, depth, and velocity downstream with change in discharge as consistent as the changes observed in the same type of data within a graded reach. The same factors which tend to maintain equilibrium when a reach becomes graded are acting also on reaches not in complete equilibrium and this action is sufficiently potent to produce consistent patterns in the relation among the hydraulic factors of channel shape.

Stations on the upstream reaches and minor tributaries, many of which are probably not graded but have been downcut over a period of time, have width-depthvelocity relations similar to those of the graded reach of the same river systam. One of the primary criteria for recognizing a graded reach is the lateral planation of a stream during a period when the longitudinal profile maintains stability (as discussed by Mackin, 1948, pp. 472-474). The same factors which operate to maintain grade are also acting during the period of downcutting.

When a stream in the process of downcutting has developed a smooth longitudinal profile through a given reach, the interaction of the hydraulic variables provides an approach to the condition of grade. That the overall longitudinal profile of a stream is in general concave upward and more or less smooth, even where only a few reaches are actually graded, is the result of the interaction of these variables. The tendency toward the condition of grade provides a tendency toward continuity in the change of width, depth, velocity, roughness, and slope in the downstream direction.
The data presented bere lend quantitative support to the idea expressed by Mackin (1948, p. 506) th a,t "*** even in the aggrading stream the declivity of each segment is approximately adjusted to the load in transit through that segment." The quantitative data show that the approximate adjustment involves not only slope but width, depth, and velocity, as Mackin's statement obviously implies. The quantitative data not only demonstrate the existence of approximate adjustment but, more importantly, describe it.

Lest the reader conclude from the consistency in the hydraulic geometry defined by the available data botween graded reaches and reaches not known to be graded, that there is no difference or that the graded condition does not exist in nature, it is emphasized here that the present study is not aimed at the quantitative differentiation of graded from nongraded reachas. A graded stream by definition (Mackin, 1948) is one which is in equilibrium through a period of years. The hydraulic geometry as defined here does not demonstrate whether gradual changes are in process, though when a stream is sufficiently lacking in equilibrium to be suffering rapid degradation or aggradation, changes in the values of factors in hydraulic geometry can be measured, as was demonstrated for Yuma.

The present study is an attempt to define in qu8.ntitative terms, insofar as available measurements pormit, how the factors operate which lead to stresm grading, which maintain the graded condition, and which cause adjustment when the equilibrium condition is upset. Mackin (1948) discussed these same factors in qualitative terms, and this study is an attempt to extend his reasoning by quantitative consideration of the hydraulic factors.

In summary, regime irrigation canals that over a period of years neither scour nor fill are observed to have a hydraulic geometry similar to that for natural rivers. Differences in the average slopes and intercepts of the lines representing width, depth, velocity, and discharge relations in canals and rivers can be qualitatively explained. One important difference lies in the load-discharge relations. The analogy of regime-canal data to those for rivers leads to the hypothesis that the $m, f, b$, and $j$ relations in figure 18 represent requirements for equilibrium.

Graded reaches of a river are shown to have width, depth, velocity, and discharge relations similar to those of reaches not known to be graded. This similarity indicates that the same factors which operate to maintain equilibrium in a graded river are also sufficiently active in nongraded reaches to provide specific and consistent patterns in the hydraulic variables both at a station and in a downstream direction. Stream-gaging data, however, are not available in sufficient quantity, in a sufficiently close geographic network, and over a Iong enough period to allow differentiation betwean 
graded and nongraded reaches by hydraulic geometry alone, though this might theoretically be possible.

The hydraulic geometry of rivers is useful in improving our understanding of the quantitative values of hydraulic factors which characterize rivers, and in understanding better the nature of the interaction of factors that lead to the condition of equilibrium or grade.

\section{SEDIMENT AND THE IONGITUDINAL PROFIIE}

The longitudinal profile of a stream might be considered primarily a product of the change in size of bed material in a downstream direction. The bed of a mountain stream is usually covered with gravel or boulders and has a steep slope. Some distance downstream the bed may be sandy, and still closer to the mouth silt or clay may predominate. At the same time, the slope progressively decreases downstream. One tends to associate the particle size and slope in a direct cause-and-effect relation. Shulits (1941) derived an equation for the stream profile from a consideration of decrease of particle size as a result of abrasion. He made the assumption that the slope was proportional to the size of the bed-load material.

To assume that slope is proportional to size of bed material requires the operation of certain other hydraulic factors. It could be argued that a given slope is required to provide the particular velocity necessary to carry the particle size present at each point. This reasoning implies that the decreasing particle size downstream requires a decreasing velocity which, in turn, is provided by a decreasing slope in the down stream direction.

Mackin (1948, p. 482) argues correctly that a similarity in curves representing the longitudinal profile and the change in particle size does not prove any direct cause-effect relationship. He (p. 481) believes the relationship to be as follows:

Graded profiles usually decrease in slope in a downvalley direction between tributary junctions, chiefly because of a downvalley decrease in caliber of load due to processes within the stream. The principle involved is that the velocity (and, other things being equal, the declivity) required for the transportation of the coarser fractions of the stream's load decreases with decrease in grain size, the total amount of the load remaining the same.

This explanation again implies a downstream decrease in velocity. The present study allows some further explanation of the mechanism implied in the phrase, "velocity required for the transportation of the coarser fractions of the stream's load." It has been pointed out that the velocity can be changed by a change in slope and a change in bed roughness or by either. One might suppose from Mackin's description that the effect of particle size on velocity is offset entirely by slope despite his qualification of "other things being equal." Examples of natural stream reaches can be found in which neither discharge nor load changes appreciably downstream. Mackin (1948, p. 482) cites a reach of the Greybull River as an example. He states that in this reach slope decreases downstream markedly and attributes this "* * * largely to a decrease in caliber of load in transit; pebbles of the valley floor and terrace gravel sheets decrease notably in size in a downvalley direction."

This observed decrease in particle size can be $\varepsilon$ ssumed to result in a decrease in channel roughness (ralue of Manning $n$ ) because the bed material being gravelly or pebbly is no doubt so large that the size of the individual particles rather than bed configuration determines the value of $n$. Consider the Manning equation

$$
v=1.5 \frac{d^{2} s^{\frac{2}{2}}}{n}
$$

If load and discharge are assumed to remain exual, as Mackin specifies in his Greybull example, then according to the relations shown in figure 15 the velocitydepth relations required for transportation of the suspended part of the load remain constant. Let it be assumed that this is the condition which prevails through the reach of river cited. Such an assumption rests again on the premise that the suspended load is a usable index to the poorly understood load conditions which affect channel shape. One could argue that the diminishing size downstream of the channel gravel increases the percentage of load carried in suspension, but no data are available to support such a contention and it is not unreasonable to suppose that suspended load remains essentially constant in this reach, as does the total load. If constant velocity and deptr downstream are required to carry the constant suspended load, an observed decrease in slope downstream results from a decrease in roughness downstream caused by the reduction in particle size.

In a stream having relatively fine bed material, sand and silt, the roughness due to particle size usually does not control. The flow may be hydrodynamically "smooth"; with this kind of flow in which the thickness of its laminar film exceeds the roughness projections of the individual particles, as in some Indian canals (Blench, 1951a, fig. 4.1), or the effective roughness is controlled by bed configuration rather than particle size.

The analysis of figure 30 indicates that in fine-grained materials, a decreasing particle size tends to increase bed roughness under conditions of constant slope and discharge. Roughness, where it is not controlled by the size of individual particles, is affected by the concentration of suspended sediment, larger concentrations being associated with smaller values of roughness, as $\mathrm{t}$ as been discussed. Bed load affects roughness but its effect is not distinguishable from that of suspended loed in the river data available. 
The tendency for particle size to decrease downstream leads to a tendency for roughness to decrease downstream. As the particles in transit become small enough, the configuration of the bed finally tends to govern, and a further decrease in particle size promotes a tendency for increased roughness. This increased roughness is also partly caused by the tendency toward decreased concentration of suspended sediment downstream.

Though the relative importance of these three factors cannot be determined from the river data available, the net result is a remarkable conservatism in the values of roughness. Particularly in streams handling finegrained material, the roughness varies between narrow limits in the downstream direction.

The relation between velocity and depth to slope, roughness remaining constant, can now be considered in the downstream direction.

It is obvious that streams having an infinite number of longitudinal channel profiles could carry the water furnished by the watershed. It will now be shown, however, that different longitudinal profiles differ in their rates of change of velocity and depth in a downstream direction.

For example, in a hypothetical stream in which sediment is not a factor, it is assumed that the only requirement of the channel system is that it carry a specified amount of water between two fixed altitudes. More specifically, it is assumed that the watershed is of such shape and hydrologic characteristics that, in the stream being considered, the discharge in the main channel increases linearly from zero at the headwater divide to $10 \mathrm{efs}$ at a point $1,000 \mathrm{ft}$ downstream from the divide.

Three completely arbitrary profiles of the stream thalweg having different concavity, as shown in figure 32 lower right, are now assumed. Profile $\mathrm{A}$ is a straight line. Each profile is drawn between the headwater divide and a point of the channel $10 \mathrm{ft}$ lower and 1,000 $\mathrm{ft}$ distant horizontally.

It is desired to show the change of velocity and depth downstream for each of two arbitrarily assumed relstions of width. The two conditions of width for which

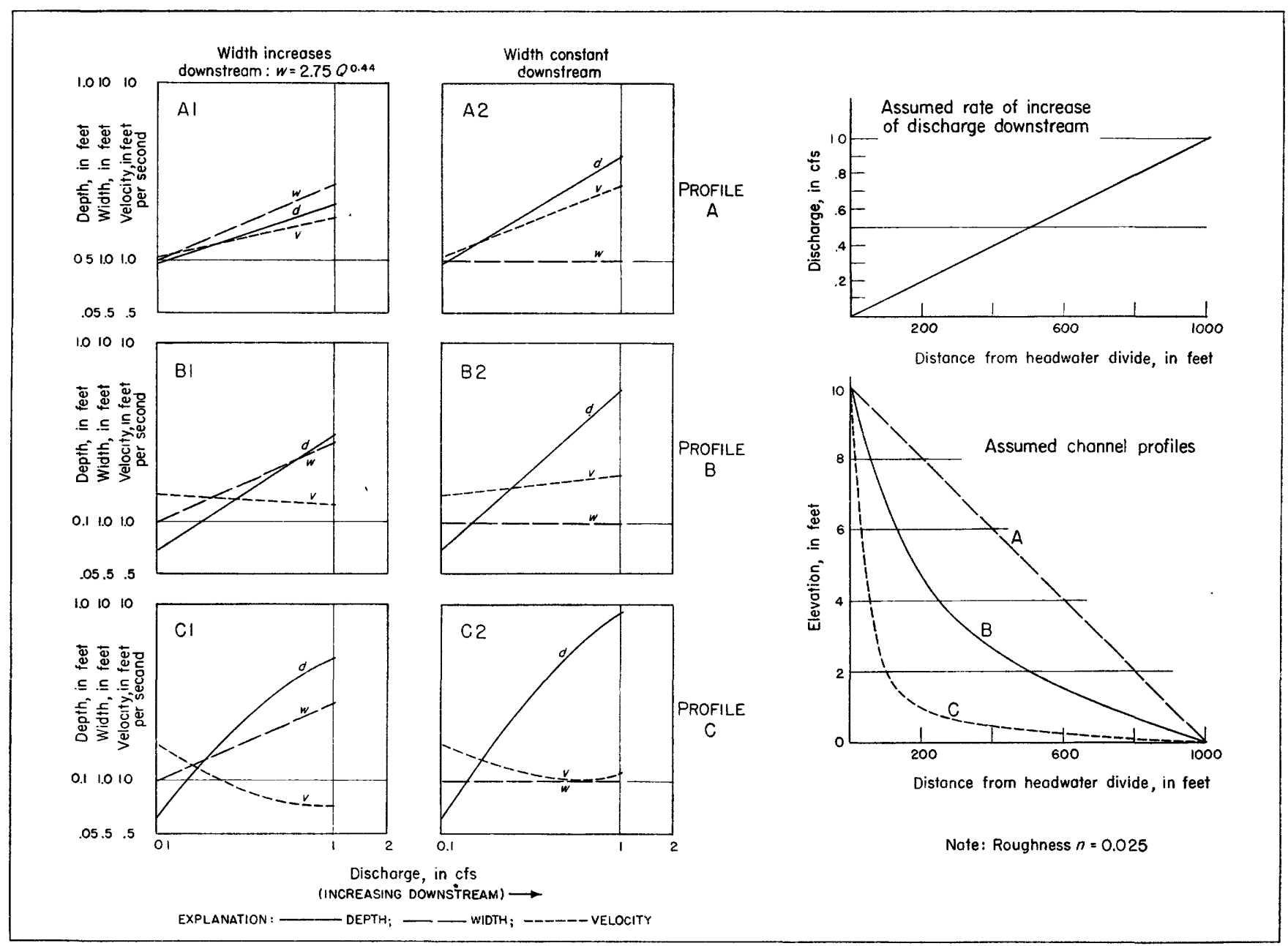

FIGURE 32.-Variation of velocity and depth downstream for three assumed longitudinal profiles; increase of discharge downstream is specified, and twa rates of change of width downstream are compared; channel roughness constant. 
computations have been made are: (1) the widthdischarge relation is

and (2)

$$
w=2.75 Q^{.44}
$$

$$
w=1
$$

Diagram A1 has an exponent $b=0.44$, which is of the order of magnitude of the 0.5 already shown for natural rivers. In diagram $\mathrm{A} 2$ the width is assumed constant downstream. Because discharge is assumed to be directly proportional to length along the channel, diagram A2 has a width-discharge relation

$$
w=Q^{0}
$$

It has been assumed in the example that the roughness, using Manning $n$ as a measure, is constant throughout and has the value 0.025 . At any position along the profile, the slope can be measured from the assumed profile curve. By assuming a depth, velocity can be computed. The discharge is given for each position by reading from the discharge curve. Width, being a function of discharge, is specified. Therefore, for each position along the stream length, two independent equations relating velocity to depth are available:

$$
v=\frac{1.5}{n} d^{\frac{2}{3}} s^{\frac{1}{2}}
$$

in which $s$ and $n$ are known. Also

$$
Q=w d v
$$

in which $Q$ and $w$ are known. The equations can be solved simultaneously to compute velocity and depth. Velocity, depth, and width have been plotted against discharge to show the changes in these factors in the downstream direction.

Inspection of the six sets of curves shows that, regardless of the manner in which width changes downstream, increase in concavity of the stream profile decreases the rate at which velocity increases downstream, and increases the rate of deepening downstream. The profiles differ, therefore, primarily in the $\frac{m}{f}$ ratio.

A channel that does not increase in width downstream obviously must accommodate the increase in discharge by increase in velocity or depth.

It will be noted that in diagram $A 1$, for which the profile is a straight line but in which the width increases downstream at approximately the natural rate, velocity increases downstream at a rate greater than for normal rivers. In diagram B1 of a profile of moderate concavity, the velocity decreases downstream. A concavity intermediate between profiles $\mathrm{A} 1$ and $\mathrm{B} 1$ would provide a combination of depth and velocity curves that would approximate conditions in a natura] stream having other characteristics similar to those assumed in the example.
The longitudinal profiles postulated in the example are but samples of an infinite number, each of which would be associated with particular channel characteristics necessary for fulfillment of the hydraulic laws. Any of these infinite number of combinations would be quite capable of carrying the discharge of water postulated. However, it may be presumed that only one of the possible combinations would obtain in nature. The equilibrium profile differs from other possible profiles in the relative rates of increase of velocity and depth in the downstream direction.

The longitudinal profile of a stream represents the simultaneous solution of eight equations involving eight unknowns. No attempt is made to indicate the nature of the relations or the hydrodynamics behird them. But, according to the reasoning in this paper the way in which the variables are dependent may be summarized as follows:

The first equation represents continuity:

$$
Q=w d v \quad \text { (The flow equation.) }
$$

The second is independent of the stream channel itself and represents the independent characteristics of the drainage basin:

$L=F(Q) \quad$ (The load-discharge relation resulting from the characteristics of the drainage area.)

The next equations represent relations in which the values of the factors and the specific relations among them depend on processes or action in the stream; that is, processes not independent of the strea $m$ itself:

$\bar{g}=F(Q) \quad$ (The particle size changes downstream.) (C)

$w=F(d) \quad$ (A width-depth relation that invc'ves the relative erodibility of bed and bank.)

$j=F\left(\frac{m}{f}, b\right) \quad\left(\right.$ The relation of $\frac{m}{f}, j$, and $b$.)

$n=F(d, \bar{g}, Q, s) \quad$ (Where $\bar{g}$ is the size of the sediment (F) particles; this relates sediment size to roughness $n$.)

$\frac{d n}{d Q}=F\left(\frac{d L}{d Q}\right)$ (There is a line on the roughness-discharge diagram corresponding to a particular rate of change of sediment concentration.)

The final equation is purely hydraulic and represents the equality between energy losses in friction and the decrease of energy potential, or head:

$$
v=1.5 d^{\frac{2}{3}} \frac{s^{\frac{1}{2}}}{n}
$$

In equation $(\mathrm{H})$ slope is the dependent factor and is adjusted by the stream to satisfy the equation; velocity, depth, and roughness $n$ were determined by equations (C) to $(\mathrm{G})$. 
The primary determinant of the slope of a stream is the past physiographic history which determines the differences in altitude and the distance between the mouth and the watershed divide. The problem discussed here concerns the form of the longitudinal profile which will be cut between these two points. It has been demonstrated that conditions of approximate equilibrium tend to be established in a reach of the stream as soon as a more or less smooth longitudinal profile has been established in that reach even though downcutting may contimue. Within the limits of the conditions determined by the physiographic history, the interactions which determine the form of the longitudinal profile can be summarized:

Channels of different shapes have characteristic distributions of velocity in the cross section. With the same discharge a very shallow and wide channel tends to have a greater average shear in the vertical plane than in the horizontal. Conversely a very deep and narrow channel tends to have greater average shear on the bank than on the bed. The relative erodibility of bed and bank allows the channel shape to develop a velocity distribution which is in approximate equilibrium with the particular erodibility characteristics. In this manner the increase of width with discharge (value of $b$ ) probably is determined. Why this exponent $b$ should so consistently be nearly equal to 0.5 in the downstream direction for widely different rivers is not known and constitutes an important unsolved problem.

Different concavities of longitudinal profile are associated with different relations of velocity and depth to discharge, as required by the hydraulics of open channels. However, a particular rate of increase of both velocity and depth downstream is necessary for maintenance of approximate equilibrium in a channel, inasmuch as the drainage area produces sediment and water in a characteristic manner.

Roughness varies with sediment load and with particle size but the interaction of opposing tendencies results in a small range of values of roughmess downstream in most rivers. The suspended load and its change downstream characteristic of natural rivers require a particular rate of increase of velocity and depth downstream. Under the conditions of a nearly constant roughness, to provide the required velocitydepth relations slope must generally decrease downstream; it is for this reason that the longitudinal profile of nearly all natural streans carrying sediment is concave to the sky.

\section{SUMMARY AND INTERPRETATION}

Rivers play a major role in the geographic cycle. As explained by Davis (1899), the successive stages of geomorphic development of a region begin ideally with uplift. Surface rocks are attacked by weathering, and rainfall washes the loosened waste down the initial slopes to incipient streams.

"The machinery of the destructive processes is thus put in motion," Davis says, "and the destructive development of the region is begun."

Larger rivers quickly deepen' their valleys; the rola'tively brief period of youth is characterized by rapidly increasing relief. The mature stage that follows is the period of maximum relief and greatest variety of f $\mathrm{c}^{\boldsymbol{r}} \mathrm{m}$. After a transition period of slowly decreasing relief is an indefinitely long old age of faint relief in which further changes are exceedingly slow.

Throughout the cycle rivers are both the routes over which the erosion products are carried to the sea, and the mechanism for effecting the transportation.

Davis (1902) not only defined stages in the deve'spment of land forms through the cycle, but described a complete cycle of river life, consisting of succes ive stages of youth, adolescence, maturity, and old ag?.

At the stage of maturity, a river attains the condition of grade which connotes the existence of equilibrium in the river system. Mackin (1948, pp. 471, 484) says:

A graded stream is one in which, over a period of years, slope [and channel characteristics are] delicately adjusted to provide, with available discharge $* * *$ just the velocity required for the transportation of the load supplied from the drainage basin.

Equilibrium, or grade, is attained by the larger streams relatively early in the geomorphic cycle, and by those of medium and smaller size at progressively later stages. But even in the youthful topography of the headlands where streams are gradually downcutting and are therefore not graded, the stream-channel characteristics and slope tend to be adjusted to the discharge and sediment load. Even the ungraded parts of a channel system exhibit a neat pattern characterized by a tendency toward a regular increase of width and depth downstream with increasing discharge and vith a concomitant decrease in slope.

The present paper describes in quantitative terms the manner in which width, depth, and velocity change with discharge downstream and at a given river c'oss section. It is demonstrated that these factors tend to change progressively downstream in all natural stream channels studied in so nearly the same way as graded reaches change that quantitative data available from the existing network of stream gaging stations are not adequate in volume or geographic coverage to differentiate graded from ungraded reaches. This demonstrates the strong tendency toward establishment of a quasi equilibrium operating in channels carrying water and sediment.

The mechanism of the interaction which promotes the development of at least quasi equilibrium may be sumniarized as follows:

Load and discharge are characteristics of the hydrol- 
ogy, geology, and physiognomy of the drainage basin. They are furnished to the trunk stream channels and are essentially independent of the trunk channel system. Flood flows are characterized by large sediment loads, and in terms of the suspended-load data available for analysis, are characterized by relatively large suspendedsediment concentrations. Low flows are characterized by low concentrations of suspended load.

Slope is the one hydraulic factor which can be adjusted over a period of time by processes within the stream and may be considered the factor which makes the final adjustment, as may be required for quasi equilibrium, after the interaction of all the other factors has resulted in establishment of mutually adjusted values of those factors.

The factors which are semidependent-that is, neither independent as are load and discharge, nor dependent as is slope--are width, depth, velocity, bed roughness, and size of sediment particles. The nature of the interdependence of these factors appears to be as follows:

The shape of the river cross section, roughly described by its width-to-depth ratio, determines the distribution of velocity and shear in the cross section. The mean velocity in an open channel usually is equalled at a position 0.6 of the distance from the surface to the bed. In two channels having the same mean velocity and discharge, the deeper one will have a smaller average shear between the bed and the position in the vertical where a velocity equal to the mean value exists. This may partly explain, at least qualitatively, why for the same discharge and mean velocity, a greater bed load characterizes a wide shallow section than a deep narrow one. Even less well understood is the observed fact that a wide, shallow stream carries less suspended load than a deep narrow one of the same velocity and discharge. It may be that more of the total load will be carried as bed load in a wide shallow reach than in a deep narrow reach of a stream if the velocity and discharge are equal. In reality, however, changes in cross section in different reaches of the same stream are usually accompanied by some change in velocity even though the discharge may be equal.

The increased bed shear in a wide shallow reach having a given velocity promotes a tendency to scour. A narrow deep reach of the same velocity is apparently characterized by less shear on the bed but greater shear on the bank. Thus there is a tendency to adjust the cross-sectional shape in accordance with the relative erodibility of bed and bank.

For a given width and discharge however, the total load depends on the velocity, and any change in velocity requires a concomitant change in depth to satisfy continuity expressed by the equation

$$
Q=w d v
$$

Thus for a given width and discharge, the total load depends on the ratio of velocity to depth.

The velocity-depth relations required for transnortation of the supplied load are provided in part by adjustment of bed roughness which is a function of the bed material size and the suspended-sediment coneentration. With the roughness so determined, slope tends to be adjusted to provide the velocity-depth relations necessary to carry the load in quasi equilibrium.

During the passage of a flood through a given cross section of a river channel, a larger velocity is ne`essary to carry in quasi equilibrium the relatively great suspended-sediment concentration of the high discharge than the small concentrations of low flow. This increase in velocity at a cross section is not provided by a marked change in slope because there is insufficient time for such an adjustment to be made, and hocause there must be some continuity of slope downstream in order that any cross section may generally be is close to equilibrium as any other.

The changes in velocity-depth relations required for quasi equilibrium with load are brought about primarily by changes in bed roughness associated with the changes in suspended-sediment concentration.

In the downstream direction, however, susfondedsediment concentration decreases only slightlr with discharge. The average decrease in the particle size downstream tends to decrease bed roughness, krit this is counteracted by the effect of decreasing sediment concentration and of changing configuration of the bed. The result is that roughness changes but little downstream. The particular rates of increase of relocity and depth with increase of discharge downstream required for transport of the load are, therefore, maintained by the downstream decrease of slope.

The interactions just summarized operate in both ungraded and graded reaches. They account for the maintenance of grade once the condition of equilibrium is achieved, but their influence is sufficiently potent, even in reaches not yet graded. to cause the drainage system to develop in a highly coordinated and systematic manner. Because of these interactions rivers tend to increase in width and depth downstream with increase of discharge in a remarkably consistent manner.

Each branch in the channel system of a river tends to occupy a valley proportioned to its size. This interrelationship is so similar in rivers widely different in physiographic setting that its importance to the understanding of land forms was recognized more than a century ago. Geomorphology cannot move ahead, however, if we remain content to describe procasses of land sculpture only in qualitative terms. When viewed quantitatively, the interactions of the various hydraulic factors are found to be more complex than the qualitative analyses have led us to believe, but the unr?velling of their complexities constitutes advance of knowledge. 


\section{REFERENCES}

Blench, Thomas, 1951a, Hydraulies of sediment-bearing canals and rivers, Evans Industries Lts., Vancouver, B. C., Canada. - 1951b, Regime theory for self-formed sediment-bearing channels: Am. Soc. Civil Eng. Proc., vol. 77, separate 70, pp. 1-18.

Brune, G. M., 1950, Dynamic concept of sediment sources: Am. Geophys. Union Trans., vol. 31, no. 4, pp. 587-594.

BuCKLEx, A. B., 1922-23, The influence of silt on the velocity of flowing water in open channels: Inst. Civil Eng. Proc., vol. 216, pp. 183-211.

CorbetT, D. M., and others, 1943, Stream-gaging procedure: U. s. Geol. Survey Water-Supply Paper 888.

Cross, W. P., and Bernhagen, R. H., 1949, Ohio stream-flow characteristics, part 1, flow duration: Ohio Dept. of Natural Resources Bull. 10.

DAs, IshaR, 1950, Theory of flow of water and universal bydraulic diagrams: Jour. Central Board of Irr. (India), vol. 7 , no. 2, pp. 151-162.

Davis, W. M., 1899, The geographical cycle, Geog. Jour. 14, pp. $481-504$.

- 1902, Base-level, grade and peneplain, Jour. Geol. 10, pp. $77-111$.

Einstein, H. A., 1950, The bed-load function for sediment transportation in open channel flows: U. S. Dept. Agr. Tech. Bull. 1026.

Einstein, H. A., and Barbarossa, N. L., 1951, River channel roughness: Am. Soc. Civil Eng. Proc., vol. 77, 12 pp.

Ellison, W. D., 1945, Some effects of raindrops and surface-flow on soil erosion and infiltration: Am. Geophys. Union Trans., vol. 26, no. 3, pp. 415-430.

GilberT, G. K., 1914, Transportation of debris by running water: U. S. Geol. Survey Prof. Paper 86.

GLYMPh, L. M., 1951, Relation of sedimentation to accelerated erosion in the Missouri River Basin, U. S. Dept. Agr. Soil Cons. Service, SCS-TP-120, $20 \mathrm{pp}$.

Gould, Howard R., 1951, Some quantitative aspects of Lake Mead turbidity currents: Soc. Econ. Paleontologists and Mineralogists, special pub., no. 2, pp. 34-52.

Griffith, W. M., 1927, A theory of silt and scour, Inst. Civil Eng. Proc., vol. 223.

HADLEY, R. F., The usefulness of small reservoirs in erosional studies of minor drainage basin. U. S. Geol. Survey, (open-file report).

- _ - Sources of sediment and sedimentation rates in small reservoirs, Cheyenne River basin above Angostura Dam: U. S. Geol. Survey (in preparation).

Hembree, C. H., Colby, B. R., Swenson, H. A., and Davis, J. R., 1952, Progress report, sedimentation and chemical quality of water in the Powder River drainage basin, Wyo. and Mont.: U. S. Geol. Survey (in preparation).

Horton, R. E.. 1945, Erosional development of streams and their drainage basins-Hydro-physical approach to quantitative morphology: Geol. Soc. Am. Bull., vol. 56, no. 3, pp. 275-370.

Johnson, J. W., 1943, Laboratory investigations on bed-load transportation and bed roughness: U. S. Dept. Agr. Soil Cons. Service, Sedimentation Sect., SCS-TP-50.
Kennedy, R. G., 1895, Prevention of silting in irrigation canals: Inst. Civil Eng. Proc., vol. 119, pp. 281-290.

Lacey, Gerald, 1930, Stable channels in alluvium: Inst. Civil Eng. Proc., vol. 229, pt. 1, pp. 259-384.

- 1939, Regime flow in incoherent alluvium: Central Board Irr. (India) pub. 20, Simla.

LANE, E. W., 1937, Stable channels in erodible materials: Am. Soc. Civil Eng. Trans., no. 102, pp. 123-194.

Lane, E. W., and Borland, W. M., 1951, Estimating bed-load: Am. Geophys. Union Trans., vol. 32, no. 1, pp. 121-123

LANGBeIN, W. B., 1942, Hydraulic criteria for sand waves, Am. Geophys. Union Trans., pt. 2, pp. 615-618.

LARA, J. M., and Miller, C. R., 1951, Conveyance channelwidening study, Middle Rio Grande project: U. S. Bur. Reclamation (open-file report).

Lindley, E. S., 1919, Regime channels, Punjab Eng. Congrress Proc., vol. 7.

Linsley, R. K., Kohler, M. A., Paulhus, J. L. H., 1949, Applied hydrology, New York, MeGraw-Hill Book Co., $689 \mathrm{pp}$.

Mackin, J. Hoover, 1948, Concept of the graded river: Geol. Soc. Am. Bull. 59, pp. 463-512.

Rubey, W. W., 1933, Equilibrium conditions in debris-laden streams: Am. Geophys. Union Trans. pp. 497-505.

- 1952, The geology and mineral resources of Hardin and Brussels quadrangles, Illinois, U. S. Geol. Survey, Prof. Paper 218.

Serr 3d, E. F., 1950, Progress report, investigations of fluvial sediments of the Niobrara River near Cody, Nebr., U. S. Geol. Survey Circ. 67.

- 1951, Measurement of bedload sediment, Am. Geof hys. Union Trans., vol. 32, pp. 123-126.

Shulits, S., 1941, Rational equation of river-bed profile: Am. Geophys. Union Trans. pt. 3, pp. 622-629.

Stevens, J. C., 1937, Discussion of LANe, E. W., Stable channels in erodible material: Am. Soc., Civil Eng. Trans., no. 102, pp. $145-149$.

Thомаs, A. R., 1946, Slope formulas for rivers and canals: Jour. Central Board of Irr. (India), vol. 3, no. 1, pp. 40-49.

- 1949, Analysis of hydraulic data of some boulder rivers: Jour. Central Board of Irr. (India), vol. 6, no. 1. pp. 67-71.

VANONI, V. A., 1941, Some experiments on the transportation of suspended load: Am. Geophys. Union Trans., pt. 3, pp. 608-620.

__ 1946, Transportation of suspended sediment by water: Am. Soc. Civil Eng. Trans., no. 111, pp. 67-133.

VICE, R. B., and SERR, E. F., 1950, Progress report, inves tigations of fluvial sediments, Middle Loup River near Dunning and Milburn, Nebr., U. S. Geol. Survey, Water Resources Division, (open-file report).

U. S. Army, Corps of Engineers, 1935, Studies of river bed materials and their movement, with special references to the lower Mississippi River: U. S. Waterways Exper. Sta. Paper 17, 161 pp., Vicksburg, Miss.

U. S. Bureau of Reclamation, 1949, Report of river control work and investigations, Lower Colorado River Basin, calendar years 1948 and 1949: Boulder City, Nev, 124 pp. (onenfile report). 


\section{APPENDIX}

APPENDIX A.-Channel-shape characteristics of rivers at stage corresponding to mean annual discharge

[Data on width, area, mean velocity, and mean depth represent approximations to the average and vary somewhat, depending on the particular section where measurements are made]

\begin{tabular}{|c|c|c|c|c|c|c|c|}
\hline & $\begin{array}{l}\text { Years of } \\
\text { record }\end{array}$ & $\begin{array}{c}\text { Mean annual } \\
\text { discharge } \\
\text { (efs) }\end{array}$ & Width (feet) & $\begin{array}{l}\text { Area of cross } \\
\text { section } \\
\text { (square feet) }\end{array}$ & $\begin{array}{l}\text { Mean veloc- } \\
\text { ity (fps) }\end{array}$ & $\underset{\text { (feet) }}{\text { Mean depth }}$ & $\begin{array}{l}\text { Drainage } \\
\text { area (square } \\
\text { miles) }\end{array}$ \\
\hline \multicolumn{8}{|l|}{ Mobile River Basin } \\
\hline 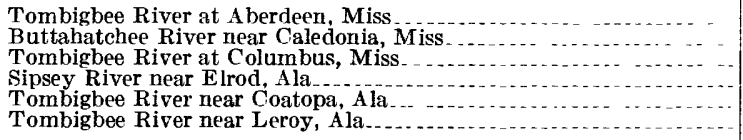 & $\begin{array}{l}19 \\
11 \\
30 \\
11 \\
19 \\
19\end{array}$ & $\begin{array}{r}2,863 \\
1,066 \\
5,791 \\
715 \\
21,450 \\
26,250\end{array}$ & $\begin{array}{r}142 \\
152 \\
270 \\
93 \\
458 \\
513\end{array}$ & $\begin{array}{r}1,633 \\
1,973 \\
3,220 \\
650 \\
10,240 \\
13,360\end{array}$ & $\begin{array}{l}1.8 \\
0.5 \\
1.8 \\
1.1 \\
2.2 \\
2.0\end{array}$ & $\begin{array}{r}11.5 \\
13.0 \\
11.9 \\
7.0 \\
22.3 \\
26.0\end{array}$ & $\begin{array}{r}2,210 \\
823 \\
4.490 \\
515 \\
15,500 \\
19,100\end{array}$ \\
\hline \multicolumn{8}{|l|}{ Scioto River Basin } \\
\hline $\begin{array}{l}\text { Scioto River at LaRue, Ohio } \\
\text { Scioto River near Prospect, Ohio } \\
\text { Scioto River near Dublin, Ohio } 1- \\
\text { Scioto River at Columbus, Ohio } \\
\text { Scioto River near Circleville, Ohio } \\
\text { Scioto River at Chillicothe, Ohio }\end{array}$ & $\begin{array}{r}18 \\
15 \\
26 \\
26 \\
8 \\
26\end{array}$ & $\begin{array}{r}198 \\
452 \\
743 \\
1,308 \\
1,815 \\
3,289\end{array}$ & $\begin{array}{r}90 \\
125 \\
200 \\
280 \\
280 \\
200\end{array}$ & $\begin{array}{r}342 \\
300 \\
860 \\
1.093 \\
3,030 \\
1,840\end{array}$ & \begin{tabular}{r|}
.6 \\
1.5 \\
.9 \\
1.2 \\
.6 \\
1.8
\end{tabular} & $\begin{array}{r}3.8 \\
2.4 \\
4.3 \\
3.9 \\
10.8 \\
9.2\end{array}$ & $\begin{array}{r}255 \\
571 \\
988 \\
1,624 \\
2,635 \\
3,847\end{array}$ \\
\hline \multicolumn{8}{|l|}{ Tennessee River Basin } \\
\hline $\begin{array}{l}\text { French Broad River at Rosman, N. C } \\
\text { French Broad River at Calvert, N. C } \\
\text { Catheys Creek near Brevard, N. C. C } \\
\text { Davidson River near Brevard, N. C, N. C. } \\
\text { French Broad River at Bent Creek, } \\
\text { French Broad River at Hot Springs, N. C } \\
\text { French Broad River near Newport, Temn } \\
\text { Watauga River near Sugar Grove, N. C } \\
\text { Noland Creek near Bryson City, N. C. } \\
\text { Tennessee River at Knoxville, Tenn }\end{array}$ & $\begin{array}{r}12 \\
23 \\
4 \\
26 \\
13 \\
13 \\
26 \\
6 \\
12 \\
48\end{array}$ & \begin{tabular}{c|}
229 \\
335 \\
34 \\
125 \\
1,589 \\
2,511 \\
2,764 \\
154 \\
42.8 \\
12,820
\end{tabular} & $\begin{array}{l}77 \\
92 \\
25.3 \\
55 \\
296 \\
190 \\
346 \\
64 \\
30.1 \\
933\end{array}$ & $\begin{array}{c}151 \\
168 \\
22.7 \\
88.0 \\
828 \\
1,115 \\
1,833 \\
115 \\
57.2 \\
13,450\end{array}$ & $\begin{array}{l}1.5 \\
2.0 \\
1.5 \\
1.4 \\
1.9 \\
2.2 \\
1.5 \\
1.3 \\
.8 \\
1.0\end{array}$ & $\begin{array}{r}2.0 \\
1.8 \\
.9 \\
1.6 \\
.8 \\
5.9 \\
5.3 \\
1.8 \\
1.9 \\
14.4\end{array}$ & $\begin{array}{c}67.9 \\
103 \\
11.7 \\
40.4 \\
676 \\
1,567 \\
1,858 \\
90.8 \\
13.8 \\
8,934\end{array}$ \\
\hline \multicolumn{8}{|l|}{ St. Lawrence River Basin } \\
\hline $\begin{array}{l}\text { St. Joseph River near Blakeslee, Ohio } \\
\text { Maumee River at Antwerp, Ohio } \\
\text { Tiffin River at Stryker, Ohio } \\
\text { Tiffin River near Brunersburg, Ohio } \\
\text { Auglaize River near Fort Jennings, Ohio } \\
\text { Ottawa River at Allentown, Ohio } \\
\text { Ottawa River at Kalida, Ohio } \\
\text { Blanchard River near Findlay, ohio } \\
\text { Blanchard River at Glendorf, Ohio } \\
\text { Blanchard River near Dupont, Ohio } \\
\text { A uglaize River near Defiance, Ohio } \\
\text { Maumee River near Defiance, Ohio } \\
\text { Maumee River at Waterville, Ohio }\end{array}$ & $\begin{array}{r}6 \\
22 \\
14 \\
7 \\
21 \\
16 \\
5 \\
18 \\
7 \\
7 \\
27 \\
19 \\
22\end{array}$ & $\begin{array}{r}292 \\
1,547 \\
292 \\
448 \\
278 \\
119 \\
141 \\
219 \\
548 \\
452 \\
1.598 \\
3.612 \\
4,269\end{array}$ & $\begin{array}{r}95 \\
245 \\
72 \\
85 \\
100 \\
61 \\
80 \\
65 \\
80 \\
120 \\
285 \\
440 \\
730\end{array}$ & $\begin{array}{r}266 \\
1,078 \\
348 \\
332 \\
285 \\
97 \\
128 \\
114 \\
304 \\
646 \\
1,054 \\
1,826 \\
1,644\end{array}$ & $\begin{array}{r}1.1 \\
1.4 \\
.8 \\
1.4 \\
1.0 \\
1.2 \\
1.1 \\
1.9 \\
1.8 \\
.7 \\
1.5 \\
2.0 \\
2.6\end{array}$ & $\begin{array}{l}2.8 \\
4.4 \\
4.8 \\
3.9 \\
2.8 \\
1.6 \\
1.6 \\
1.8 \\
3.8 \\
5.4 \\
3.7 \\
4.2 \\
2.2\end{array}$ & $\begin{array}{r}369 \\
2,049 \\
444 \\
766 \\
333 \\
168 \\
315 \\
343 \\
643 \\
749 \\
2,329 \\
5,530 \\
6,314\end{array}$ \\
\hline \multicolumn{8}{|l|}{ Yellowstone River Basin } \\
\hline Yellowstone River at Corwin Springs, Mor & 37 & 2.969 & 242 & 813 & 3.6 & 3.4 & 2,630 \\
\hline Yellowstone River at Billings, Mont & 16 & 6.331 & 253 & 1,343 & 4.8 & 5.3 & 11,180 \\
\hline $\begin{array}{l}\text { Wind River near Dubois, Wyo } \\
\text { Wind River near Burris, Wyo }\end{array}$ & $\begin{array}{l}3 \\
3\end{array}$ & $\begin{array}{l}177 \\
828\end{array}$ & $\begin{array}{r}68 \\
134\end{array}$ & $\begin{array}{r}97 \\
335\end{array}$ & $\begin{array}{l}1.8 \\
2.5\end{array}$ & $\begin{array}{l}1.4 \\
2.5\end{array}$ & $\begin{array}{r}233 \\
1,220\end{array}$ \\
\hline Wind River near Crowheart, wyo & $\stackrel{0}{3}$ & 1.315 & 155 & 372 & 3.5 & 2.4 & 1,920 \\
\hline Wind River at Riverton, Wyo & 34 & 1,106 & 159 & 318 & 3. 5 & 2.0 & 2.320 \\
\hline Popo Agie River near Riverton, Wyo- & 6 & 683 & 123 & 406 & 1.7 & 3.3 & 2,010 \\
\hline $\begin{array}{l}\text { Bighorn River at Thermopolis, Wyo } \\
\text { North Fork Owl Creek near Anchor, Wyo.... }\end{array}$ & $\begin{array}{r}42 \\
5\end{array}$ & $\begin{array}{l}1,908 \\
16.2\end{array}$ & $\begin{array}{r}218 \\
17\end{array}$ & $\begin{array}{c}543 \\
9.3\end{array}$ & $\begin{array}{l}3.5 \\
1.7\end{array}$ & $\begin{array}{r}2.5 \\
6\end{array}$ & $\begin{array}{l}8.080 \\
58.2\end{array}$ \\
\hline Owl Creek near Thermopolis, Wyo. & 10 & 45.5 & 26 & 24.1 & 1.9 9 & .0 & 484 \\
\hline Gooseberry Creek near Grass Creek, wyo.. & 4 & 20.8 & 19.5 & 10.9 & 1.9 & 0.6 & 155 \\
\hline Bighorn River at Manderson, w yo & 6 & 1,950 & 258 & 650 & 3.0 & 2.5 & 11,900 \\
\hline $\begin{array}{l}\text { Medicine Lodge Creek near Hyattville, Wyo... } \\
\text { Greybull River at Meeteetse, Wyo }\end{array}$ & 5 & 38 & 24 & 21 & 1.8 & .9 & 86 \\
\hline $\begin{array}{l}\text { Greybull River at Meeteetse, Wyo } \\
\text { Greybull River near Basin, Wyo }\end{array}$ & 27 & 364 & 87 & 122 & 3.0 & 1.4 & $\begin{array}{r}690 \\
130\end{array}$ \\
\hline $\begin{array}{l}\text { Greybull River near Basin, Wyo } \\
\text { Bighorn River at Kane, Wyo }\end{array}$ & $\begin{array}{l}17 \\
19\end{array}$ & $\begin{array}{r}200 \\
2,383\end{array}$ & $\begin{array}{r}77 \\
175\end{array}$ & $\begin{array}{l}100 \\
627\end{array}$ & $\begin{array}{l}2.0 \\
3.8\end{array}$ & $\begin{array}{l}1.3 \\
3.6\end{array}$ & $\begin{array}{r}1,130 \\
15,900\end{array}$ \\
\hline Bighorn River near St. Xavier, Mont. & 13 & 3,676 & 264 & 1,296 & 2.8 & 4.9 & \\
\hline Bighorn River near Hardin, Mont.. & 14 & 4,535 & 371 & 1,855 & 2.4 & 5.0 & 20,700 \\
\hline Little Bighorn River at Stateline, near W yola. Mon & 5 & 154 & 41 & 68 & 2.3 & 1.6 & 199 \\
\hline Little Bighorn River below Pass Creek, near W yola, & 5 & 202 & 57 & 86 & 2.4 & 1.5 & 429 \\
\hline Little Bighorn River near Crow Agency, Mont. & 8 & 294 & 96 & 116 & 2. 5 & 1.2 & 1,190 \\
\hline Red Fork near Barnum. Wyo ... & $\begin{array}{r}13 \\
1\end{array}$ & $\begin{array}{r}11,860 \\
50\end{array}$ & $\begin{array}{r}308 \\
25\end{array}$ & $\begin{array}{r}3, \sqrt{30} \\
26\end{array}$ & $\begin{array}{l}5.2 \\
1.9\end{array}$ & $\begin{array}{r}11.9 \\
1.0\end{array}$ & 142 \\
\hline Middle Fork Powder River above Kaycee, w yo & 1 & 74 & 41 & 56 & 1.3 & 1.4 & 450 \\
\hline Middle Fork Powder River near Kayd & 11 & 157 & 54 & 77 & 2.0 & 1.4 & 980 \\
\hline North Fork Powder River near Hazelton, wyo. & 2 & 13 & 16 & 15 & .9 & .9 & 25 \\
\hline North Fork Powder River near Mayoworth, wyo. & 8 & 39 & 22 & 26 & 1.5 & 1.2 & 69 \\
\hline South Fork Powder River near Kaycee, w yo... & 2 & 48 & 57 & 27 & 1.8 & .5 & 1,150 \\
\hline Powder River at Sussex, Wyo ....... & 1 & 136 & 84 & 75 & 1.8 & .9 & 3,090 \\
\hline Middle Fork Crazy Woman Creek ne & 6 & 20 & 19 & 15 & 1.3 & .8 & 83 \\
\hline North Fork Crazy Woman Creek near Bufialo, W yo_. & 3 & 21 & 19 & 19 & 1. 1 & 1.0 & 52 \\
\hline North Fork Crazy Woman Creek near Greub, w yo & 1 & 22 & 24 & 18 & 1.2 & .7 & 174 \\
\hline Crazy Woman Creek near Arvada, Wyo........ & 3 & 63 & 33 & 38 & 1.7 & 1.1 & 956 \\
\hline Powder River at Arvada, $W$ yo & 31 & 434 & 112 & 138 & 3.2 & 1.2 & 6,050 \\
\hline North Fork Clear Creek near Buffalo, Wyo & 1 & 16 & 23 & 19 & .8 & .8 & 29 \\
\hline Clear Creek near Buffalo, Wyo & 3 & 70 & 42 & 39 & 1.8 & .9 & 120 \\
\hline South Fork Rock Creek near Buffalo, w yo & 1 & 17 & 20 & 19 & 1.0 & .9 & 44 \\
\hline Rock Creek near Buffalo, Wyo...... & 5 & 37 & 19 & 23 & 1. 6 & 1.2 & 60 \\
\hline South Piney Creek at Willow Park, W yo & 3 & 47 & 33 & 33 & 1.4 & 1.0 & 29 \\
\hline Piney Creek at Kearney, Wyo......... & 9 & 101 & 45 & 69 & 1.5 & 1.5 & 106 \\
\hline Piney Creek at Ucross, W yo & 1 & 70 & 55 & 63 & 1.2 & 1.1 & 267 \\
\hline Clear Creek near Arvada, Wyo- & 12 & 222 & 94 & 124 & 1.8 & 1.3 & 1,110 \\
\hline Little Powder River near Broadus, Mont. & 2 & 56 & 24 & 29 & 1.9 & 1.2 & \\
\hline $\begin{array}{l}\text { Powder River at Moorhead, Mont. - } \\
\text { Powder River near Locate, Mont.. }\end{array}$ & 17 & 526 & 124 & 211 & 2.5 & 1.7 & 8,030 \\
\hline Powder River near Locate, Mont & 12 & 763 & 168 & 273 & 2.8 & 1.6 & 12,900 \\
\hline
\end{tabular}


APPENDIX

APPENDIX A.-Channel-shape characteristics of rivers at stage corresponding to mean annual discharge-Continued

[Data on width, area, mean velocity, and mean depth represent approximations to the average and vary somewhat, depending on the narticular section where measurernents are made]

\begin{tabular}{|c|c|c|c|c|c|c|c|}
\hline & $\begin{array}{l}\text { Years of } \\
\text { record }\end{array}$ & $\begin{array}{c}\text { Mean annual } \\
\text { discharge } \\
\text { (cfs) }\end{array}$ & Width (feet) & $\begin{array}{l}\text { A rea of cross } \\
\text { section } \\
\text { (square feet) }\end{array}$ & $\begin{array}{c}\text { Mean veloc- } \\
\text { ity (fps) }\end{array}$ & $\underset{\text { (feet) }}{\text { Mean depth }}$ & $\begin{array}{l}\text { Drainage } \\
\text { area (square } \\
\text { miles) }\end{array}$ \\
\hline \multicolumn{8}{|l|}{ Belle Fourche River Basin } \\
\hline $\begin{array}{l}\text { Belle Fourche River below Moorcroft, W yo } \\
\text { Belle Fourche River at Hulett, W yo } \\
\text { Belle Fourche River at Wyo.-S. Dak. State line } 3 . \\
\text { Belle Fourche River near Fruitdale, S. Dak } \\
\text { Belle Fourche River near Sturgis, S. Dak } \\
\text { Belle Fourche River near Elm Springs, S. Dak }\end{array}$ & \begin{tabular}{r|r}
7 \\
12 \\
2 \\
3 \\
2 \\
16
\end{tabular} & \begin{tabular}{l|}
79 \\
69.5 \\
150 \\
250 \\
500 \\
447
\end{tabular} & $\begin{array}{r}39 \\
50 \\
59 \\
66 \\
134 \\
112\end{array}$ & $\begin{array}{r}47 \\
40 \\
65 \\
112 \\
228 \\
168\end{array}$ & \begin{tabular}{l|l}
1.7 \\
1.8 \\
2.3 \\
2.2 \\
2.2 \\
2.7
\end{tabular} & $\begin{array}{l}1.2 \\
.8 \\
1.1 \\
1.7 \\
1.7 \\
1.5\end{array}$ & $\begin{array}{r}1,730 \\
2,800\end{array}$ \\
\hline \multicolumn{8}{|l|}{ Kansas River Basin } \\
\hline 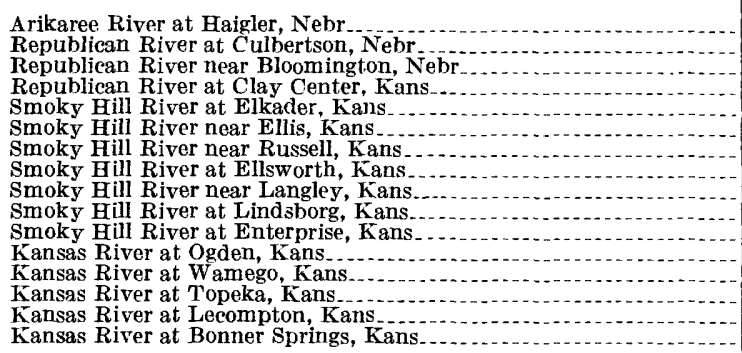 & $\begin{array}{r}15 \\
16 \\
18 \\
30 \\
5 \\
5 \\
4 \\
34 \\
4 \\
17 \\
13 \\
30 \\
28 \\
30 \\
17 \\
30\end{array}$ & \begin{tabular}{c|}
31.7 \\
226 \\
724 \\
1,093 \\
36 \\
66.3 \\
223 \\
215 \\
362 \\
292 \\
1,419 \\
2,514 \\
4,114 \\
4,655 \\
7,838 \\
5,874
\end{tabular} & $\begin{array}{r}45 \\
120 \\
230 \\
272 \\
41 \\
60 \\
104 \\
90 \\
92 \\
80 \\
102 \\
342 \\
525 \\
481 \\
728 \\
563\end{array}$ & $\begin{array}{c}23.4 \\
101 \\
390 \\
544 \\
24.6 \\
48 \\
114 \\
126 \\
193 \\
192 \\
736 \\
1,300 \\
2,150 \\
2,210 \\
3,352 \\
3,320\end{array}$ & \begin{tabular}{l|}
1.4 \\
2.2 \\
1.8 \\
2.0 \\
1.5 \\
1.4 \\
2.0 \\
1.7 \\
1.9 \\
1.5 \\
1.9 \\
1.9 \\
1.9 \\
2.1 \\
2.3 \\
1.8
\end{tabular} & $\begin{array}{r}.5 \\
.8 \\
1.7 \\
2.0 \\
.6 \\
.8 \\
1.1 \\
1.4 \\
2.1 \\
2.4 \\
7.2 \\
3.8 \\
4.1 \\
4.6 \\
4.6 \\
5.9\end{array}$ & $\begin{array}{r}41,460 \\
410600 \\
420800 \\
424 \\
4570 \\
3555 \\
5630 \\
6965 \\
7,580 \\
7,857 \\
8110 \\
19200 \\
45240 \\
55240 \\
54710 \\
58420 \\
59890\end{array}$ \\
\hline \multicolumn{8}{|l|}{ Missouri River Basin } \\
\hline $\begin{array}{l}\text { Missouri River at Bismarck, N. Dak. } \\
\text { Missouri River at Pierre, S. Dak } \\
\text { Missouri River at St. Joseph, Mo } \\
\text { Missouri River at Kansas City, Mo } \\
\text { Missouri River at Hermann, Mo }\end{array}$ & $\begin{array}{l}21 \\
20 \\
20 \\
20 \\
20\end{array}$ & $\begin{array}{l}20,320 \\
22,080 \\
35,440 \\
43,710 \\
69,170\end{array}$ & $\begin{array}{r}1,202 \\
962 \\
863 \\
1,093 \\
1,578\end{array}$ & $\begin{array}{r}7,323 \\
8,718 \\
9,927 \\
12,750 \\
22,950\end{array}$ & $\begin{array}{l}2.9 \\
2.5 \\
3.6 \\
3.4 \\
3.0\end{array}$ & \begin{tabular}{r|r}
6.1 \\
9.1 \\
11.5 \\
11.7 \\
14.5
\end{tabular} & $\begin{array}{l}186,400 \\
243500 \\
424300 \\
489,200 \\
528200\end{array}$ \\
\hline \multicolumn{8}{|l|}{ Mississippi River Basin } \\
\hline $\begin{array}{l}\text { Mississippi River at Alton, Ill } \\
\text { Mississippi River at St. Louis, Mo Monn } \\
\text { Mississippi River at Memphis, Tenn } \\
\text { Mississippi River near Vicksburg, Miss... }\end{array}$ & $\begin{array}{l}12 \\
14 \\
13 \\
16\end{array}$ & $\begin{array}{r}96,670 \\
166,700 \\
454,900 \\
554,600\end{array}$ & $\begin{array}{l}1,750 \\
1,586 \\
1,950 \\
2,610\end{array}$ & $\begin{array}{r}32,500 \\
44,440 \\
99,400 \\
105,650\end{array}$ & $\begin{array}{l}3.0 \\
3.8 \\
4.6 \\
5.3\end{array}$ & $\begin{array}{l}18.6 \\
28.0 \\
51.0 \\
40.1\end{array}$ & $\begin{array}{r}171.500 \\
701,000 \\
932.800 \\
1,144.500\end{array}$ \\
\hline
\end{tabular}

1 Located at a dam.

2 Concrete walls on side.

noncontributing area.

Long-term mean should be ahont $5,200 \mathrm{cfs}$. 
APPENDix B.-Average channel characteristics and average suspended-sediment load at fixed discharges

[Data on width, average depth, velocity, and suspended load represent approximations to mean values of their respective factors at the discharge specified. Exronents $b$, and $m$ are defined by the equations on p. 8]

\begin{tabular}{|c|c|c|c|c|c|c|c|c|c|}
\hline \multirow{2}{*}{ Station } & \multirow{2}{*}{$\underset{\text { charge }}{\text { (cfs) }}$} & \multirow{2}{*}{$\begin{array}{l}\text { Width } \\
\text { (feet) }\end{array}$} & \multirow{2}{*}{$\begin{array}{c}\text { A verage } \\
\text { depth } \\
\text { (feet) }\end{array}$} & \multirow{2}{*}{$\begin{array}{l}\text { Velocity } \\
\text { (fps) }\end{array}$} & \multirow{2}{*}{$\begin{array}{l}\text { Suspended } \\
\text { load (tons } \\
\text { per day) }\end{array}$} & \multicolumn{4}{|c|}{ Rate of increase with discharge $(Q)$} \\
\hline & & & & & & $b$ & $f$ & $m$ & Remarks \\
\hline Cheyenne River near Hot Springs, s. Dak ... & $\begin{array}{r}250 \\
500 \\
1,000 \\
2,000 \\
\end{array}$ & $\begin{array}{l}107 \\
150 \\
200 \\
215 \\
\end{array}$ & $\begin{array}{l}1.1 \\
1.3 \\
1.7 \\
2.5 \\
\end{array}$ & $\begin{array}{l}2.2 \\
2.6 \\
3.1 \\
3.9 \\
\end{array}$ & $\begin{array}{r}3,100 \\
13,000 \\
46,000 \\
155,000 \\
\end{array}$ & 0.50 & 0.25 & 0.25 & For $Q$ belov $800 \mathrm{efs}$. \\
\hline Middle Loup River at St. Paul, Nebr & $\begin{array}{r}250 \\
500 \\
1,000 \\
2,000\end{array}$ & $\begin{array}{l}192 \\
253 \\
302 \\
384\end{array}$ & $\begin{array}{l}0.8 \\
1.0 \\
1.3 \\
1.57\end{array}$ & $\begin{array}{l}1.6 \\
2.0 \\
2.5 \\
3.3\end{array}$ & $\begin{array}{r}120 \\
500 \\
3,100 \\
22,000 \\
\end{array}$ & .32 & .31 & .37 & . \\
\hline Rio Grande at San Acacia, N. Mex............. & $\begin{array}{r}250 \\
500 \\
1,000 \\
2,000\end{array}$ & $\begin{array}{r}94 \\
140 \\
182 \\
218\end{array}$ & $\begin{array}{l}1.0 \\
1.1 \\
1.4 \\
2.0\end{array}$ & $\begin{array}{l}2.6 \\
3.3 \\
3.8 \\
4.6\end{array}$ & $\begin{array}{r}3,000 \\
10,000 \\
30,000 \\
80,000\end{array}$ & .59 & .13 & .28 & For $O$ belort $700 \mathrm{cfs}$ \\
\hline Rio Grande at San Felipe, N. Mex. & $\begin{array}{r}250 \\
500 \\
1,000 \\
2,000\end{array}$ & $\begin{array}{l}175 \\
205 \\
235 \\
273\end{array}$ & $\begin{array}{l}0.8 \\
1.1 \\
1.6 \\
2.3\end{array}$ & $\begin{array}{l}1.7 \\
2.1 \\
2.6 \\
3.2\end{array}$ & $\begin{array}{r}400 \\
1,400 \\
5,500 \\
21,000\end{array}$ & .22 & .48 & .30 & \\
\hline Middle Loup River at Arcadia, Nebr........ & $\begin{array}{r}250 \\
500 \\
1,000 \\
2,000\end{array}$ & $\begin{array}{l}181 \\
189 \\
203 \\
217 \\
\end{array}$ & $\begin{array}{l}0.9 \\
1.3 \\
1.9 \\
2.7\end{array}$ & $\begin{array}{l}1.5 \\
2.0 \\
2.6 \\
3.3\end{array}$ & $\begin{array}{r}150 \\
650 \\
4,800 \\
26.000\end{array}$ & .13 & .52 & .35 & \\
\hline Smoky Hill River near Ellis, Kans......... & $\begin{array}{r}250 \\
500 \\
\end{array}$ & $\begin{array}{l}115 \\
\mathbf{1 4 8} \\
\end{array}$ & $\begin{array}{l}1.2 \\
1.6\end{array}$ & $\begin{array}{l}1.8 \\
2.1 \\
\end{array}$ & $\begin{array}{l}1,000 \\
3,900 \\
\end{array}$ & .36 & .48 & .16 & For 0 belor $400 \mathrm{cfs}$. \\
\hline Powder River at Arvada, Wyo & $\begin{array}{r}250 \\
500 \\
1,000 \\
2,000\end{array}$ & $\begin{array}{l}\overline{105} \\
116 \\
125 \\
135\end{array}$ & $\begin{array}{l}1.0 \\
1.5 \\
2.3 \\
3.4\end{array}$ & $\begin{array}{l}2.3 \\
2.8 \\
3.5 \\
4.3\end{array}$ & $\begin{array}{r}8,000 \\
26,000 \\
90,000 \\
320,000\end{array}$ & .10 & .59 & .31 & For $O$ above $200 \mathrm{cfs}$ \\
\hline Moreau River near Faith, S. Dak ......... & $\begin{array}{r}250 \\
500 \\
1,000 \\
2,000\end{array}$ & $\begin{array}{l}118 \\
129 \\
135 \\
140 \\
\end{array}$ & $\begin{array}{l}1.3 \\
1.9 \\
2.8 \\
4.1 \\
\end{array}$ & $\begin{array}{l}1.6 \\
2.0 \\
2.6 \\
3.5 \\
\end{array}$ & $\begin{array}{r}1,200 \\
3,400 \\
9,000 \\
24,000\end{array}$ & .10 & .56 & .34 & For $O$ above $400 \mathrm{cfs}$. \\
\hline White River near Oglala, S. Dak ........ & $\begin{array}{r}250 \\
500 \\
1,000 \\
2,000\end{array}$ & $\begin{array}{l}39 \\
48 \\
59 \\
72\end{array}$ & $\begin{array}{r}3.6 \\
5.6 \\
8.8 \\
13.6\end{array}$ & $\begin{array}{l}1.8 \\
1.9 \\
1.9 \\
2.1\end{array}$ & $\begin{array}{r}2,600 \\
6,000 \\
13.200 \\
30,000\end{array}$ & .30 & .63 & $.0 \bar{t}$ & \\
\hline Belle Fourche River below Moorcroft, Wyo.... & $\begin{array}{r}250 \\
500 \\
1,000 \\
2,000 \\
\end{array}$ & $\begin{array}{r}59 \\
74 \\
92 \\
115 \\
\end{array}$ & $\begin{array}{l}2.1 \\
2.9 \\
4.0 \\
5.5\end{array}$ & $\begin{array}{l}2.0 \\
2.3 \\
2.7 \\
3.2 \\
\end{array}$ & $\begin{array}{r}1,700 \\
6,500 \\
28,000 \\
110,000\end{array}$ & .31 & .44 & .25 & \\
\hline Virgin River at Virgin, Utah & $\begin{array}{r}250 \\
500 \\
1,000 \\
2,000 \\
\end{array}$ & $\begin{array}{r}92 \\
111 \\
134 \\
160 \\
\end{array}$ & $\begin{array}{l}1.0 \\
1.2 \\
1.5 \\
1.8 \\
\end{array}$ & $\begin{array}{l}2.7 \\
3.7 \\
5.1 \\
6.9 \\
\end{array}$ & $\begin{array}{r}15,000 \\
90,000 \\
400,000 \\
1,600,000 \\
\end{array}$ & .26 & .29 & .45 & Curves poorly defined. \\
\hline Rio Puerco at Rio Puerco, N. Mex & $\begin{array}{r}250 \\
500 \\
1,000 \\
2,000\end{array}$ & $\begin{array}{r}66 \\
89 \\
122 \\
133 \\
\end{array}$ & $\begin{array}{l}1.2 \\
1.4 \\
1.5 \\
2.2\end{array}$ & $\begin{array}{l}3.1 \\
4.1 \\
5.4 \\
6.8\end{array}$ & $\begin{array}{r}57,000 \\
140,000 \\
360,000 \\
1,000,000 \\
\end{array}$ & .43 & .16 & .41 & \\
\hline Rio Grande near Bernalillo, N. Mex ...... & $\begin{array}{r}250 \\
500 \\
1,000 \\
2,000 \\
\end{array}$ & $\begin{array}{r}95 \\
.156 \\
260 \\
265 \\
\end{array}$ & $\begin{array}{l}1.5 \\
1.6 \\
1.7 \\
2.3 \\
\end{array}$ & $\begin{array}{l}1.7 \\
2.0 \\
2.3 \\
3.3 \\
\end{array}$ & $\begin{array}{r}200 \\
1,000 \\
4,500 \\
15,000 \\
\end{array}$ & .03 & .46 & .51 & For $Q$ above $1,000 \mathrm{cfs}$ \\
\hline Saline River near Russell, Kans............ & $\begin{array}{r}250 \\
500 \\
1,000 \\
2,000 \\
\end{array}$ & $\begin{array}{r}66 \\
85 \\
112 \\
145 \\
\end{array}$ & $\begin{array}{l}1.8 \\
2.4 \\
3.1 \\
4.2\end{array}$ & $\begin{array}{r}2.0 \\
2.4 \\
2.9 \\
3.4 \\
\end{array}$ & $\begin{array}{r}1,350 \\
6,100 \\
15,100 \\
29,200\end{array}$ & .37 & .38 & .25 & \\
\hline Smoky Hill River at Ellsworth, Kans............. & $\begin{array}{r}250 \\
500 \\
1,000 \\
2,000\end{array}$ & $\begin{array}{r}92 \\
100 \\
111 \\
122 \\
\end{array}$ & $\begin{array}{l}1.4 \\
2.2 \\
3.4 \\
5.1\end{array}$ & $\begin{array}{l}1.9 \\
2.2 \\
2.6 \\
3.1 \\
\end{array}$ & $\begin{array}{r}1,620 \\
4,700 \\
12,400 \\
32,400 \\
\end{array}$ & .14 & .60 & .26 & . \\
\hline Republican River near Bloomington, Nebr... & $\begin{array}{r}250 \\
500 \\
1,000 \\
2,000\end{array}$ & $\begin{array}{r}92 \\
135 \\
200 \\
210\end{array}$ & $\begin{array}{l}1.8 \\
1.9 \\
2.0 \\
3.2\end{array}$ & $\begin{array}{l}1.5 \\
2.0 \\
2.7 \\
2.9\end{array}$ & $\begin{array}{r}940 \\
2,970 \\
12,700 \\
43,700 \\
\end{array}$ & .50 & .06 & .44 & For $Q$ below $1,000 \mathrm{cfs}$. \\
\hline Bighorn River at Kane, Wyo $\ldots \ldots \ldots$ & $\begin{array}{r}250 \\
500 \\
1,000 \\
2,000 \\
\end{array}$ & $\begin{array}{l}152 \\
160 \\
168 \\
175 \\
\end{array}$ & $\begin{array}{l}1.3 \\
1.8 \\
2.5 \\
3.6\end{array}$ & $\begin{array}{l}1.3 \\
1.7 \\
2.3 \\
3.2 \\
\end{array}$ & $\begin{array}{r}300 \\
2,600 \\
14,000\end{array}$ & .06 & .51 & .43 & \\
\hline Bighorn River at Thermopolis, Wyo......... & $\begin{array}{r}500 \\
1,000 \\
2,000 \\
\end{array}$ & $\begin{array}{l}179 \\
195 \\
215 \\
\end{array}$ & $\begin{array}{l}1.7 \\
2.1 \\
2.7\end{array}$ & $\begin{array}{l}1.6 \\
2.4 \\
3.5 \\
\end{array}$ & $\begin{array}{r}150 \\
3,700 \\
20,000 \\
\end{array}$ & .14 & .31 & .55 & \\
\hline 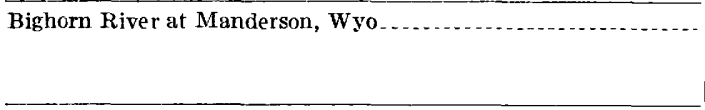 & $\begin{array}{r}250 \\
500 \\
1,000 \\
2,000\end{array}$ & $\begin{array}{l}130 \\
150 \\
179 \\
210 \\
\end{array}$ & $\begin{array}{l}1.0 \\
1.4 \\
2.0 \\
2.8 \\
\end{array}$ & $\begin{array}{l}1.9 \\
2.3 \\
2.8 \\
3.4 \\
\end{array}$ & $\begin{array}{r}70 \\
800 \\
9,000 \\
30,000 \\
\end{array}$ & .22 & .50 & .28 & \\
\hline Grand River at Shadehill, S. Dak ....... & $\begin{array}{r}250 \\
500 \\
1,000 \\
2,000\end{array}$ & $\begin{array}{r}80 \\
105 \\
125 \\
140\end{array}$ & $\begin{array}{l}2.0 \\
2.2 \\
2.8 \\
3.8\end{array}$ & $\begin{array}{l}1.6 \\
2.2 \\
2.8 \\
3.4\end{array}$ & $\begin{array}{r}2,430 \\
5,700 \\
12,200 \\
26,500\end{array}$ & .25 & .36 & .39 & \\
\hline
\end{tabular}




\section{INDEX}

A

Acknowledgments

At a station, defined

B

Bed configuration, in relation to roughness

Belle Fourche River

Bighorn River and tributaries, data.

Blench, Thomas, quoted.

C

Canals, stable, similarity to graded streams slope of

Channel control, defined

Channel shape, relation to width-depth ratio

Channel shape factors, interrelations at given discharge

Cbannel-shape adjustment, fiood in Colorado River fiood in Rio Grande food in San Juan River

Colorado River, adjustment of channel during fiood suspended-load measurements

Current-meter data

Curve, cumulative frequency.

flow-duration. See Curve, cumulative frequency.

Das, Ishar, quoted

Davis, W. M., quoted.

Depth, defined

Discharge, cumulative frequency

daily mean

frequency.

given, in relation to channel-shape factor

in relation to depth (equation 2)

in relation to suspended load at cross section

in relation to suspended load in a downstream direction

in relation to velocity (equation 3 )

in relation to wetted perimeter

in relation to width (equation 1)

mean annual.

median

records, method of selection

variable, in relation to channel-shape factors

$\mathbf{E}$

Einstein equation

Equation 1

3.

4 4.

Equations determining longitudinal profile of streams.

Equilibrium, in channels, requisites for

summarized

Frodibility of bank and bed

Exponents, $b, f, m$, a verage values

F

Flumes, experimental

French Broad River

(1)

15

Gage height. See Stage.

Gaging station, location of

Gilbert, G. K., data on experimental fumes

Glossary of terms used

Griffith, W. M., quoted

$\mathbf{H}-\mathbf{K}$

Hoover Dam, effect on channel shape

In a downstream direction, defined.

Kansas River system, data
$\mathrm{L}$

Page
43
29
19
48
29
30
19
36
$36-42,48$
21
15

$\mathbf{M}$

Mackin, J. H., quoted ....................... 29, 33-34, 45, 46, 47, 48, 51

Madras irrigation canals

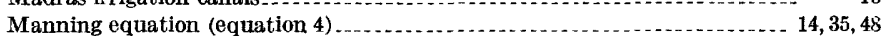

Manning roughness factor-..................... 40,41

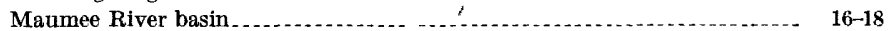

Mean depth. See Depth.

Mean velocity. See Velocity.

Middle Loup River, bed-load $m_{t y}$ suretnents

Mississippi River, lower, data

main stem

Missouri River, main trunk, data . . . . . .

$\mathrm{N}$

Niobrara River, bed-load measurements ............................... 29

$P$

Powder River, data on tributaries

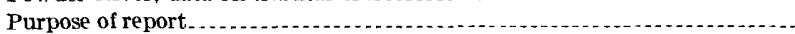

R

Regime channels, defined.................. 43

Republican and Kansas Rivers......

Rio Grande, adjustment of channel during flood...................... 33, 34, 37

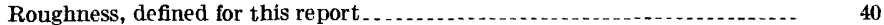

factors affecting

in relation to bed configuration.

in relation to particle size......................................... 48

in relation to sand sizes. . . . . . . . . . . .

in relation to suspended load . . . . . . . . . . $36-40,42$ Roughness factor. See Manning equation.

Rubey, W. W., cited

San Juan River, adjustment of channel during fiood ................ 30-33, 34, 37

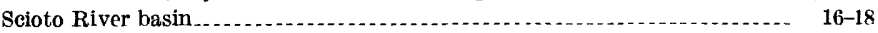
Sediment rating curve, defined ........................................... 20

Sedimentation, of Lake Mead . . . . . . . . .

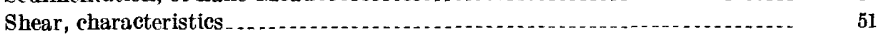

Slope, effects summarized

relation to velocity and depth in a downstream direction ......... 49-51

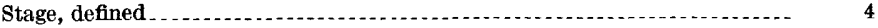

Streams, graded defined. $\begin{array}{ll}\text { method of identifying } & 47\end{array}$ slope of

profiles, eight equations for determining longitudingl in equilibrium and all others ......................... 50 Summary and interpretation.

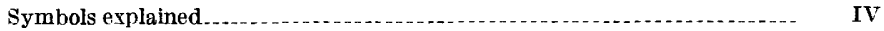

$\mathbf{T}-\mathbf{Y}$

Tombigbee River

Velocity

Yellowstone and Bighorn Rivers

Yuma, Ariz., gaging station. See Hoover Dam.

.

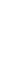

.


